INSTITUTO DE QUÍMICA DE SÃO CARLOS

\title{
DERIVADOS DE TIOXANTONAS COMO FOTOESTABILIZADORES OU ACELERADORES NA FOTODEGRADAÇÃO DE POLÍMEROS
}

\author{
Leticia Felipe Abdias Pinto
}

\begin{abstract}
Dissertação apresentada ao Instituto de
Química de São Carlos da Universidade de São

Paulo, como um dos requisitos para obtenção do título de mestre em Ciências (Físico-Química)
\end{abstract}

Orientadora: Dra. Carla Cristina Schmitt Cavalheiro

São Carlos 
Dedicatória

Aos meus pais, José e Luzia, pelo amor, respeito, confiança e total dedicação. 


\section{AGRADECIMENTOS}

À Dra. Carla Cristina Schmitt Cavalheiro pela dedicação, confiança e orientação.

À Dra. Beatriz Eleutério Goi pelo carinho, e principalmente pelo apoio durante todo o meu mestrado.

Ao Prof. Dr. Miguel Guillermo Neumann pelas sugestões e confiança.

Aos amigos do grupo de Fotoquímica do Instituto de Química de São Carlos pela amizade e colaboração.

Aos docentes e funcionários do Instituto de Química de São Carlos.

Aos amigos do Instituto de Química de São Carlos.

Às minhas amigas Analine Crespo Ziglio e Edilaine Martins Soler pelo carinho e pelos momentos de descontração.

Ao Instituto de Química de São Carlos pela oportunidade e infraestrutura oferecidas.

À todas as pessoas que contribuíram para a realização deste trabalho.

À FAPESP pela bolsa concedida. 


\section{ÍNDICE}

LISTA DE FIGURAS 6

LISTA DE TABELAS

RESUMO

$\begin{array}{ll}\text { ABSTRACT } & 12\end{array}$

1. INTRODUÇÃO 13

$\begin{array}{ll}\text { 1.1. Processos de Degradação } & 13\end{array}$

$\begin{array}{ll}\text { 1.1.1. Fotodegradação } & 14\end{array}$

$\begin{array}{ll}\text { 1.1.2. Degradação Oxidativa } & 17\end{array}$

1.2. Fotodegradação do Poliestireno 17

1.3. Sensibilizadores $\quad 21$

1.4. Fotoestabilidade $\quad 23$

1.5. Processos Fotoquímicos e Fotofísicos $\quad 24$

1.5.1. Supressão de Fluorescência $\quad 25$

2. OBJETIVOS 28

3. PARTE EXPERIMENTAL 29

3.1. Reagentes utilizados

3.2. Equipamentos Utilizados

3.3. Técnicas Instrumentais $\quad 30$

3.3.1. Espectroscopia de Absorção no UV-vis 30

3.3.2. Espectroscopia de Infravermelho com Transformada de 31 Fourier

3.3.3. Cromatografia de Exclusão por Tamanho 31

3.3.4. Fotólise por pulso de Laser $\quad 32$

3.4. Procedimento Experimental 33

3.4.1. Estudo dos Processos de Fotodegradação dos Filmes de 33 Poliestireno

3.4.2. Estudo da Fotoestabilidade da Tioxantona e dos $\quad 34$ Copolímeros PS-TX I e PS-TX II em Solução

3.4.3. Estudo das Reações Elementares de Tioxantonas 34

4. RESULTADOS E DISCUSSÃO 36

4.1. FOTODEGRADAÇÃO DOS FILMES DE POLIESTIRENO 36

4.1.1.Estudo da Fotodegradação do Poliestireno na Presença do 36 Sensibilizador Tioxantona

$\begin{array}{llllll}\text { 4.1.2.Fotodegradação do Poliestireno na } & \text { Presença do } & 42\end{array}$ 
Sensibilizador Benzofenona

4.1.3.Fotodegradação do Poliestireno 48

4.1.4. Comparação da Fotodegradação do Poliestireno Puro e na 53

Presença dos Sensibilizadores Tioxantona e Benzofenona em ar

4.1.5. Comparação da Fotodegradação do Poliestireno puro e na

presença dos sensibilizadores Tioxantona e Benzofenona em Atmosfera

Inerte

4.1.6. Resultados da Cromatografia de Exclusão por Tamanho

4.2.CARACTERIZAÇÃO DO COPOLÍMERO SINTETIZADO ESTIRENO-CO-TIOXANTONA (PS-TX I)

4.3.ESTUDO DA FOTOESTABILIDADE DA TIOXANTONA E DOS COPOLÍMEROS PS-TX I E PS-TX II EM SOLUÇÃO

4.4.ESTUDOS DAS REAÇÕES ELEMENTARES ("Flash Photolysis")

4.4.1.Estudo dos Transientes da Tioxantona Livre (TX)

4.4.2.Estudo dos Transientes de Tioxantona na Presença de 64 Poliestireno (PS+TX)

4.4.3.Estudo dos Transientes do Copolímero PS-TX I

4.4.4.Estudo dos transientes do copolímero PS-TX II

4.4.5.Estudo de Supressão do Estado Triplete Utilizando 81 Trietanolamina (TEOHA)

5. CONCLUSÕES 90 REFERÊNCIAS BIBLIOGRÁFICAS 


\section{LISTA DE FIGURAS}

Figura 1.Mecanismo para fotodegradação do poliestireno. $\quad 18$

Figura 2.Mecanismo para fotodegradação do poliestireno na presença de benzofenona. 19

Figura 3.Mecanismo para fotodegradação de filmes de poliestireno na presença de benzofenona.

Figura 4.Estrutura química da tioxantona.

Figura 5.Formação do radical cetila da tioxantona a partir do estado excitado triplete.

Figura 6.Formação do radical cetila da benzofenona a partir do estado triplete.

Figura 7.Ação do corante no mecanismo de fotodegradação dos polímeros.

Figura 8.Câmara de irradiação (TECNAL) utilizada nos experimentos de fotodegradação.

Figura 9.Síntese do copolímero PS-TX I.

Figura 10.Espectro de absorção do PS na presença de tioxantona $\left(1,0 \times 10^{-3} \mathrm{~mol} \mathrm{~L}^{-1}\right)$ antes da irradiação.

Figura 11.Espectros de absorção do filme PS/TX antes e após 20 horas de irradiação com luz visível, (A) em ar e (B) em atmosfera inerte.

Figura 12.Mudança na absorbância em $250 \mathrm{~nm}$ (A) e em $283 \mathrm{~nm}$ (B) ocorridas nos filmes PS/TX em ar e PS/TX, sob atmosfera de $\mathrm{N}_{2}$.

Figura 13.Mudança na absorbância em 318 nm (A) e em 345 nm (B) ocorridas nos filmes PS/TX na presença de ar e PS/TX em atmosfera inerte.

Figura 14. Mudança na absorbância em $380 \mathrm{~nm}$ ocorridas nos filmes PS/TX na presença de ar e PS/TX em atmosfera inerte.

Figura 15.Espectro de FTIR do filme PS na presença de TX $\left(1,0 \times 10^{-3} \mathrm{~mol} \mathrm{~L}^{-1}\right)$ antes da irradiação.

Figura 16.Espectros de FTIR do filme PS/TX antes e após diferentes tempos irradiação com luz visível sob ar, $\mathrm{T}=40{ }^{\circ} \mathrm{C}$. (A) 1800 a $1600 \mathrm{~cm}^{-1}$ e (B) 3850 a $3450 \mathrm{~cm}^{-1}$.

Figura 17.Espectro de FTIR do filme PS/TX antes e após 20 horas de irradiação com luz visível em atmosfera inerte. (A) 1800 a $1600 \mathrm{~cm}^{-1} \mathrm{e}$ (B) 3900 a $3400 \mathrm{~cm}^{-1}$.

Figura 18. Mudança na absorbância em (A) $1740 \mathrm{~cm}^{-1}$ e (B) em $3645 \mathrm{~cm}^{-1}$, ocorridas nos filmes PS/TX em ar e PS/TX, sob atmosfera $\mathrm{N}_{2}$.

Figura 19.Espectro de absorção do PS na presença de benzofenona $\left(5,0 \times 10^{-3} \mathrm{~mol} \mathrm{~L}^{-1}\right)$ antes da irradiação.

Figura 20.Espectro de absorção do filme PS/BP antes e após 20 horas de irradiação com luz visível, (A) em ar, e (B) em atmosfera inerte.

Figura 21.Mudança na absorbância em (A) $250 \mathrm{~nm}$ e em (B) $310 \mathrm{~nm}$, ocorridas nos filmes PS/BP sob ar e PS/BP sob $\mathrm{N}_{2}$.

Figura 22.Mudança na absorbância em (A) $331 \mathrm{~nm}$ e em (B) $361 \mathrm{~nm}$ ocorridas nos filmes PS/BP sob ar e PS/BP sob $\mathrm{N}_{2}$.

Figura 23.Espectro de FTIR do filme PS/BP antes e após 5 horas de irradiação com luz visível, sob ar. (A) 1900 a $1600 \mathrm{~cm}^{-1} 1$ e (B) 4000 a $3200 \mathrm{~cm}^{-1}$.

Figura 24.Espectro de absorção do filme PS/BP antes e após 4 horas de irradiação com luz visível em atmosfera inerte. (A) 1850 a $1650 \mathrm{~cm}^{-1} \mathrm{e}$ (B) 4000 a $3200 \mathrm{~cm}^{-1}$.

Figura 25.Mudança na absorbância (A) em $1740 \mathrm{~cm}^{-1}$ e (B) em $3645 \mathrm{~cm}^{-1}$ ocorridas nos filmes PS/BP na presença de $\mathrm{O}_{2}$ e PS/BP em atmosfera inerte.

Figura 26.Espectro de absorção do filme PS antes da irradiação com luz ultravioleta.

Figura 27.Espectro de absorbância do filme PS antes e após 21 horas de irradiação com luz ultravioleta, (A) em ar, (B) sob atmosfera de $\mathrm{N}_{2}$.

Figura 28.Mudança na absorbância em (A) 250 nm e (B) em 318 nm ocorridas nos 
filmes PS em ar e PS em atmosfera inerte.

Figura 29.Espectro de FTIR do PS antes da irradiação com luz ultravioleta.

Figura 30.Espectro de FTIR do filme PS antes e após 21 horas de irradiação com luz ultravioleta, sob ar.

Figura 31.Espectro de FTIR do filme PS antes e após 21 horas de irradiação com luz ultravioleta em atmosfera inerte. (A) 1850 a $1650 \mathrm{~cm}^{-1}$ e (B) 4000 a $3200 \mathrm{~cm}^{-1}$.

Figura 32.Mudança na absorbância em (A) $1740 \mathrm{~cm}^{-1}$ e em (B) $3645 \mathrm{~cm}^{-1}$ ocorridas nos filmes PS na presença de $\mathrm{O}_{2}$ e PS em atmosfera inerte.

Figura 33.Mudança na absorbância em $250 \mathrm{~nm}$ ocorridas nos filmes PS, PS/TX e PS/BP em ar.

Figura 34.Mudança na absorbância em 318 nm ocorridas nos filmes PS e PS/TX na presença de ar.

Figura 35.Mudança na absorbância em $1740 \mathrm{~cm}^{-1}$ (A) e em $3645 \mathrm{~cm}^{-1}$ (B) ocorridas nos filmes PS, PS/TX e PS/BP na presença de ar.

Figura 36.Mudança na absorbância em $250 \mathrm{~nm}$ ocorridas nos filmes PS, PS/TX e PS/BP em atmosfera inerte.

Figura 37.Mudança na absorbância em 318 nm ocorridas nos filmes PS, PS/TX em atmosfera inerte.

Figura 38.Mudança na absorbância em $1740 \mathrm{~cm}^{-1}$ (A) e em $3645 \mathrm{~cm}^{-1}$ (B) ocorridas nos filmes PS, PS/TX e PS/BP em atmosfera inerte.

Figura 39. Espectro de absorção (A) do copolímero PS-TX I em dimetilformamida e (B) espectro de absorção do copolímero PS-TX comparada a absorção da tioxantona livre.

Figura 40. Espectro de infravermelho do copolímero PS-TX I.

Figura 41. Região característica do espectro de ${ }^{1} \mathrm{H}-\mathrm{NMR}$ do copolímero PS-TX I.

Figura 42. Espectros de absorção da tioxantona livre em solução de benzeno antes e após 25 horas de irradiação com luz visível na presença de ar.

Figura 43. Espectros de absorção da tioxantona na presença de poliestireno em solução de benzeno antes e após 150 horas de irradiação com luz visível na presença de ar.

Figura 44. (A) Espectros de absorção do copolímero PS-TX I em solução de dimetilformamida antes e após 25 horas de irradiação. (B) Variação da absorção em $380 \mathrm{~nm}$ do copolímero PS-TX I.

Figura 45. (A) Espectros de absorção do copolímero PS-TX II antes e após 2 horas de irradiação com luz visível em ar. (B) Variação da absorção em $380 \mathrm{~nm}$ do copolímero PS-TX II.

Figura 46. (A) Espectro de absorção do transiente de TX em dimetilformamida em atmosfera de $\mathrm{N}_{2}$, de 390 a $760 \mathrm{~nm}$. (B) Decaimento de absorção do transiente de TX em dimetilformamida, em $660 \mathrm{~nm}, \mathrm{t}_{\mathrm{d}}=2,5 \mu \mathrm{s}$, em atmosfera de $\mathrm{N}_{2}$.

Figura 47. (A) Espectro de absorção de transiente de TX em dimetilformamida, em ar, de 400 a $760 \mathrm{~nm}$. (B) Decaimento de absorção do transiente de TX em dimetilformamida, em $660 \mathrm{~nm}, \mathrm{t}_{\mathrm{d}}=500 \mathrm{~ns}$, em ar.

Figura 48. (A) Espectro de absorção de transiente de TX em tetrahidrofurano, em atmosfera de $\mathrm{N}_{2}$, de 360 a $760 \mathrm{~nm}$. (B) Decaimento de absorção do transiente de TX em tetrahidrofurano, em $660 \mathrm{~nm}, \mathrm{t}_{\mathrm{d}}=1 \mu \mathrm{s}$, em atmosfera de $\mathrm{N}_{2}$.

Figura 49. (A) Espectro de absorção de transiente de TX em tetrahidrofurano, em ar, de 390 a $760 \mathrm{~nm}$. (B) Decaimento de absorção do transiente de TX em tetrahidrofurano, em $660 \mathrm{~nm}, \mathrm{t}_{\mathrm{d}}=250 \mathrm{~ns}$, em ar.

Figura 50. (A) Espectro de absorção de transiente de TX em acetonitrila, em atmosfera de $\mathrm{N}_{2}$, de 400 a $760 \mathrm{~nm}$. (B) Decaimento de absorção do transiente de TX em 
acetonitrila, em $660 \mathrm{~nm}, \mathrm{t}_{\mathrm{d}}=1 \mu \mathrm{s}$, em atmosfera de $\mathrm{N}_{2}$.

Figura 51. (A) Espectro de absorção de transiente de TX em acetonitrila, em ar, de 400 a $760 \mathrm{~nm}$. (B) Decaimento de absorção do transiente de TX em acetonitrila, em $660 \mathrm{~nm}$, $\mathrm{t}_{\mathrm{d}}=250 \mathrm{~ns}$, em ar.

Figura 52. (A) Espectro de absorção de transiente de TX em benzene, em atmosfera de $\mathrm{N}_{2}$, de 400 a $760 \mathrm{~nm}$. (B) Decaimento de absorção do transiente de TX em benzeno, em $660 \mathrm{~nm}, \mathrm{t}_{\mathrm{d}}=5 \mu \mathrm{s}$, em atmosfera de $\mathrm{N}_{2}$.

Figura 53. (A) Espectro de absorção de transiente de TX em benzeno, em ar, de 400 a $760 \mathrm{~nm}$. (B) Decaimento de absorção do transiente de TX em benzeno, em $660 \mathrm{~nm}, \mathrm{t}_{\mathrm{d}}=$ $250 \mathrm{~ns}$, em ar.

Figura 54. Máximos de absorção na região de $600 \mathrm{~nm}$ em função do parâmetro de polaridade $\mathrm{E}_{\mathrm{T}}(30)$.

Figura 55. (A) Espectro de absorção de transiente de PS+TX em dimetilformamida, em atmosfera de $\mathrm{N}_{2}$, de 360 a $760 \mathrm{~nm}$. (B) Decaimento de absorção do transiente de PS+TX em dimetilformamida, em $660 \mathrm{~nm}, \mathrm{t}_{\mathrm{d}}=2,5 \mu \mathrm{s}$, em atmosfera de $\mathrm{N}_{2}$.

Figura 56. (A) Espectro de absorção de transiente de PS+TX em dimetilformamida, em ar, de 390 a $760 \mathrm{~nm}$. (B) Decaimento de absorção do transiente de PS+TX em dimetilformamida, em $660 \mathrm{~nm}, \mathrm{t}_{\mathrm{d}}=500 \mathrm{~ns}$, em ar.

Figura 57. (A) Espectro de absorção de transiente de PS+TX em tetrahidrofurano, em atmosfera de $\mathrm{N}_{2}$, de 360 a $760 \mathrm{~nm}$. (B) Decaimento de absorção do transiente de PS+TX em tetrahidrofurano, em $660 \mathrm{~nm}, \mathrm{t}_{\mathrm{d}}=500 \mathrm{~ns}$, em atmosfera de $\mathrm{N}_{2}$.

Figura 58. (A) Espectro de absorção de transiente de PS+TX em tetrahidrofurano, em ar, de 360 a $760 \mathrm{~nm}$. (B) Decaimento de absorção do transiente de PS+TX em tetrahidrofurano, em $660 \mathrm{~nm}, \mathrm{t}_{\mathrm{d}}=500 \mathrm{~ns}$, em ar.

Figura 59. (A) Espectro de absorção de transiente de PS-TX I em dimetilformamida, em atmosfera de $\mathrm{N}_{2}$, de 360 a $760 \mathrm{~nm}$. (B) Decaimento de absorção do transiente de PSTX I em dimetilformamida, em $660 \mathrm{~nm}, \mathrm{t}_{\mathrm{d}}=2,5 \mu \mathrm{s}$, em atmosfera de $\mathrm{N}_{2}$.

Figura 60. (A) Espectro de absorção de transiente de PS-TX I em dimetilformamida, em ar, de 360 a $760 \mathrm{~nm}$. (B) Decaimento de absorção do transiente de PS-TX I em dimetilformamida, em $660 \mathrm{~nm}, \mathrm{t}_{\mathrm{d}}=1 \mu \mathrm{s}$, em ar.

Figura 61. (A) Espectro de absorção de transiente de PS-TX I em tetrahidrofurano, em atmosfera de $\mathrm{N}_{2}$, de 360 a $760 \mathrm{~nm}$. (B) Decaimento de absorção do transiente de PS-TX I em tetrahidrofurano, em $660 \mathrm{~nm}, \mathrm{t}_{\mathrm{d}}=250 \mathrm{~ns}$, em atmosfera de $\mathrm{N}_{2}$.

Figura 62. (A) Espectro de absorção de transiente de PS-TX I em tetrahidrofurano, em ar, de 360 a $760 \mathrm{~nm}$. (B) Decaimento de absorção do transiente de PS-TX I em tetrahidrofurano, em $660 \mathrm{~nm}, \mathrm{t}_{\mathrm{d}}=500 \mathrm{~ns}$, em ar.

Figura 63. (A) Espectro de absorção de transiente de PS-TX II em dimetilformamida, em atmosfera de $\mathrm{N}_{2}$, de 360 a $760 \mathrm{~nm}$. (B) Decaimento de absorção do transiente de PSTX II em dimetilformamida, em $660 \mathrm{~nm}, \mathrm{t}_{\mathrm{d}}=2,5 \mu \mathrm{s}$, em atmosfera de $\mathrm{N}_{2}$.

Figura 64. (A) Espectro de absorção de transiente de PS-TX II em dimetilformamida, em ar, de 360 a $760 \mathrm{~nm}$. (B) Decaimento de absorção do transiente de PS-TX II em dimetilformamida, em $660 \mathrm{~nm}, \mathrm{t}_{\mathrm{d}}=500 \mathrm{~ns}$, em ar.

Figura 65. (A) Espectro de absorção de transiente de PS-TX II em tetrahidrofurano, em atmosfera de $\mathrm{N}_{2}$, de 360 a $760 \mathrm{~nm}$. (B) Decaimento de absorção do transiente de PS-TX II em tetrahidrofurano, em $660 \mathrm{~nm}, \mathrm{t}_{\mathrm{d}}=2,5 \mu \mathrm{s}$, em atmosfera de $\mathrm{N}_{2}$.

Figura 66. (A) Espectro de absorção de transiente de PS-TX II em tetrahidrofurano, em ar, de 360 a $760 \mathrm{~nm}$. (B) Decaimento de absorção do transiente de PS-TX II em tetrahidrofurano, em $660 \mathrm{~nm}, \mathrm{t}_{\mathrm{d}}=250 \mathrm{~ns}$, em ar.

Figura 67. (A) Decaimentos de absorção do transiente de TX em $660 \mathrm{~nm}$ no solvente dimetilformamida, em diferentes concentrações de TEOHA. (B) Gráfico de Stern- 
Volmer da supressão de TX em dimetilformamida por diferentes concentrações de TEOHA.

Figura 68. (A) Decaimentos de absorção do transiente de TX em $660 \mathrm{~nm}$ no solvente tetrahidrofurano, em diferentes concentrações de TEOHA. (B) Gráfico de Stern-Volmer da supressão de TX em tetrahidrofurano por diferentes concentrações de TEOHA.

Figura 69. (A) Decaimentos de absorção do transiente de TX em 660 nm no solvente acetonitrila, em diferentes concentrações de TEOHA. (B) Gráfico de Stern-Volmer da supressão de TX em acetonitrila por diferentes concentrações de TEOHA.

Figura 70. (A) Decaimentos de absorção do transiente de TX em $660 \mathrm{~nm}$ no solvente benzeno, em diferentes concentrações de TEOHA. (B) Gráfico de Stern-Volmer da supressão de TX em benzeno por diferentes concentrações de TEOHA.

Figura 71. (A) Decaimentos de absorção do transiente de PS+TX em $660 \mathrm{~nm}$ no dimetilformamida, em diferentes concentrações de TEOHA. (B) Gráfico de SternVolmer da supressão de PS+TX em dimetilformamida por diferentes concentrações de TEOHA.

Figura 72. (A) Decaimentos de absorção do transiente de PS+TX em $660 \mathrm{~nm}$ no solvente tetrahidrofurano, em diferentes concentrações de TEOHA. (B) Gráfico de Stern-Volmer da supressão de PS+TX em tetrahidrofurano por diferentes concentrações de TEOHA.

Figura 73. Gráfico de Stern-Volmer da supressão de PS-TX I em dimetilformamida por diferentes concentrações de TEOHA.

Figura 74. Gráfico de Stern-Volmer da supressão de PS-TX I em tetrahidrofurano por diferentes concentrações de TEOHA.

Figura 75. Gráfico de Stern-Volmer da supressão de PS-TX II em dimetilformamida por diferentes concentrações de TEOHA.

Figura 76. Gráfico de Stern-Volmer da supressão de PS-TX II em tetrahidrofurano por diferentes concentrações de TEOHA. 


\section{LISTA DE TABELAS}

Tabela 1. Principais reagentes utilizados

Tabela 2. Números de onda e modos de vibração característicos do poliestireno

Tabela 3. Mudanças na massa molar ponderal média $\left(\overline{\mathrm{M}}_{\mathrm{w}}\right)$ provocadas pela irradiação com luz visível do filme de poliestireno sensibilizado por tioxantona e benzofenona, em ar ou nitrogênio nos diferentes tempos de irradiação

Tabela 4. Tempos de vida do estado triplete em $660 \mathrm{~nm}$ para o sistema TX

Tabela 5. Solvente utilizado, $\mathrm{E}_{\mathrm{T}}(30)$, máximo de absorção na região de $600 \mathrm{~nm}$ e $v$ $\left(\mathrm{cm}^{-1}\right)$

Tabela 6. Tempos de vida do estado triplete em $660 \mathrm{~nm}$ para o sistema PS+TX

Tabela 7. Tempos de vida do estado triplete em $660 \mathrm{~nm}$ para o sistema PS-TX I

Tabela 8. Tempos de vida do estado triplete em $660 \mathrm{~nm}$ para o sistema PS-TX II

Tabela 9. Constantes de velocidade de supressão dos tempos de vida do estado triplete dos sistemas estudados 


\section{RESUMO}

A Tioxantona (TX) e a Benzofenona (BP) são cetonas frequentemente utilizadas como sensibilizadores em reações fotoquímicas. Assim, foi investigada a degradação de filmes de poliestireno (PS) contendo TX e BP como fotossensibilizadores. Os filmes foram irradiados em $\lambda \geq 350 \mathrm{~nm}$, em condições e tempos diferentes. As mudanças espectrais dos filmes foram acompanhadas por espectroscopia de infravermelho e UV-Vis e as mudanças no peso molecular foram acompanhadas por cromatografia de exclusão por tamanho (SEC). Os espectros UV-Vis mostraram que TX sofre fotobranqueamento após $5 \mathrm{~h}$, ao contrário de BP que é fotoestável. Simultaneamente, os polímeros contendo grupos cromóforos são formados e a luz é absorvida. Os fotoprodutos nos filmes contendo TX e BP mostraram um aumento de absorbância entre $280-360 \mathrm{~nm}$ e $310-370 \mathrm{~nm}$, respectivamente. Os picos de IV em torno de 3645 e $1740 \mathrm{~cm}^{-1}$ indicam a geração de hidroperóxidos e espécies carbonílicas, respectivamente. Os resultados mostraram que TX gerou mais fotoprodutos do que a BP. Os filmes de PS irradiados apresentaram uma diminuição no peso molecular indicando que ocorreu a cisão na cadeia polimérica.

A fotofísica dos estados excitados de TX e TX quimicamente incorporada no poliestireno (PS-TX I e PS-TX II) foi estudada, com a finalidade de estudar o comportamento como fotossensibilizador na fotodegradação do PS. O triplete-triplete (T-T) e transientes de TX e TX contendo poliestireno foram estudados em diferentes solventes, para verificar o efeito de polaridade do solvente. Uma boa correlação foi encontrada entre o solvente $\mathrm{E}_{\mathrm{T}}(30)$ e parâmetro de energia do T-T. A constante de velocidade de supressão para a desativação do triplete de TX por trietanolamina diminuiu quando aumentou-se a polaridade do solvente. Essa variação é representada pela escala de polaridade do solvente através dos parâmetros $\pi^{*}$, $\beta$ e $\alpha^{*}$. 


\begin{abstract}
Many ketones, quinones and peroxides are initiators of different reactions such as polymerization, degradation, chemical modification that occur in organic compounds.

Thioxanthone (TX) and Benzophenone (BP) are ketones often used as photosensitizers in photochemical reactions. The degradation of polystyrene films containing TX and BP was investigated. Films were irradiated at $\lambda \geq 350 \mathrm{~nm}$ in different conditions at different times. The changes were investigated by infrared and UV-Vis spectroscopies and the molecular weight were determined by gel permeation chromatography (GPC). The UV-Vis spectra showed that TX is photobleached after $5 \mathrm{~h}$, unlike BP which is photostable. Simultaneously, polymers containing chromoforic groups are formed and the light is absorbed by them. The formation of photoproducts films containing TX and BP showed an increase of absorbance between $280-360 \mathrm{~nm}$ and 310-370 nm, respectively. The IR peaks around 3645 and $1740 \mathrm{~cm}^{-1}$ indicated the generation of hydroperoxide and carbonyl species, respectively. The results showed that thioxanthone has generated more photoproducts than benzophenone. The UV-Vis irradiation of PS films in both samples presented a decrease in the molecular weight after irradiation, indicating that polymer chain scission occurs.

The photophysics of the excited states of thioxanthone (TX) and thioxanthone which was chemically incorporated in polystyrene (PS-TX I and PS-TX II) have been studied in order to be able to predict their behavior as photoinitiator in photodegradation of PS. The triplet-triplet (TT) and transient absorptions of thioxanthone and thioxanthone-containing polystyrene (PS-TX I and PS-TX II) has been studied in different solvents in order to ascertain the effect of the solvent. A good correlation is found between the solvent $\mathrm{E}_{\mathrm{T}}(30)$ parameter and the energy of the triplet-triplet. The quenching rate constants for the deactivation of triplet thioxanthone by triethanolamine decreases when the solvent polarity increases. This variation is represented by the $\pi^{*}, \alpha$ and $\beta$ scale of solvent polarity.
\end{abstract}




\section{INTRODUÇÃO}

\subsection{Processos de Degradação}

Degradação é qualquer reação química destrutiva em polímeros, que pode ser causada por agentes físicos e/ou químicos. A degradação causa uma modificação irreversível nas propriedades dos materiais poliméricos, incluindo o aspecto visual dos polímeros. Geralmente as reações de degradação são indesejáveis, pois procura-se nos materiais poliméricos uma alta durabilidade ou vida útil elevada. As reações de degradação poderão ser benéficas para casos de rejeitos poliméricos não recicláveis, devido a suas características de contaminação ou por inviabilidade econômica ${ }^{1}$.

Os tipos de degradação são geralmente analisados pelos seguintes aspectos:

$>$ Em relação à severidade, sendo classificado em superficial e estrutural. Na degradação superficial há alteração do aspecto visual do material polimérico, principalmente da coloração, enquanto que na degradação estrutural há alterações das propriedades mecânicas, térmicas, elétricas, entre outras, comprometendo o desempenho estrutural do material polimérico.

$>$ Em relação aos mecanismos gerais das reações, pode ser classificada como degradação com ou sem cisão da cadeia principal do polímero. Na degradação sem cisão da cadeia principal pode ocorrer a formação excessiva de ligações cruzadas ${ }^{2}$, a substituição ou a eliminação de grupos laterais e reações entre os próprios grupos laterais, incluindo a ciclização. Na degradação com cisão da cadeia principal do polímero, ocorre uma redução considerável da massa molar média das cadeias poliméricas ${ }^{3}$, que acontece de forma aleatória, ou de forma inversa ao processo de polimerização, denominado despolimerização.

$>$ Em relação ao ambiente de atuação dos agentes de degradação consideram-se três casos distintos: degradação causada pelo processamento do polímero, pelas condições de serviço e após o uso do material polimérico.

$>$ Em relação aos tipos de agentes ou fatores causadores da degradação pode ser classificado como: química, física e biológica. Na degradação física os agentes podem ser a radiação solar, o calor e o atrito mecânico intenso. Os agentes químicos como a água, os ácidos, as bases, os solventes, o oxigênio, o ozônio e outros poluentes atmosféricos produzem a degradação química. Os agentes de degradação biológica são os microorganismos, como fungos e bactérias ${ }^{1}$. 
$>$ Em relação aos processos responsáveis pela degradação dos polímeros a classificação das reações é dividida em: degradação térmica, degradação mecânica, degradação química (incluindo oxidação), biodegradação, fotodegradação, termo-oxidação, fotoxidação, degradação termomecânica, degradação mecanoquímica e fotobiodegradação.

A seguir serão abordados os processos de fotodegradação e degradação oxidativa que estão envolvidos neste trabalho.

\subsubsection{Fotodegradação}

O estudo das reações de fotodegradação vem sendo muito investigada devido à importância que as mudanças provocadas por esse processo podem causar nos materiais poliméricos, uma vez que esses materiais são empregados em produtos industriais e o conhecimento dos processos de desgaste e de envelhecimento por exposição à luz tem extremo valor. A degradação do polímero é provocada por energia radiante e inclui processos de quebra das cadeias poliméricas, formações de ligações cruzadas e reações oxidativas ${ }^{4}$.

A fotodegradação de polímeros coloridos também é de grande interesse, o corante incorporado como aditivo no polímero pode agir como um cromóforo e sensibilizar o polímero para a degradação ${ }^{5}$.

Apesar de sua relevância, os mecanismos de fotodegradação dos polímeros, que desencadeiam modificações em suas propriedades físicas e químicas, ainda não estão completamente elucidados.

Os mecanismos dos processos de fotodegradação podem ser divididos em dois tipos:

\section{Degradação Direta}

O polímero contém grupos capazes de absorver luz na região do ultravioleta, por exemplo, a maioria dos polímeros convencionais possui grupos carbonilas em sua cadeia, formados durante a síntese, transformação ou até mesmo no armazenamento do polímero. Esses grupos funcionais apresentam atividade quando irradiados com luz ultravioleta, promovendo a fotodegradação do material polimérico.

\section{Degradação Indireta}

Quando o polímero não possui nenhum cromóforo, mas outras moléculas estão presentes, como os aditivos ou até mesmo impurezas capazes de absorver luz, pode ocorrer a 
degradação do polímero por meio de processos secundários. Estes processos podem ocorrer através de reações via radicais ou por transferência de energia.

\section{$>$ Reações por Radicais}

Os resíduos de catalisadores de polimerização, tais como metais e peróxidos presentes na maior parte dos polímeros comerciais, absorvem luz gerando radicais livres ${ }^{6}$. Os radicais livres gerados podem reagir com as moléculas do polímero, por adição ou abstração da molécula de hidrogênio, produzindo por sua vez radicais livres sobre a cadeia polimérica, os quais seguem os mecanismos clássicos de decomposição.

$\mathrm{A} \rightarrow \mathrm{A}^{\bullet}$

$\mathrm{A}^{\bullet}+\mathrm{PH} \rightarrow \mathrm{AH}+\mathrm{P}^{\bullet} \rightarrow$ Degradação

A é uma molécula de aditivo ou impureza e PH é o polímero.

\section{$>$ Reações de Transferência de Energia}

As reações de transferência de energia em sistemas poliméricos ocorrem quando o fotossensibilizador está ligado covalentemente à cadeia ou quando se encontra na forma de aditivo ou impureza. No caso em que o fotossensibilizador está ligado covalentemente na cadeia polimérica a transferência de energia ocorre intramolecularmente e no segundo caso intermolecularmente.

Os corantes que são freqüentemente utilizados em processos de coloração de polímeros podem atuar como estabilizantes ou sensibilizadores desses polímeros ${ }^{7,8}$.

A fotoestabilidade de um corante em um polímero depende de muitos fatores e os principais fatores que podem influenciar os sistemas poliméricos contendo corantes são:

$>$ Natureza física e química do polímero, este fator está relacionado com a interação entre a radiação ultravioleta e o polímero, neste caso, grupos carbonilas e hidroperóxidos formados durante a síntese e armazenamento do polímero irão absorver a radiação e passar por reações fotoquímicas que levarão à quebra da cadeia polimérica.

Ambiente em que o sistema é exposto, como por exemplo, a temperaura, a umidade, presença de oxigênio e a fonte de luz na qual o polímero é exposto podem afetar a estabilidade do polímero, uma vez que o aumento de algum destes fatores irá ocasionar o aumento da velocidade de degradação fotoquímica.

$>$ Natureza física e química do corante, o tamanho da partícula de corante, a estrutura química, a presença de superfície tratada e a ligação química envolvida entre o corante e o 
polímero irão influenciar nos efeitos de estabilização e desestabilização do corante no polímero, como por exemplo, um aumento no tamanho da partícula de corante e a presença de uma superfície tratada reduzem a atividade fotocatalítica.

Presença de antioxidantes e estabilizadores de luz, estes aditivos são sempre usados em polímeros comerciais e podem inibir a atividade catalítica e/ou realçar a fotoestabilidade do polímero.

Há dois mecanismos propostos para a fotodegradação de polímeros sensibilizada por corantes. No primeiro, o corante (D) absorve um fóton e é excitado para o estado excitado singlete $\left({ }^{1} \mathrm{D}^{*}\right)$, que por cruzamento entresistemas passa para o estado triplete $\left({ }^{3} \mathrm{D}^{*}\right)$, o qual pode ser desativado por uma molécula de oxigênio, produzindo oxigênio singlete $\left({ }^{1} \mathrm{O}_{2}\right)$. O oxigênio singlete pode reagir com o polímero e levar a formação de produtos de oxidação e na presença de água, o ${ }^{1} \mathrm{O}_{2}$ forma hidroperóxido $\left(\mathrm{H}_{2} \mathrm{O}_{2}\right)$, que induz a oxidação e quebra do polímero $^{6,9}$.

$$
\begin{aligned}
& \mathrm{D} \rightarrow{ }^{1} \mathrm{D}^{*} \rightarrow{ }^{3} \mathrm{D}^{*} \\
& { }^{3} \mathrm{D}^{*}+{ }^{3} \mathrm{O}_{2} \rightarrow \mathrm{D}+{ }^{1} \mathrm{O}_{2} \\
& { }^{1} \mathrm{O}_{2}+\mathrm{P}-\mathrm{H} \rightarrow \text { Produtos de Oxidação } \\
& { }^{1} \mathrm{O}_{2}+2 \mathrm{H}_{2} \mathrm{O} \rightarrow 2 \mathrm{H}_{2} \mathrm{O}_{2} \\
& \mathrm{H}_{2} \mathrm{O}_{2}+\mathrm{P}-\mathrm{H} \rightarrow \text { Produtos de Oxidação }
\end{aligned}
$$

O segundo mecanismo propõe uma interação entre o corante excitado e o polímero através da abstração de um átomo de hidrogênio, resultando em um centro radicalar no polímero, o qual é atacado pelo oxigênio, formando a espécie $\mathrm{POO}^{\bullet}$, que posteriormente resulta em $\mathrm{PO}_{2} \mathrm{H}$, em condições anidras ${ }^{7,9}$.

$$
\begin{aligned}
& \mathrm{D} \rightarrow \mathrm{D}^{*} \\
& \mathrm{D}^{*} \mathrm{P}-\mathrm{H} \rightarrow \mathrm{DH}^{\bullet}+\mathrm{P}^{\bullet} \\
& \mathrm{P}^{\bullet}+\mathrm{O}_{2} \rightarrow \mathrm{POO}^{\bullet} \\
& \mathrm{POO}^{\bullet}+\mathrm{P}-\mathrm{H} \rightarrow \mathrm{POOH}+\mathrm{P}^{\bullet} \\
& \mathrm{POO}^{\bullet}+\mathrm{D}^{\bullet} \rightarrow \mathrm{POOH}+\mathrm{D} \\
& \mathrm{D}^{*}+\mathrm{D}^{-} \mathrm{H}^{-} \rightarrow \mathrm{D}^{\bullet}+\mathrm{HO}^{\bullet} \\
& \mathrm{HO}^{\bullet}+\mathrm{P}-\mathrm{H} \rightarrow \mathrm{H}_{2} \mathrm{O}+\mathrm{P}^{\bullet}
\end{aligned}
$$

Para que ocorra a reação por transferência de energia, a energia do estado excitado do doador deve ser maior que a do aceptor, polímero, caso contrário ocorre a estabilização do mesmo. 


\subsubsection{Degradação Oxidativa}

Muitos polímeros estão sujeitos ao ataque do oxigênio durante a sua síntese, armazenamento, processamento e também no produto final, isto torna muito importante o estudo do processo oxidativo de degradação, que tipicamente ocorre por reações em cadeia, via radicais livres. Nesses processos que deterioram gradativamente as propriedades dos polímeros, acontecem cisões e/ou ramificações das cadeias poliméricas.

Algumas das reações mais importantes do processo de oxidação de polímeros estão apresentadas abaixo, envolvendo as etapas de iniciação, propagação e terminação. A molécula polimérica é representada por $\mathrm{PH}$.

a) Iniciação, formação de radicais livres, $P^{\bullet}$

$$
\begin{aligned}
& \mathrm{PH}+\mathrm{O}_{2} \rightarrow \mathrm{P}^{\bullet}+\mathrm{HOO}^{\bullet} \\
& \mathrm{HOO}^{\bullet} \mathrm{PH} \rightarrow \mathrm{P}^{\bullet}+\mathrm{H}_{2} \mathrm{O}_{2} \\
& \mathrm{P}^{\bullet}+\mathrm{O}_{2} \rightarrow \mathrm{POO}^{\bullet}
\end{aligned}
$$

\section{b) Propagação}

$$
\begin{aligned}
& \mathrm{POO}^{\bullet}+\mathrm{PH} \rightarrow \mathrm{POOH}+\mathrm{P}^{\bullet} \\
& \mathrm{POO}^{\bullet}+\mathrm{PH} \rightarrow \mathrm{P}^{\bullet}+\text { produtos estáveis } \\
& \mathrm{POOH} \rightarrow \mathrm{PO}^{\bullet}+\mathrm{HO}^{\bullet} \\
& \mathrm{PO}^{\bullet}+\mathrm{PH} \rightarrow \mathrm{P}^{\bullet}+\mathrm{POH} \\
& \mathrm{HO}^{\bullet}+\mathrm{PH} \rightarrow \mathrm{P}^{\bullet}+\mathrm{H}_{2} \mathrm{O}
\end{aligned}
$$

\section{c) Terminação}

$$
\begin{aligned}
& \mathrm{P}^{\bullet}+\mathrm{P}^{\bullet} \rightarrow \mathrm{P}-\mathrm{P} \\
& \mathrm{POO}^{\bullet}+\mathrm{P}^{\bullet} \rightarrow \text { produto estável } \\
& \mathrm{POO}^{\bullet}+\mathrm{POO}^{\bullet} \rightarrow \text { produto estável }
\end{aligned}
$$

\subsection{Fotodegradação do Poliestireno}

O poliestireno é um dos polímeros comerciais mais utilizados e estudados por apresentar uma variedade de aplicações. Deste modo, é importante a investigação da estabilidade do poliestireno contra a luz.

Um mecanismo clássico para a degradação do poliestireno sob o efeito da radiação ultravioleta está ilustrado na Figura 1. Tal mecanismo mostra que o poliestireno ao ser irradiado gera o radical [PS ${ }^{\bullet}$ (1), o qual na presença de ar leva à formação do radical 
peróxido. Outra possibilidade é a formação do radical hidroperóxido (2), que pode levar a produção do radical alcóxi (3). Por outro lado, a fotólise do radical alcóxi leva à formação de pequenas cadeias de radicais $\left[\mathrm{PS}^{\bullet}\right]$ e espécies carbonilas (4). Ao mesmo tempo em que ocorre a quebra da cadeia do poliestireno, são formados dienos conjugados na parte alifática na cadeia de poliestireno (5). A formação de insaturação na cadeia polimérica leva ao amarelamento do poliestireno.<smiles>CCC(CC(C)c1ccccc1)c1ccccc1</smiles><smiles>CCC(CC(C)([O-])c1ccccc1)c1ccccc1</smiles>

$\left[\mathrm{PSOO}^{*}\right]$

$\mathrm{PSOOH} \stackrel{\text { hv }}{\longrightarrow} \mathrm{PSO}^{\cdot}+\mathrm{HO}^{*}$<smiles>CCC(CC)c1ccccc1</smiles>

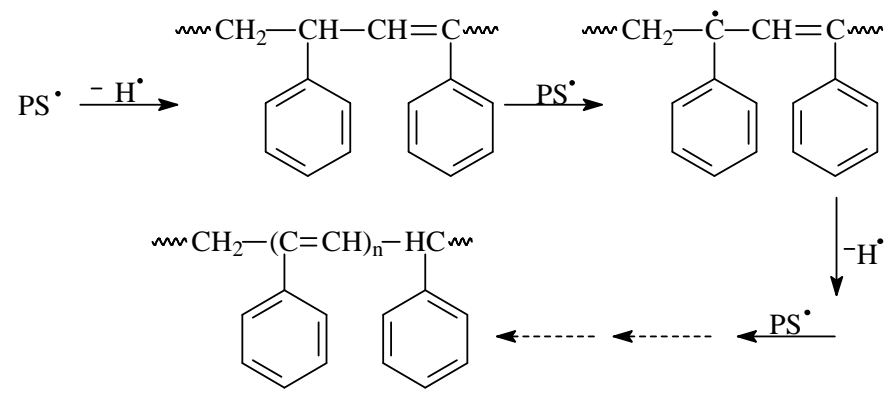

Figura 1. Mecanismo para fotodegradação do poliestireno ${ }^{10}$.

Os mecanismos de fotodegradação do poliestireno e de outros polímeros vêm sendo estudados utilizando-se sensibilizadores externos, como peróxidos, benzofenona e outras cetonas e aldeídos, com o intuito de se avaliar a velocidade e a eficiência da degradação. $\mathrm{O}$ uso destes iniciadores pode levar a um aumento da velocidade de degradação ou retardar este processo, por isso a importância de se estudar tal comportamento. 
O aumento da fotodegradabilidade do poliestireno, especialmente em filmes, pela adição de fotossensibilizadores como a benzofenona e benjoim foi investigado por SIKKEMA et al. (1991). A benzofenona foi o primeiro sensibilizador a ser estudado na fotodegradação do poliestireno, e com isso pode-se investigar o seu mecanismo de fotodegradação. A benzofenona ao absorver energia, passa ao estado excitado singlete, e posteriormente decai ao triplete. No estado triplete a benzofenona abstrai um átomo de hidrogênio do polímero formando um radical poliestirilo e o radical cetila. $\mathrm{O}$ radical poliestirilo reage com oxigênio formando o radical peróxido poliestirilo, que após várias reações, resulta na quebra da cadeia polimérica. Os filmes de poliestireno contendo diferentes concentrações do fotossensibilizador foram irradiados por diferentes horas, e a degradação medida através da diminuição do peso molecular utilizando-se a técnica de cromatografia de exclusão por tamanho (SEC). Os resultados mostraram que os fotossensibilizadores utilizados no estudo aceleraram a fotodegradação do poliestireno, principalmente nas amostras em filmes. Ao aumentar a quantidade do fotossensibilizador nas amostras, os autores observaram um aumento da velocidade de degradação, mas com uma baixa eficiência.

A Figura 2 ilustra o mecanismo de fotodegradação do poliestireno na presença de benzofenona.

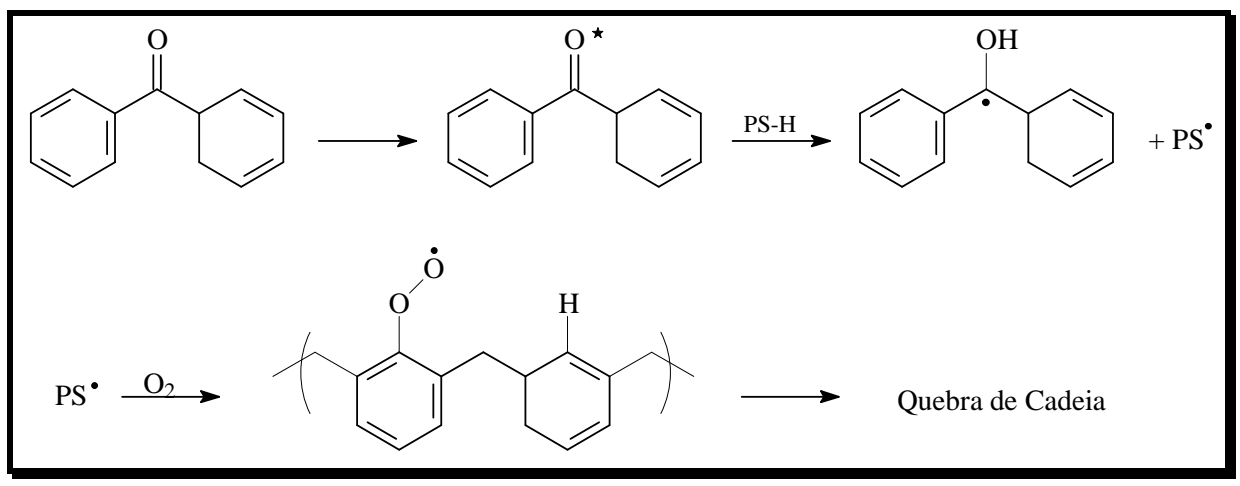

Figura 2. Mecanismo para fotodegradação do poliestireno na presença de benzofenona ${ }^{11}$.

A influência de compostos orgânicos como a benzofenona, antraquinona e peróxido de benzoíla na fototransformação do poliestireno foi estudada por Kaczmarek et al. (2000). A investigação foi realizada através da irradiação de filmes poliméricos. O experimento de fotodegradação dos filmes foi realizado com uma lâmpada de mercúrio por até duas horas à temperatura ambiente e na presença de ar. As mudanças ocorridas foram acompanhadas através das técnicas de viscosimetria, gravimetria, espectroscopia de infravermelho e espectroscopia de UV. Os resultados indicaram que os aditivos aceleraram e aumentaram a eficiência da fotodegradação, da fotodestruição e dos processos de fotoxidação nos filmes de 
poliestireno. Houve também a diminuição de ligações cruzadas e a formação de duplas ligações no polímero. Em todos os processos, a benzofenona mostrou-se mais eficiente como fotoiniciador quando comparada com a antraquinona e o peróxido de benzoíla. Os autores concluíram que a adição de uma pequena quantidade de compostos orgânicos, tais como benzofenona, antraquinona e peróxido de benzoíla, influencia efetivamente nos fotoprocessos do poliestireno. A fotodegradação do poliestireno foi mais eficiente na presença destes aditivos, principalmente da benzofenona. As reações competitivas, a formação de ligações cruzadas e de duplas ligações que ocorrem quando o poliestireno é irradiado são retardadas na presença desses iniciadores. Os resultados obtidos sugerem que a efeciência do fotossensibilizador depende da sua estrutura química, da concentração, do tempo de vida do estado excitado e da estabilidade dos estados excitados e dos radicais formados durante sua fotólise $^{12}$.

A fotodegradação de filmes de poliestireno também foi estudada por Torikai, Takeuchi e Fueki (1983) tanto na ausência quanto na presença do sensibilizador benzofenona. Nesse caso, os filmes de poliestireno foram irradiados com lâmpada de mercúrio a $45^{\circ} \mathrm{C}$ à vácuo, e os autores observaram um aumento da formação do radical poliestirilo. Quando a irradiação foi realizada em ar permitiu-se verificar a presença do radical peróxido. No entanto, a quebra da cadeia principal do poliestireno foi observada predominantemente em ar. Conclui-se através da investigação da degradação dos filmes de poliestireno na presença de benzofenona que este aditivo atua como um sensibilizador da fotodegradação. Um possível mecanismo para a formação de radicais e degradação do poliestireno na presença de benzofenona irradiado com lâmpada de mercúrio em ar e a vácuo foi proposto pelos autores (Figura 3).

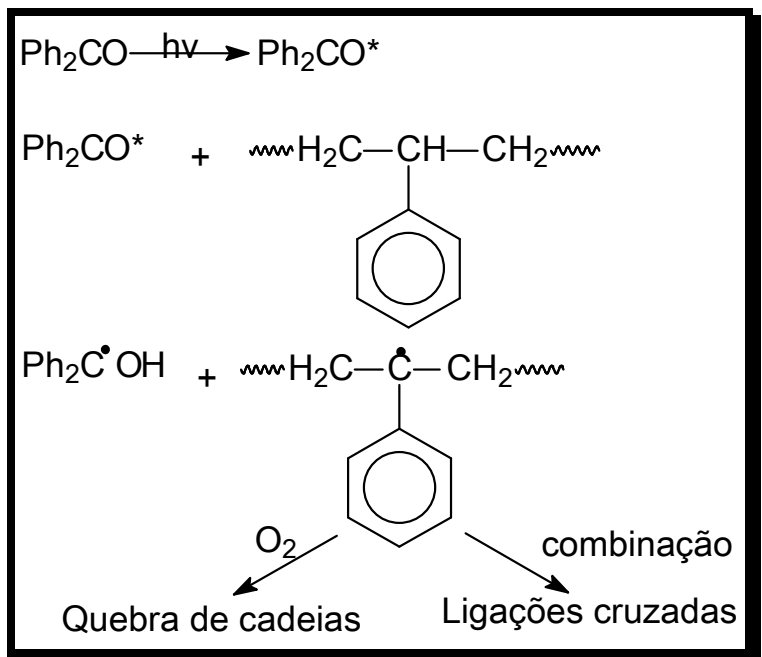

Figura 3. Mecanismo para fotodegradação de filmes de poliestireno na presença de benzofenona ${ }^{13}$. 


\subsection{Sensibilizadores}

Os sensibilizadores são substâncias que absorvem radiação de menor energia, permitindo assim a iniciação de uma reação fotoquímica. A tioxantona (TX) e a benzofenona (BP) foram utilizadas como sensibilizadores neste estudo e seus respectivos comportamentos foram investigados para a elucidação dos mecanismos de fotodegradação.

A seguir serão descritas algumas características dos sensibilizadores tioxantona e benzofenona.

\section{Tioxantona}

A tioxantona é uma cetona aromática que tem sido alvo de numerosos estudos fotoquímicos. Na fotopolimerização, sua atividade tem sido investigada sob várias condições para melhorar formulações ou desenvolver sistemas fotoiniciadores mais eficientes. As tioxantonas são fotoiniciadores do Tipo II, isto é, ao absorver luz a molécula interage com outra, doadora de elétrons, para que os radicais possam ser gerados. Nesse caso a molécula que absorve luz é denominada fotoiniciador e a doadora de elétrons, de co-iniciador. Assim, as tioxantonas como também outras cetonas aromáticas e corantes vêm sendo utilizadas como fotoiniciadores na polimerização de moléculas insaturadas. A Figura 4 ilustra a estrutura química da tioxantona.

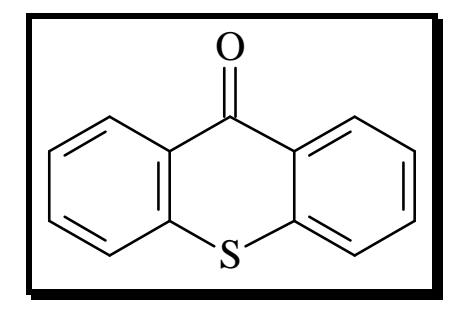

Figura 4. Estrutura química da tioxantona.

As tioxantonas e seus derivados adquiriram uma importância industrial como fonte de radicais, em fotocura de superfícies, absorvendo em comprimentos de onda entre 350 e $450 \mathrm{~nm}$ são especialmente recomendadas no caso de formulações pigmentadas.

A tioxantona apresenta duas transições eletrônicas diferentes do grupo carbonila no estado triplete excitado, pois possui uma dependência com a polaridade do solvente: $T_{1}\left(\pi, \pi^{*}\right)$ para solventes polares e $T_{2}\left(n, \pi^{*}\right)$ para solventes não polares. Na polimerização fotoiniciada por tioxantona os radicais são formados a partir da reação entre tioxantona e uma amina doadora de hidrogênio formando um sistema híbrido. $\mathrm{O}$ estado excitado triplete da tioxantona 
$\left(\mathrm{T}_{1}\right)$ forma, com a amina, um exciplexo que posteriormente se dissocia em um radical cetila tioxantona e um radical amino proporcionando a iniciação da polimerização.

$\mathrm{Na}$ fotodegradação, a tioxantona pode agir como um sensibilizador da reação de degradação. $\mathrm{O}$ triplete $\mathrm{T}_{1}\left(\pi, \pi^{*}\right)$ da tioxantona pode abstrair hidrogênio de moléculas doadoras, por exemplo um polímero $\mathrm{PH}$, produzindo o radical cetila, que poderá iniciar a reação de degradação, Figura $5^{14}$.

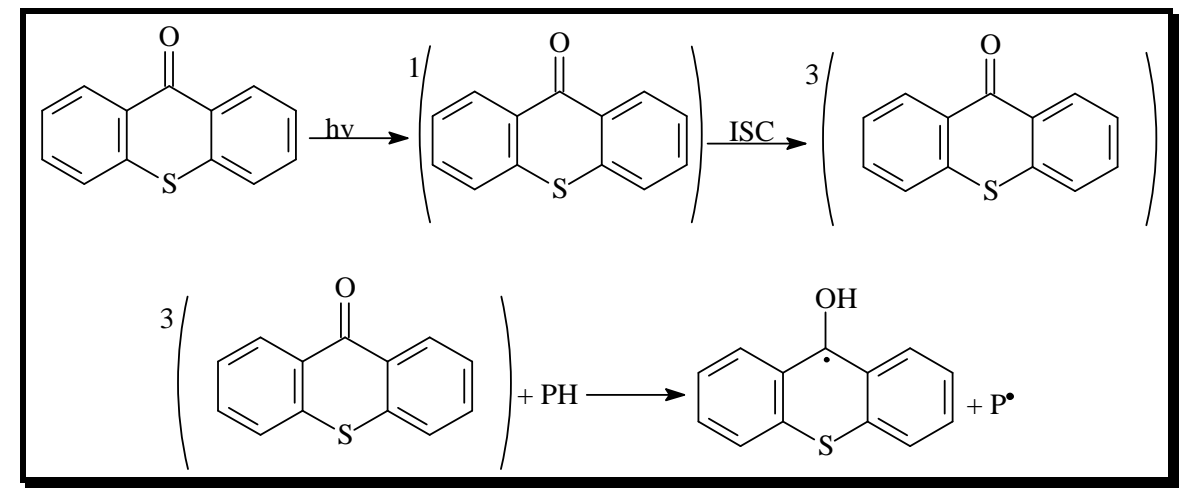

Figura 5. Formação do radical cetila da tioxantona a partir do estado excitado triplete.

\section{Benzofenona}

Benzofenona, uma cetona aromática, é um dos fotoiniciadores e fotossensibilizadores mais estudados na fotorreação de polímeros. A irradiação da benzofenona promove a molécula de benzofenona para o primeiro estado singlete excitado $S_{1}\left(n, \pi^{*}\right)$ ou $S_{2}\left(\pi, \pi^{*}\right)$ dependendo da energia utilizada. A conversão interna (IC) do estado $S_{2}$ para $S_{1}$ é bem rápida $\left(10^{-12} \mathrm{~s}\right)$. O cruzamento entresistemas (ISC) de $S_{1}\left(n, \pi^{*}\right)$ para o estado triplete $T_{1}\left(n, \pi^{*}\right)$ ocorre eficientemente $\left(\Phi_{\text {ISC }} \sim 1\right)$ durante $10^{-10} \mathrm{~s}$, portanto o estado quimicamente ativo na molécula de benzofenona é o estado triplete $T_{1}\left(\mathrm{n}, \pi^{*}\right)\left(\mathrm{E}_{\mathrm{T}}=69,3 \mathrm{kcal} \mathrm{mol}^{-1}\right)$ e não o estado excitado singlete $S_{1}\left(n, \pi^{*}\right)$.

Durante a excitação do grupo carbonila, a ligação $\pi$ é quebrada e o elétron $n$ do oxigênio está fracamente correlacionado com o elétron $\pi$ do sistema. O estado triplete da benzofenona pode ser considerado como um 1,2-dirradical. A conjugação do grupo carbonila com o anel benzeno diminui a energia da ligação $\pi$ da carbonila resultando em um dirradical estabilizado por ressonância.

O 1,2-dirradical formado no estado triplete $T_{1}$ da benzofenona pode abstrair hidrogênio de moléculas doadoras de hidrogênio (RH) como, por exemplo, hidrocarbonetos, álcoois, éteres, aminas, macromoléculas $(\mathrm{PH})$ e produzem o radical cetila benzofenona ${ }^{3}$. A partir dessa etapa inicia-se a cadeia degradativa do polímero (Figura 6). 


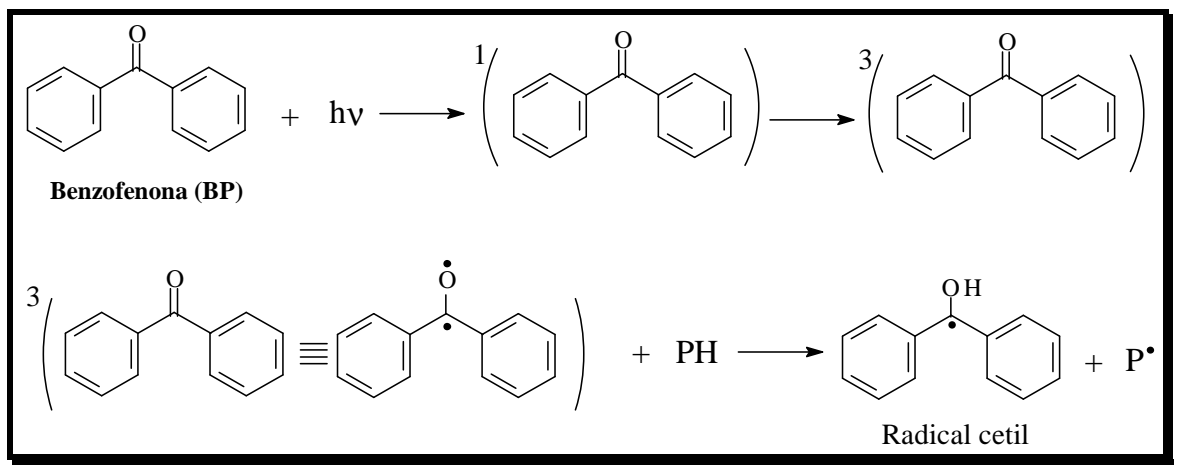

Figura 6. Formação do radical cetila da benzofenona a partir do estado triplete.

\subsection{Fotoestabilidade}

Existem dois tipos de compostos que quando adicionados ao sistema polimérico evitam sua degradação. Estes compostos são os absorvedores de luz e os antioxidantes.

$>$ Absorvedores de luz competem com o substrato na absorção da radiação, evitando que o polímero excitado sofra reações de degradação.

$>$ Antioxidantes reagem com intermediários (radicais livres ou hidroperóxidos) que são formados durante a fotodegradação evitando assim a propagação da cadeia degradativa.

Em geral, a faixa de comprimento de onda que pode ocasionar fotodegradação se situa na faixa do UV próximo, de forma que a maioria dos fotoestabilizadores comerciais é desenvolvida para evitar a ação de radiações entre 290 e $400 \mathrm{~nm}$. Um fotoestabilizador deve satisfazer três condições importantes:

i) Absorver a radiação que seria prejudicial para o polímero com eficiência;

ii) Dissipar a energia absorvida por meio de processos que não interfiram no sistema;

iii) Permanecer na matriz do polímero durante um longo período, sem se degradar.

Os fotoestabilizadores podem seqüestrar ou reagir com os intermediários da cadeia degradativa. Embora os mecanismos ainda não estejam muito bem definidos, supõe-se que as reações com grupos peróxido formados durante a fotoxidação inicial possa inibir a continuação deste processo.

Os corantes também são utilizados para acelerar a fotodegradação dos polímeros. Entretanto, em alguns casos os corantes não influenciam na degradação, mas agem como fotoestabilizantes retardando a mesma ${ }^{15,16}$. 


\subsection{Processos Fotoquímicos e Fotofísicos}

A fotoquímica envolve o estudo de absorção da radiação, assim como o comportamento de átomos e moléculas eletronicamente excitados, produzido pela absorção da luz. Após a absorção de luz, seguidos por mudanças na distribuição eletrônica, as moléculas excitadas podem sofrer vários tipos de desativação fotofísica ou fotoquímica.

Algumas moléculas aromáticas apresentam um comportamento fotofísico e fotoquímico bem característico, muitas moléculas orgânicas possuem um par de elétrons em seu estado fundamental $\left(S_{0}\right)$ e com a absorção de luz há uma mudança na distribuição eletrônica, onde elétrons são promovidos para um estado singlete de maior energia $\left(\mathrm{S}_{1}, \mathrm{~S}_{2}\right)$ com a conservação da configuração do spin de elétrons. Parte dessa energia absorvida sem rearranjo molecular pode resultar em uma conversão interna ou em um processo radiativo de fluorescência.

Em outros casos pode ocorrer a mudança na configuração do spin através de um cruzamento entresistemas levando ao estado triplete. A emissão de luz a partir do triplete resulta no processo radiativo de fosforescência.

Como toda substância que absorve luz, os processos que podem acontecer com as tioxantonas estão associados ao comportamento de seus estados excitados. São possíveis interações com outras substâncias, a partir de qualquer um dos estados excitados, que leva a supressão desses. No entanto, os estados excitados podem dar lugar a reações químicas por decomposição ou com outras substâncias ${ }^{17}$.

Sensibilizadores, como por exemplo os corantes, incorporados como aditivos na cadeia polimérica podem agir como cromóforos, sensibilizando o polímero para a degradação. O mecanismo de interação dos corantes com os polímeros pode ocorrer por dois caminhos diferentes. No caminho A, o corante, após absorver luz na presença de oxigênio $\left(\mathrm{O}_{2}\right)$, produz espécies químicas como oxigênio singlete $\left({ }^{1} \mathrm{O}_{2}\right)$ e ânion superóxido $\left(\mathrm{O}_{2}^{-}\right)$. O oxigênio pode também participar diretamente na oxidação através de reações de redução com o polímero, gerando espécies químicas reativas que aceleram a degradação do polímero. Já no caminho B, o corante após absorver luz, atinge o estado excitado singlete $\left(S_{1}, S_{2}\right)$ e os estados tripletes $\left(\mathrm{T}_{1}, \mathrm{~T}_{2}\right)$ por cruzamento entresistemas. A energia absorvida pelo sensibilizador é transferida para o polímero por transferência de energia intermolecular. A excitação do polímero através do corante aumenta a formação de radicais livres poliméricos $\left(\mathrm{P}^{*}\right)$.

Com isso, pode-se dizer que a tioxantona como a maioria dos corantes, depois de excitados se comportam de acordo com os processos ilustrados pela Figura 7. As importâncias 
relativas desses processos dependem, em grande parte, das características dos corantes envolvidos e do meio nos quais se encontram.

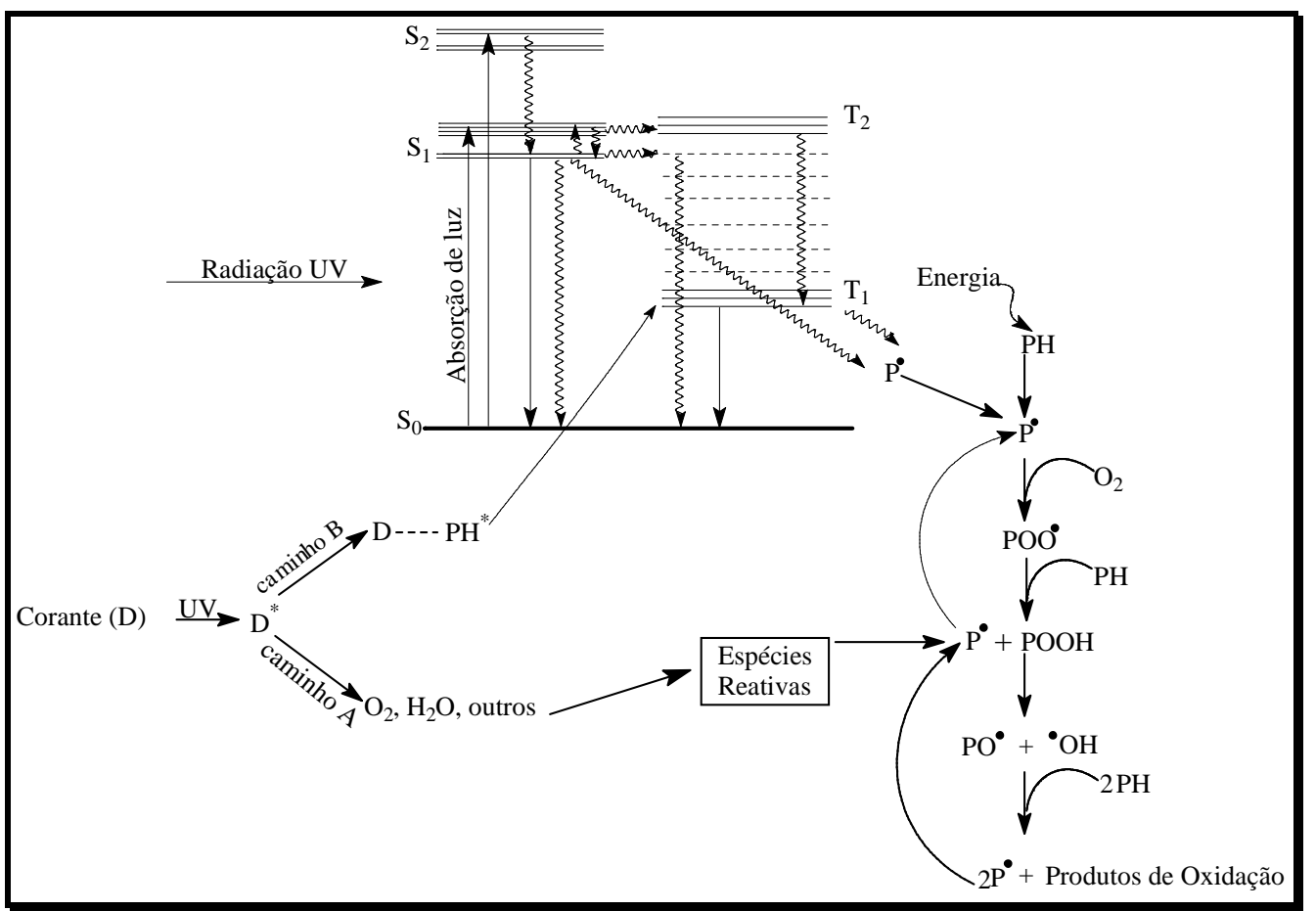

Figura 7. Ação do corante no mecanismo de fotodegradação dos polímeros ${ }^{5}$.

\subsubsection{Supressão de fluorescência}

A emissão de fluorescência é definida como sendo uma transição radiativa entre estados de mesma multiplicidade (singlete $\rightarrow$ singlete). O tempo de vida natural de fluorescência para moléculas orgânicas é compreendido no intervalo entre $10^{-7}$ e $10^{-9}$ segundos.

A supressão é definida como um processo que compete com o processo de emissão espontânea, de modo que o tempo de vida da molécula no estado excitado é reduzido. Isto é, um processo que diminui a intensidade de fluorescência de um dado emissor. Basicamente, essas reações de supressão são processos de transferência de energia ou de elétron. Em muitos casos pode estar envolvida a formação de um complexo no estado excitado, chamado exciplexo.

A supressão pode ocorrer devido a vários processos, um deles é denominado supressão colisional ou dinâmica. O supressor tem que difundir até o fluoróforo durante o tempo de vida do estado excitado resultando em uma colisão bimolecular. Após o contato, o fluoróforo retorna ao estado fundamental, sem emissão de um fóton. 
Devido à necessidade de difusão das moléculas, uma ao encontro da outra, este processo de supressão pode ser estudado por teorias de reações controladas difusionalmente. De acordo com o modelo de difusão de Smoluchowski ${ }^{18}$, quando não existe energia de ativação a velocidade de reação é controlada somente pela velocidade de difusão dos reagentes. Uma expressão aproximada da constante de difusão para reações bimoleculares em solução pode ser representada pela equação de Debye:

$$
k_{\text {difusão }} \approx \frac{8 . R \cdot T}{3000 \cdot \eta} \mathrm{M}^{-1} \cdot s^{-1}
$$

Onde: $\eta$ é a viscosidade do solvente e $R$ é a constante dos gases. Em água, à temperatura ambiente, $\eta \approx 10^{-3} \mathrm{~N} \mathrm{~s} \mathrm{~m}^{-2}$ e $\mathrm{k}_{\text {difusão }} \approx 10^{10} \mathrm{M}^{-1} \mathrm{~s}^{-1}$. A supressão dinâmica próxima ao limite difusional é fortemente dependente do solvente e da temperatura.

A supressão dinâmica ou colisional envolve duas reações competitivas: a desativação unimolecular do estado excitado da molécula fluorescente $\left(\mathrm{F}^{*}\right)$ e a desativação bimolecular por meio de interações com moléculas do supressor (Q).

$$
\begin{aligned}
& \mathrm{F}^{*} \stackrel{\mathrm{k}_{\mathrm{f}}}{\longrightarrow} \mathrm{F}_{\mathrm{o}}+\mathrm{h} v_{\mathrm{f}} \\
& \mathrm{F}^{*} \stackrel{\Sigma \mathrm{k}_{\mathrm{i}}}{\longrightarrow} \mathrm{F}_{\mathrm{o}}+\text { calor } \\
& \mathrm{F}^{*}+\mathrm{Q} \stackrel{\mathrm{k}_{\mathrm{q}}}{\longrightarrow} \mathrm{F}_{\mathrm{o}}+\mathrm{Q}
\end{aligned}
$$

Processo de Fluorescência

Processo não Radiativo

Processo de Supressão

A concentração de $\mathrm{F}^{*}$ na ausência de supressor é dada por:

$$
\left[\mathrm{F}^{*}\right]^{\mathrm{o}}=\frac{\mathrm{I}_{\mathrm{a}}}{\mathrm{k}_{\mathrm{f}}+\mathrm{k}_{\mathrm{IC}}+\mathrm{k}_{\mathrm{ISC}}}=\frac{\mathrm{I}_{\mathrm{a}}}{\mathrm{k}_{\mathrm{f}}+\sum \mathrm{k}_{\mathrm{i}}}
$$

Na qual $I_{a}$ é a intensidade de absorção ou a proporção da formação de moléculas excitadas, $k_{f}$ é a constante de fluorescência e $\Sigma k_{i}$ é a soma de todas as outras constantes dos processos de desativação unimolecular, tais como a conversão interna $\left(k_{I C}\right)$ e o cruzamento entre-sistemas $\left(k_{I S C}\right)$.

A concentração da substância fluorescente [F*] na presença de supressor é dada por:

$$
\left[\mathrm{F}^{*}\right]=\frac{\mathrm{I}_{\mathrm{a}}}{\mathrm{k}_{\mathrm{f}}+\sum \mathrm{k}_{\mathrm{i}}+\mathrm{k}_{\mathrm{q}}[\mathrm{Q}]}
$$

Temos que $\left[F^{*}\right]^{o}$ e $\left[F^{*}\right]$ são as concentrações da substância fluorescente na ausência e na presença do supressor, respectivamente. Em termos dos rendimentos quânticos tem-se: 


$$
\begin{aligned}
& \Phi_{\mathrm{f}}^{\mathrm{o}}=\frac{\mathrm{k}_{\mathrm{f}} \cdot\left[\mathrm{F}^{*}\right]^{\mathrm{o}}}{\mathrm{I}_{\mathrm{a}}}=\frac{\mathrm{k}_{\mathrm{f}}}{\mathrm{k}_{\mathrm{f}}+\sum \mathrm{k}_{\mathrm{i}}} \\
& \Phi_{\mathrm{f}}=\frac{\mathrm{k}_{\mathrm{f}} \cdot\left[\mathrm{F}^{*}\right]}{\mathrm{I}_{\mathrm{a}}}=\frac{\mathrm{k}_{\mathrm{f}}}{\mathrm{k}_{\mathrm{f}}+\sum \mathrm{k}_{\mathrm{i}}+\mathrm{k}_{\mathrm{q}} \cdot[\mathrm{Q}]}
\end{aligned}
$$

Dividindo-se as Equações (4) por (5) obtém-se:

$$
\frac{\Phi_{\mathrm{f}}^{o}}{\Phi_{\mathrm{f}}}=\frac{\mathrm{k}_{\mathrm{f}}+\sum \mathrm{k}_{\mathrm{i}}+\mathrm{k}_{\mathrm{q}} \cdot[\mathrm{Q}]}{\mathrm{k}_{\mathrm{f}}+\sum \mathrm{k}_{\mathrm{i}}}=1+\frac{\mathrm{k}_{\mathrm{q}} \cdot[\mathrm{Q}]}{\mathrm{k}_{\mathrm{f}}+\sum \mathrm{k}_{\mathrm{i}}}
$$

O tempo de vida da substância fluorescente na ausência de supressor $\left(\tau_{0}\right)$ é dado por:

$$
\tau_{\mathrm{o}}=\frac{1}{\mathrm{k}_{\mathrm{f}}+\sum \mathrm{k}_{\mathrm{i}}}
$$

Substituindo-se a Equação (7) em (6) obtém-se:

$$
\frac{\Phi_{\mathrm{f}}^{\mathrm{o}}}{\Phi_{\mathrm{f}}}=1+\mathrm{k}_{\mathrm{q}} \cdot \tau_{\mathrm{o}} \cdot[\mathrm{Q}]=1+\mathrm{K}_{\mathrm{SV}} \cdot[\mathrm{Q}]
$$

A Equação 8 é conhecida como equação de Stern-Volmer, na qual $K_{S V}$ é a constante de Stern-Volmer, $\Phi_{\mathrm{f}}^{0}$ e $\Phi_{\mathrm{f}}$ são rendimentos quânticos de fluorescência na ausência e presença de supressor, $k_{q}$ é a constante de velocidade de supressão bimolecular, $\tau_{0}$ é o tempo de vida da substância fluorescente na ausência de supressor e $[Q]$ é a concentração do supressor.

Para simplificar, assume-se que os rendimentos quânticos de emissão são proporcionais às intensidades de fluorescência,

$$
\frac{\Phi_{\mathrm{f}}^{\mathrm{o}}}{\Phi_{\mathrm{f}}}=\frac{\mathrm{I}_{0}}{\mathrm{I}}
$$

Onde $I_{0}$ e $I$ representam as intensidades de fluorescência na ausência e presença de supressor, respectivamente.

O gráfico de Stern-Volmer para $I_{0} / I$ versus $[Q]$ é linear. Conhecendo-se $\tau_{0}$, pode-se calcular $k_{q}$ a partir da inclinação da reta.

Outro processo de supressão pode ocorrer devido à formação de um complexo no estado fundamental entre o supressor e a substância fluorescente. Este processo é denominado supressão estática. 


\section{OBJETIVOS}

O objetivo principal desse trabalho foi investigar o comportamento da tioxantona e do copolímero estireno-co-tioxantona na fotodegradação do poliestireno. Para que este objetivo fosse alcançado, uma série de objetivos secundários foram propostos:

* Investigação do comportamento espectral dos filmes de poliestireno contendo os sensibilizadores, tioxantona e benzofenona, irradiados com luz visível. Por um lado, observando-se as modificações espectrais do polímero através da espectroscopia de infravermelho e por outro o comportamento espectral dos sensibilizadores utilizando-se a técnica de UV-Vis.

* Síntese e caracterização do copolímero estireno-co-tioxantona (PS-TX I).

* Estudo do estado excitado dos copolímeros (PS-TX I e PS-TX II), da tioxantona livre e da tioxantona na presença do poliestireno. Portanto, foram enfocados processos que levam à formação de intermediários radicalares e a fotoestabilização desta e de derivados no polímero.

Investigação da fotoestabilidade em solução dos copolímeros (PS-TX I e PS-TX II) e da tioxantona livre na presença do poliestireno utilizando-se radiação visível. 


\section{PARTE EXPERIMENTAL}

\subsection{Reagentes utilizados}

Os reagentes e solventes foram usados como recebidos do fornecedor sem purificação prévia. Algumas informações sobre os reagentes usados neste estudo estão apresentadas naTabela 1.

Tabela 1. Principais reagentes utilizados

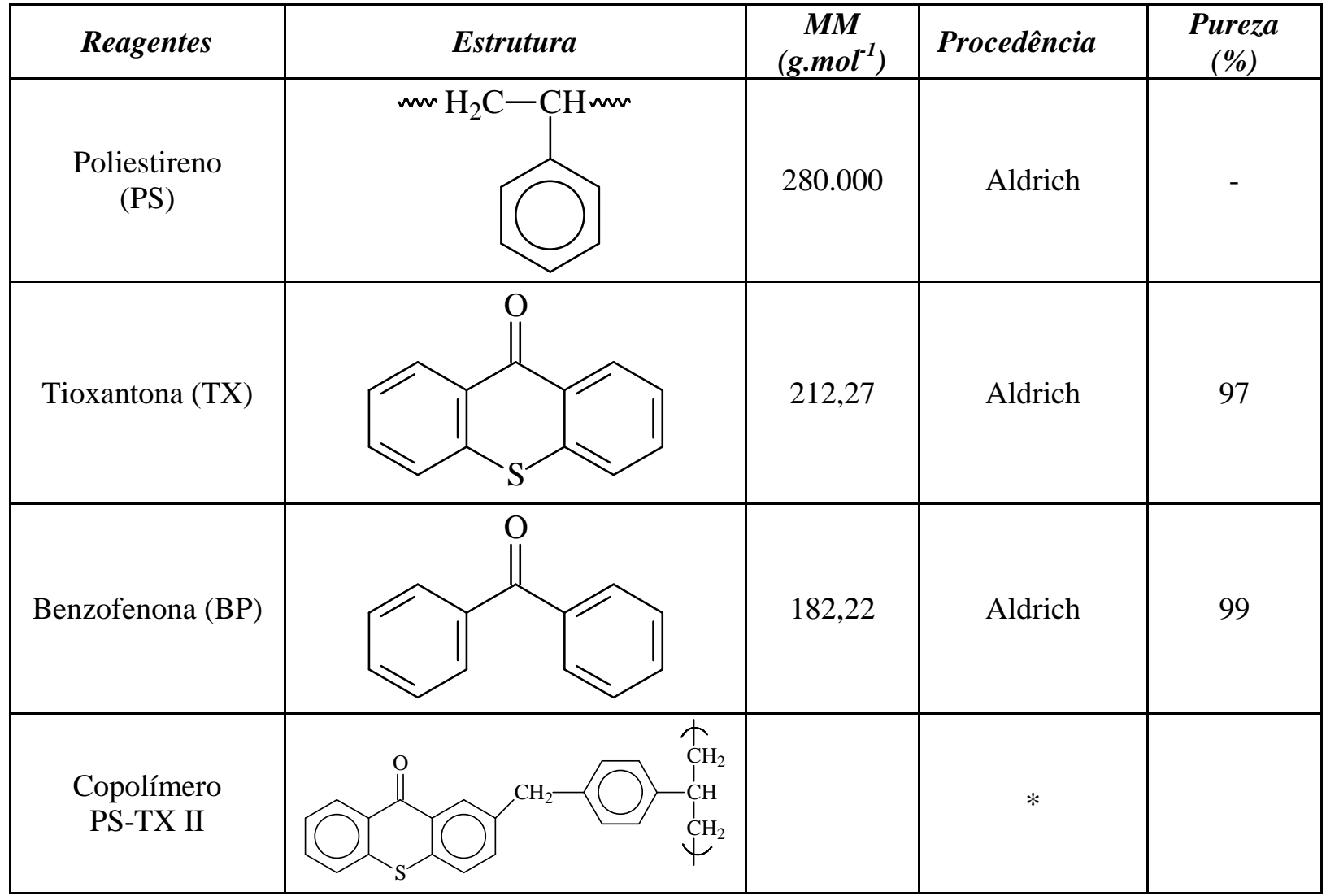

* Gentilmente cedido pelo Prof. Dr. Fernando Catalina, CSIC, Madri, Espanha.

Outros reagentes utilizados: clorofórmio (Mallinckrodt), metanol (Mallinckrodt), tetrahidrofurano (HPLC, Tedia), trietanolamina (90\%, Aldrich), acetonitrila (HPLC, Tedia), benzeno (PA, Merck) e dimetilformamida (99,8\%, Mallinckrodt).

\subsection{Equipamentos Utilizados}

$>$ Espectrofotômetro UV-2550, Shimadzu com acessório para filmes e para amostras sólidas, Reflectância Difusa.

Espectrofotômetro de Infravermelho com Transformada de Fourier, BOMEM 100 MS, com acessório de Reflectância Especular. 
Sistema de Flash Photolysis Luzchem. Laser de Nd-YAG, (Brilliant B, Quantel, 5,2 ns e 165 mJ/pulso), com acessório para amostras sólidas, Reflectância Difusa.

Câmara de irradiação contínua TECNAL TE-383, com 16 lâmpadas de luz visível, 6 W G5 XELUX.

$>$ Cromatógrafo Líquido de Alta Eficiência, com acessório para Cromatografia de Exclusão por Tamanho, Shimadzu.

\subsection{Técnicas Instrumentais}

\subsubsection{Espectroscopia de Absorção no UV-vis}

A espectroscopia de absorção no Ultravioleta e visível é uma técnica na qual a molécula, cromóforo, é irradiada com luz ultravioleta ou visível podendo assim ocorrer uma transição eletrônica quando a molécula absorve uma quantidade de energia e um dos elétrons é excitado do orbital que ocupa no estado fundamental a outro orbital de maior energia. Quando este grupo de moléculas passa pela mesma transição eletrônica, ocorrem simultaneamente transições vibracionais e rotacionais. A soma destas absorções leva ao aparecimento de bandas.

As características principais de uma banda de absorção são: posição e intensidade. A posição de absorção corresponde ao comprimento de onda da radiação, cuja energia é igual à necessária para que ocorra a transição eletrônica. A intensidade de uma determinada banda é relacionada com o coeficiente de absortividade molar, $\varepsilon$, também se relaciona com a concentração e com a distância percorrida pela luz na amostra, podendo ser expressa pela Lei de Lambert-Beer, de acordo com a Equação 14.

$$
\mathrm{A}=\log \left(\mathrm{I}_{0} / \mathrm{I}\right)=\varepsilon \cdot l \cdot \mathrm{c}
$$

onde,

$\mathrm{I}_{0}$ é a intensidade da luz incidente;

I é a intensidade da luz transmitida;

A é a absorbância;

c é a concentração em mols por litro;

lé o comprimento do caminho ótico.

Rearranjando a Equação 14, pode-se usá-la para determinar o coeficiente de absortividade molar, $\varepsilon$ : 


$$
\varepsilon=\log \left(I_{0} / I\right) / l c=A / l c
$$

A espectroscopia de absorbância no UV-Vis pode monitorar as mudanças causadas no polímero devido à fotodegradação por meio da mudança na absorção de determinada banda. O máximo de absorção em $250 \mathrm{~nm}$ tem sido atribuído à formação de dienos ${ }^{10}$. Dessa forma, a espectroscopia UV-Vis é um método conveniente para observar o aspecto da fotodegradação do poliestireno, principalmente a formação de dienos conjugados.

\subsubsection{Espectroscopia de Infravermelho com Transformada de Fourier}

A espectroscopia de infravermelho com transformada de Fourier é uma técnica nãodestrutiva muito utilizada para o acompanhamento rápido e contínuo do processo de fotopolimerização e também de fotodegradação.

As reações fotoquímicas no poliestireno podem ser facilmente detectadas por FTIR. Os espectros do poliestireno obtidos através da técnica de FTIR permitem acompanhar a mudança na intensidade da banda na região de $1740 \mathrm{~cm}^{-1}$, atribuída ao grupo carbonila e a mudança na região de 3400 a $3645 \mathrm{~cm}^{-1}$, atribuída a hidroxila e hidroperóxidos ${ }^{19}$.

\subsubsection{Cromatografia de Exclusão por Tamanho, SEC}

A Cromatografia de Exclusão por Tamanho, SEC do inglês size exclusion chromathography, é um dos métodos mais utilizados de separação e análise de materiais poliméricos. A separação ocorre exclusivamente pela diferença de tamanho das moléculas. As macromoléculas maiores não entram nos poros e atravessam a coluna mais rapidamente, já as partículas menores penetram nos poros e ficam retidas na coluna por um tempo maior.

Através desta técnica, determina-se simultaneamente a massa molar numérica média, a massa molar ponderal média e a polidispersidade de uma amostra polimérica.

A massa molar média depende do número de moléculas de polímero presentes na solução, qualquer que seja a estrutura ou tamanho e é representado pela Equação 16.

$$
\overline{\mathrm{M}}_{\mathrm{n}}=\frac{\sum_{\mathrm{i}=1}^{\infty} \mathrm{n}_{\mathrm{i}} \mathrm{M}_{\mathrm{i}}}{\sum_{\mathrm{i}=1}^{\infty} \mathrm{n}_{\mathrm{i}}}
$$

onde:

$\overline{\mathrm{M}}_{\mathrm{n}}$ é a massa molar média;

$\mathrm{M}_{\mathrm{i}}$ é a massa molar de moléculas de classe $\mathrm{i}$;

$\mathrm{n}_{\mathrm{i}}$ é o número de moléculas de classe $\mathrm{i}$. 
A massa molar ponderal média, representada pela Equação 17, depende do número e da massa de cada molécula presente na solução:

$$
\overline{\mathrm{M}}_{\mathrm{w}}=\frac{\sum_{\mathrm{i}=1}^{\infty} \mathrm{n} \mathrm{M}_{\mathrm{i}}^{2}}{\mathrm{n}_{\mathrm{i}} \mathrm{M}_{\mathrm{i}}}
$$

sendo:

$\overline{\mathrm{M}}_{\mathrm{w}}$ é a massa molar ponderal média;

$\mathrm{M}_{\mathrm{i}}$ é a massa molar das moléculas de classe $\mathrm{i}$;

ni é o número de moléculas de classe i.

A relação entre $\overline{\mathrm{M}}_{\mathrm{w}}$ e $\overline{\mathrm{M}}_{\mathrm{n}},\left(\overline{\mathrm{M}}_{\mathrm{w}} / \overline{\mathrm{M}}_{\mathrm{n}}\right)$, define a polidispersidade da amostra polimérica e é tanto maior quanto mais heterogêneo forem as massas molares dos polímeros obtidos $^{20}$.

\subsubsection{Fotólise por pulso de Laser}

Fotólise por pulso de laser é um método largamente usado na investigação fotoquímica, foi usado primeiramente por Norrish e Porter para estudo direto de espécies com tempos de vida curtos, como exemplo tripletes e radicais ${ }^{3}$.

A radiação laser é altamente eficiente na produção destas espécies, pois além de apresentar elevada intensidade $\left(10^{20}\right.$ fótons), possui ainda a vantagem de ser altamente monocromática. A técnica de fotólise por pulso de laser consiste basicamente de duas etapas:

$>$ Produção de um número razoável de moléculas no estado triplete de menor energia, $\left(\mathrm{T}_{1}\right)$

$>$ Detecção espectroscópica da concentração de tripletes por absorção de luz, que leva ao segundo estado triplete, $\left(\mathrm{T}_{2}\right)$.

Esta técnica utiliza duas fontes de luz, na primeira a luz do laser excita uma quantidade razoável de moléculas da amostra, que por cruzamento entresistemas (ISC) gera espécies no estado triplete $T_{1}$. Antes que as mesmas retornem ao estado fundamental, uma segunda fonte de luz é utilizada para excitar estas espécies ao segundo estado triplete $\left(\mathrm{T}_{2}\right)$ por absorção de um fóton. Ou seja, a técnica consiste em submeter a amostra a ação de um pulso de luz de alta intensidade e de curta duração, com o objetivo de gerar uma alta concentração de transientes. Após esta etapa, as espécies transientes podem ser observadas por absorção óptica ou espectroscopia de emissão ${ }^{21}$. 


\subsection{Procedimento Experimental}

\subsubsection{Estudo dos Processos de Fotodegradação dos Filmes de Poliestireno}

\section{Fotodegradação}

As amostras poliméricas contendo tioxantona e benzofenona foram estudadas na forma de filmes. Os filmes de poliestireno foram preparados a partir da solubilização de $5 \%(\mathrm{~m} / \mathrm{m})$ do polímero no solvente clorofórmio. A seguir, adicionou-se em cada solução polimérica o sensibilizador tioxantona ou benzofenona na concentração de $1,0 \times 10^{-3} \mathrm{~mol} \mathrm{~L}^{-1} \mathrm{e}$ $5,0 \times 10^{-3} \mathrm{~mol} \mathrm{~L}^{-1}$, respectivamente. Os filmes foram colocados em placas de Petri e secos a temperatura ambiente por aproximadamente 5 horas.

Os espectros de absorção UV-Vis e de FTIR foram obtidos antes de se iniciar a fotodegradação do polímero na câmara de irradição e após cada intervalo de irradiação determinado.

As degradações foram realizadas em uma câmara de irradiação contendo 16 lâmpadas fluorescentes de 6W G5 XELUX (Fotoreator modelo-Te-383, Tecnal) para uma irradiação uniforme dos sistemas. A Figura 8 ilustra a câmara de irradiação utilizada nas degradações.
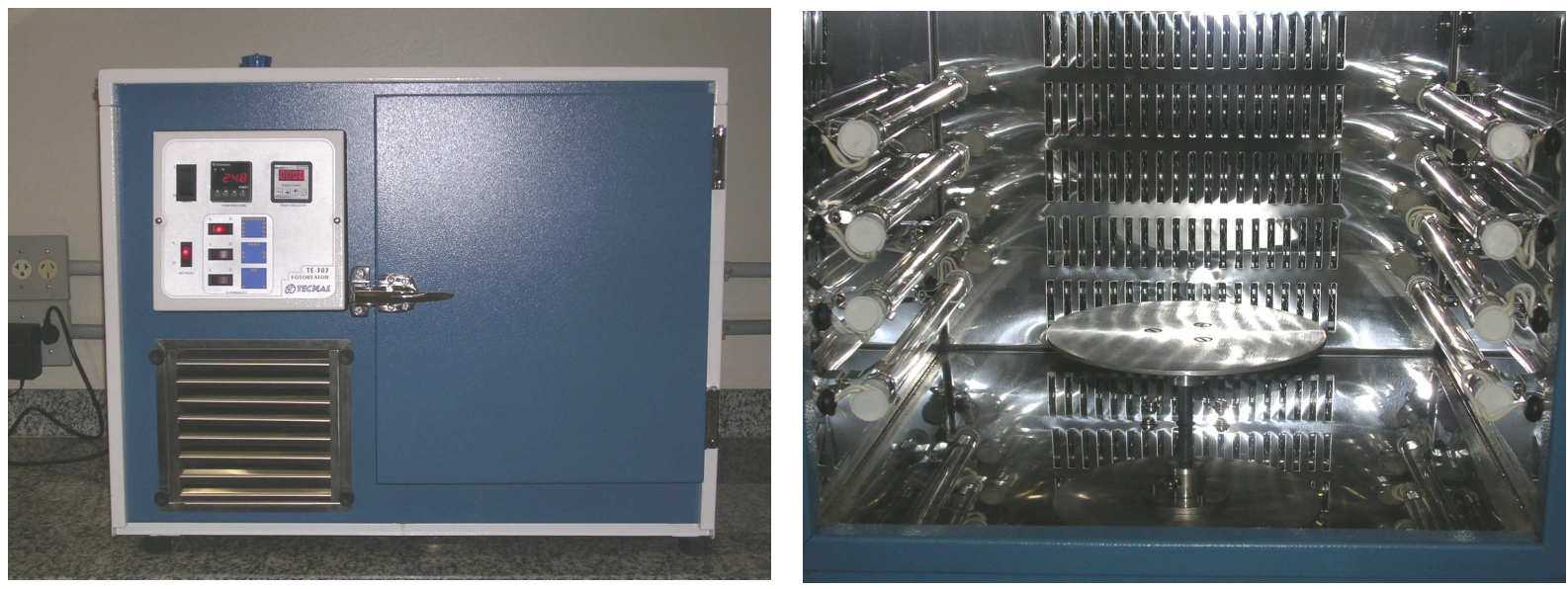

Figura 8. Câmara de irradiação (TECNAL) utilizada nos experimentos de fotodegradação.

\section{Cromatografia de Exclusão por Tamanho, SEC}

As amostras dos filmes de poliestireno/tioxantona e poliestireno/benzofenona não irradiadas e irradiadas tiveram suas massas molares e as correspondentes distribuições determinadas a partir da análise dos cromatogramas obtidos em um cromatógrafo HPLC Shimadzu modelo LC-10 AD com detector de índice de refração. Para as medidas utilizou-se 
uma combinação de quatro colunas, sendo duas Styragel HR 4 e duas Styragel HR 5, cujo preenchimento é constituído por partículas rígidas do copolímero poli(estireno-codivinilbenzeno). A calibração foi feita usando padrões de poliestireno, Scientific Polymer Products, com massas molares compreendidas entre 2.500 e $600.000 \mathrm{~g} \mathrm{~mol}^{-1}$. Utilizou-se tetrahidrofurano como eluente e para o preparo dos padrões e das amostras utilizou-se massa de $5 \mathrm{mg}$ dissolvida em $2 \mathrm{~mL}$ de tetrahidrofurano. As medidas foram realizadas a $40{ }^{\circ} \mathrm{C}$ com fluxo de $1 \mathrm{~mL} \mathrm{~min}^{-1}$.

\subsubsection{Estudo da Fotoestabilidade da Tioxantona e dos Copolímeros PS-TX I e PS-TX II em Solução}

\section{Fotodegradação}

As soluções contendo tioxantona livre, tioxantona adicionada ao poliestireno e as contendo os copolímeros PS-TX I e PS-TX II foram irradiadas e estudadas através dos espectros de absorção UV-Vis. Estes foram obtidos antes de se iniciar a fotodegradação na câmara de irradiação e após cada intervalo de irradiação determinado. As degradações foram realizadas na mesma câmara de irradiação, Figura 8, com acessório para solução.

\subsubsection{Estudo das Reações Elementares de Tioxantonas}

\section{Preparo da solução de tioxantona em diferentes solventes}

As soluções de tioxantona, $1,0 \times 10^{-4} \mathrm{~mol} \mathrm{~L}^{-1}$ foram preparadas em diferentes solventes. Os espectros de absorbância dos transientes e os decaimentos dos tempos de vida foram medidos com o sistema de fotólise por pulso de laser.

\section{Síntese do copolímero estireno-co-tioxantona (PS-TX I)}

Para o preparo do copolímero PS-TX I adicionou-se $1,7 \mathrm{~g}$ de ácido tiosalicílico vagarosamente à $15 \mathrm{~mL}$ de ácido sulfúrico concentrado e a mistura foi agitada por 10 minutos. Posteriormente, adicionou-se $0,2 \mathrm{~g}$ de poliestireno (comercial) triturado lentamente à mistura em agitação ao longo de um período de 30 minutos. Após a adição, a mistura reacional foi agitada à temperatura ambiente por 1 hora e depois a $80{ }^{\circ} \mathrm{C}$ por 3 horas. Após esta etapa, a mistura foi deixada em repouso a temperatura ambiente por uma noite. A mistura 
resultante foi derramada cuidadosamente em um volume de água fervente 10 vezes maior que a mistura, sob agitação e fervido por mais 5 minutos. A solução foi resfriada e filtrada.

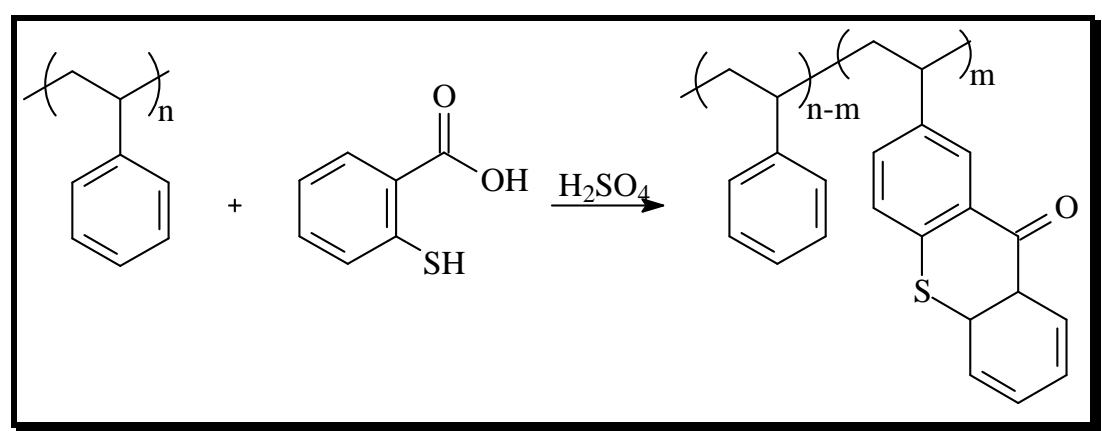

Figura 9. Síntese do copolímero PS-TX I²2. 


\section{RESULTADOS E DISCUSSÃO}

\subsection{FOTODEGRADAÇÃO DOS FILMES DE POLIESTIRENO}

\subsubsection{Estudo da Fotodegradação do Poliestireno na Presença do Sensibilizador} Tioxantona

Análise dos Espectros de Absorção na região $U V$-vis

A Figura 10 ilustra o espectro de absorção do filme PS na presença de tioxantona $\left(1,0 \times 10^{-3} \mathrm{~mol} \mathrm{~L}^{-1}\right)$ antes de ser irradiado. A banda de absorção da TX aparece entre 340 e $410 \mathrm{~nm}$.

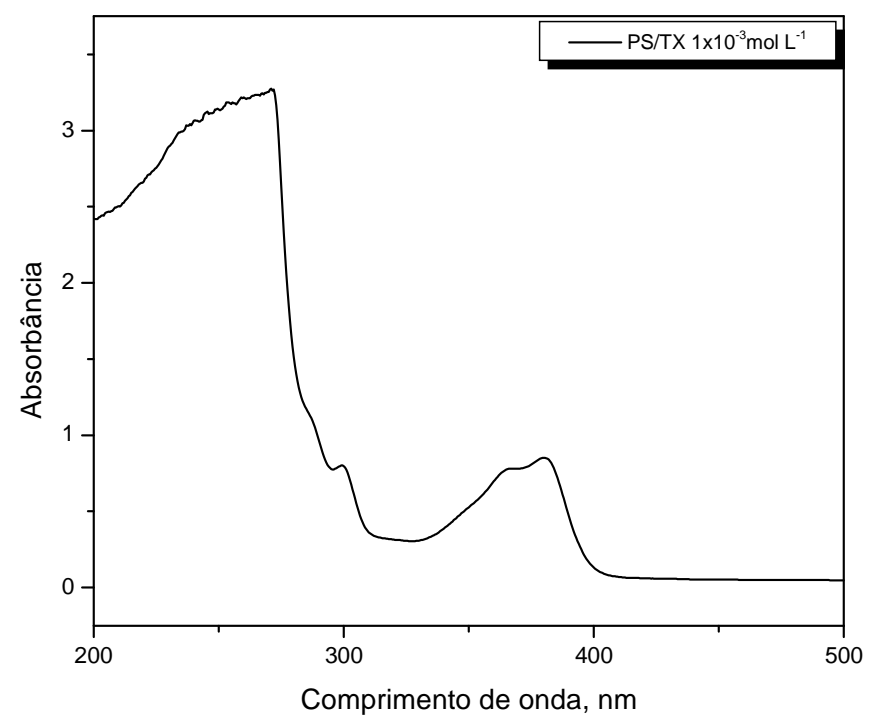

Figura 10. Espectro de absorção do PS na presença de tioxantona $\left(1,0 \times 10^{-3} \mathrm{~mol} \mathrm{~L}^{-1}\right)$ antes da irradiação.

Os filmes de poliestireno (PS) foram submetidos à irradiação na região do visível sob duas condições distintas, em ar e em atmosfera de $\mathrm{N}_{2}$. As mudanças provocadas nos filmes pela irradiação foram monitoradas pelas técnicas UV-vis e FTIR.

A Figura 11 ilustra os espectros de absorção do filme PS/TX em diferentes tempos de irradiação (A) em ar, e (B) em atmosfera inerte. A região entre 250 e $380 \mathrm{~nm}$ foi monitorada para se avaliar os processos de degradação. 


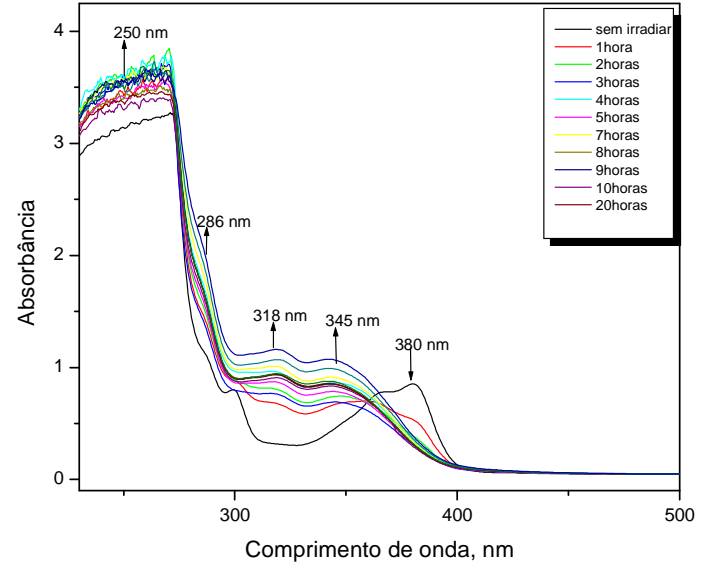

A

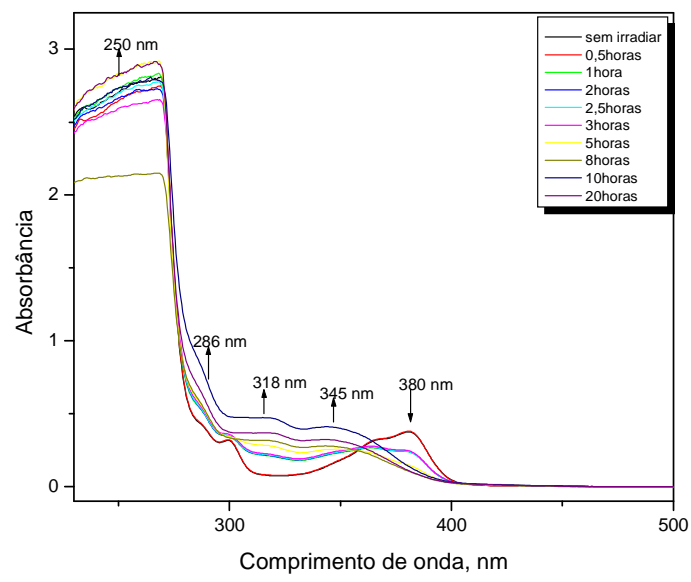

B

Figura 11. Espectros de absorção do filme PS/TX antes e após 20 horas de irradiação com luz visível, (A) em ar e (B) em atmosfera inerte.

Observando-se os espectros de absorbância da Figura 11, referentes ao filme PS/TX irradiado a diferentes tempos de irradiação, notam-se as seguintes variações espectrais:

$>$ Diminuição da banda em $380 \mathrm{~nm}$;

Aumento das bandas de absorção em 283, 318, 345 e $250 \mathrm{~nm}$;

A diminuição da banda em $380 \mathrm{~nm}$ pode ser atribuída ao consumo da tioxantona, (TX). Observa-se também, nos espectros apresentados na Figura 11, a existência de um ponto isosbéstico em $360 \mathrm{~nm}$, o qual indica a presença de duas espécies, ou seja, ao mesmo tempo em que há a formação de produtos de degradação, há também o consumo desses produtos gerando novas moléculas. Assim, o aparecimento das bandas em 345, 318, $283 \mathrm{~nm}$ e o aumento da banda em $250 \mathrm{~nm}$ podem ser atribuídos à formação de fotoprodutos gerados a partir da degradação do poliestireno.

A absorbância em $250 \mathrm{~nm}$ aumenta rapidamente no PS/TX em ar, principalmente nas horas iniciais de irradiação, ilustrado pela Figura 12A. Este aumento da absorbância pode ser atribuído ao aumento de duplas ligações conjugadas referentes a um rearranjo dado a partir do radical formado do poliestireno por ação fotoxidativa ${ }^{3}$.

As mudanças ocorridas na banda de absorção em $283 \mathrm{~nm}$ apresentam um aumento da absorbância, indicando que a formação de um cromóforo nesse comprimento de onda é bem mais evidente nas primeiras horas de irradiação em ar do que em atmosfera inerte, como ilustrado pela Figura 12B. 


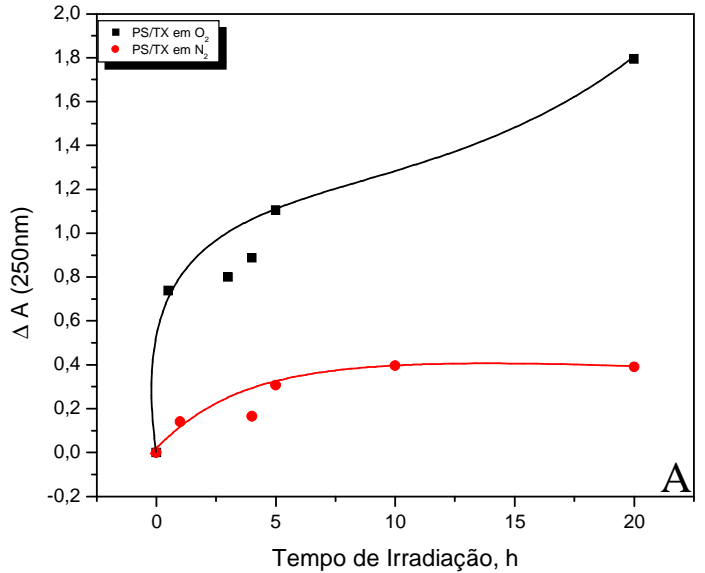

A

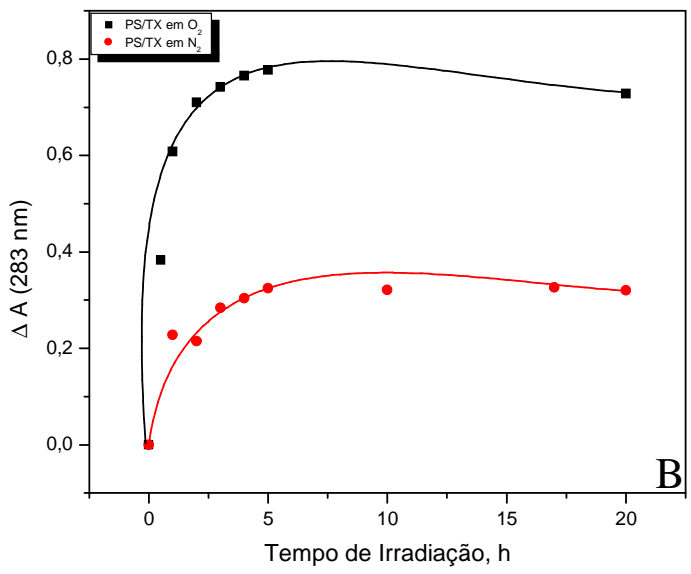

B

Figura 12. Mudança na absorbância em 250 nm (A) e em 283 nm (B) ocorridas nos filmes PS/TX em ar e PS/TX, sob atmosfera de $\mathrm{N}_{2}$.

A Figura 13 ilustra as mudanças ocorridas nas bandas em 318 e $345 \mathrm{~nm}$ provocadas pela irradiação do poliestireno. As mudanças foram mais acentuadas nas primeiras horas de irradiação. Em atmosfera inerte foi observado um comportamento estável quando comparado a presença de $\mathrm{O}_{2}$, o que pode evidenciar a formação de produtos de oxidação.

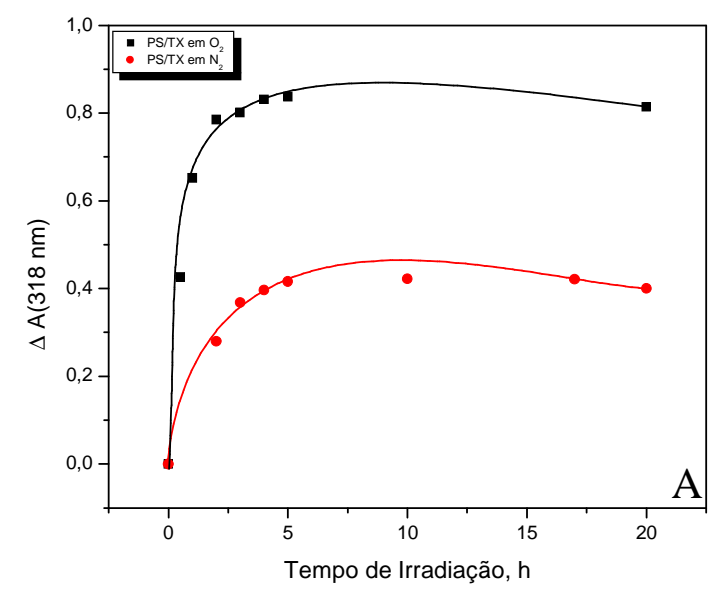

A

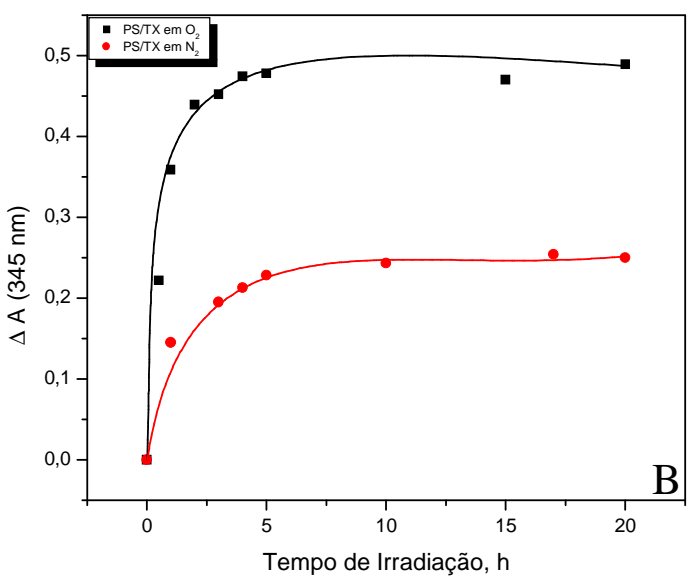

B

Figura 13. Mudança na absorbância em 318 nm (A) e em 345 nm (B) ocorridas nos filmes PS/TX na presença de ar e PS/TX em atmosfera inerte.

A Figura 14 ilustra a diminuição da absorbância da tioxantona em 380 nm. Observa-se um decréscimo na absorbância quando irradiado na presença de ar indicando uma instabilidade referente a fotoxidação. 


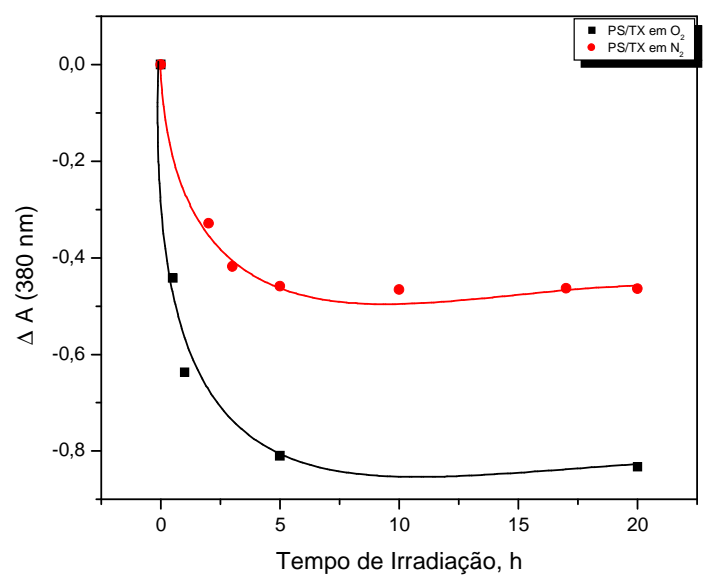

Figura 14. Mudança na absorbância em 380 nm ocorridas nos filmes PS/TX na presença de ar e PS/TX em atmosfera inerte.

Análise dos Espectros de FTIR

Os filmes poliméricos contendo o sensibilizador TX foram irradiados com luz visível e as variações espectrais foram acompanhadas por FTIR.

A Figura 15 ilustra o espectro de FTIR do filme de PS na presença do sensibilizador.

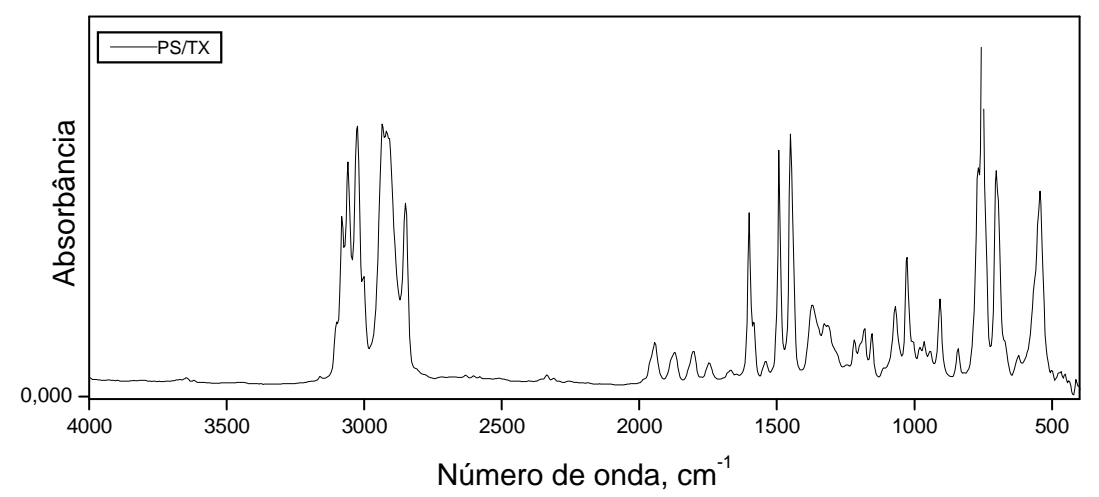

Figura 15. Espectro de FTIR do filme PS na presença de TX $\left(1,0 \times 10^{-3} \mathrm{~mol} \mathrm{~L}^{-1}\right)$ antes da irradiação. 
A Tabela 2 resume as bandas de absorção e os respectivos modos de vibração característicos das ligações do poliestireno.

Tabela 2. Números de onda e modos de vibração característicos do poliestireno ${ }^{23}$

\begin{tabular}{ll}
\hline Número de onda $\left(\mathbf{c m}^{-1}\right)$ & Modo de Vibração \\
\hline $3001-3103$ & $\mathrm{C}-\mathrm{H}($ de anel aromático), estiramento \\
2925 & $\mathrm{C}-\mathrm{H}\left(\right.$ de $\left.\mathrm{CH}_{2}\right)$ estiramento assimétrico \\
2850 & $\mathrm{C}-\mathrm{H}\left(\right.$ de $\left.\mathrm{CH}_{2}\right)$ estiramento simétrico \\
1601 e 1583 & $\mathrm{C}-\mathrm{C}$ estiramento do anel no plano \\
1493 & C-H estiramento do anel no plano \\
1452 & $\mathrm{C}-\mathrm{H}$ dobramento devido ao $\mathrm{CH}_{2}$ \\
1069 e 1029 & $\mathrm{C}-\mathrm{H}$ dobramento do anel no plano \\
1003 & $\mathrm{C}=\mathrm{C}$ dobramento fora do plano \\
840,757 e 699 & $\mathrm{C}-\mathrm{H}$ dobramento fora do plano \\
\hline
\end{tabular}

O acompanhamento das variações espectrais permitiu verificar a formação de novas bandas e o desaparecimento de outras.

A Figura 16 ilustra duas regiões do espectro de FTIR de uma amostra de filme de PS/TX irradiado na presença de ar. As mudanças espectrais nessa região foram:

Aumento da banda em $1740 \mathrm{~cm}^{-1}$ que pode ser atribuído à formação da carbonila $(\mathrm{C}=\mathrm{O})^{10}$

Aumento da absorção na região em torno de $3645 \mathrm{~cm}^{-1}$ que indica a formação de hidroxila/hidroperóxido $(-\mathrm{OH} /-\mathrm{OOH})^{10}$.

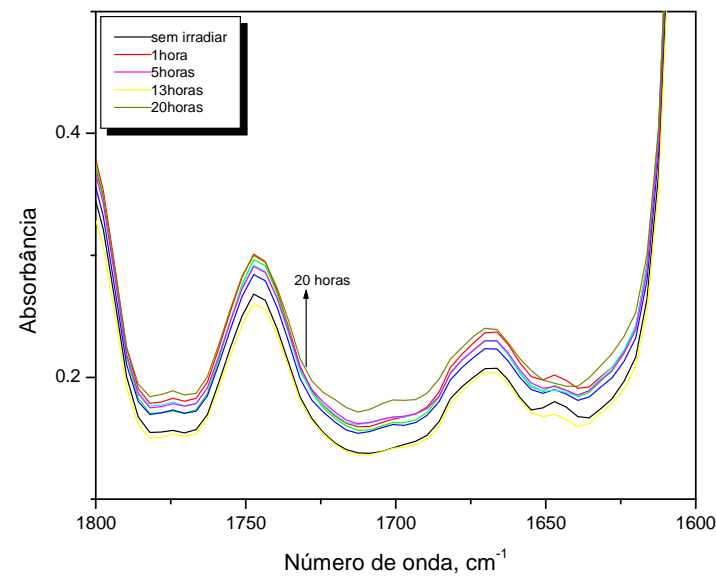

A

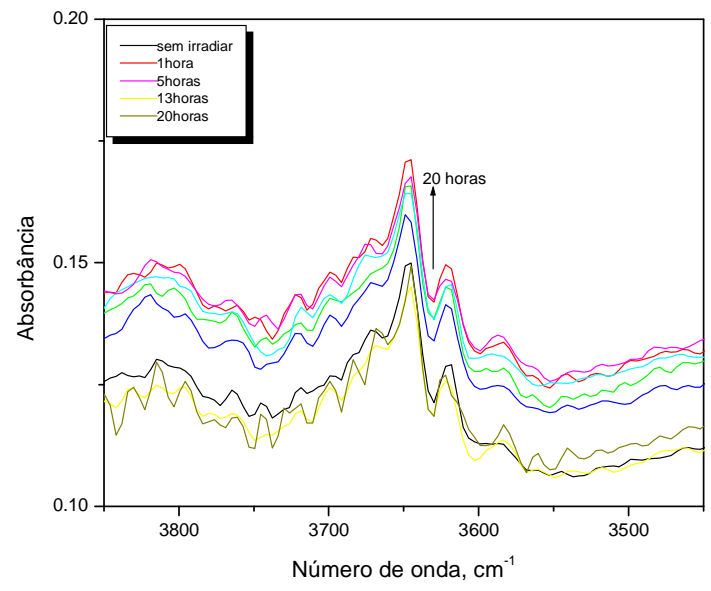

B

Figura 16. Espectros de FTIR do filme PS/TX antes e após diferentes tempos irradiação com luz visível sob ar, $\mathrm{T}=40{ }^{\circ} \mathrm{C}$. (A) 1800 a $1600 \mathrm{~cm}^{-1}$ e (B) 3850 a $3450 \mathrm{~cm}^{-1}$. 
A Figura 17 ilustra as mudanças ocorridas nas principais bandas de absorção IR durante a fotodegradação do PS na presença do sensibilizador TX, em atmosfera inerte.

Aumento progressivo da banda da carbonila $(\mathrm{C}=\mathrm{O})$ em $1740 \mathrm{~cm}^{-1}$;

A banda em $3645 \mathrm{~cm}^{-1}$ referente a hidroxila/hidroperóxido (-OH/-OOH) não sofreu modificação significativa.

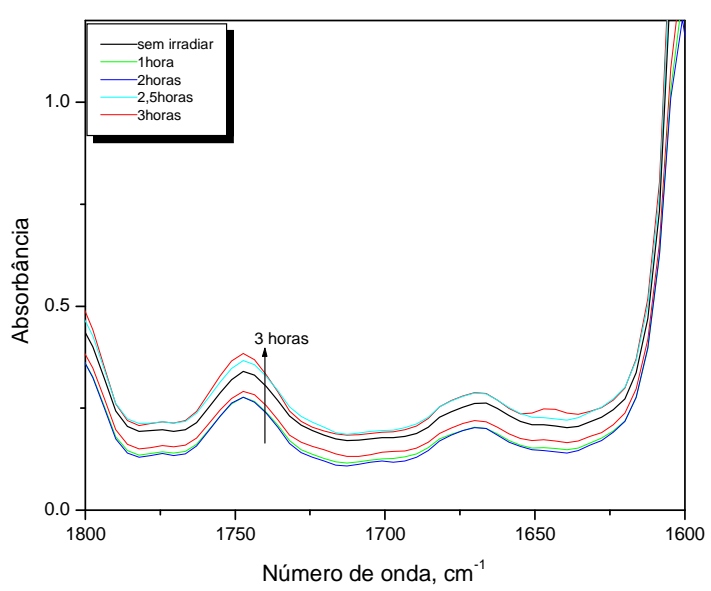

A

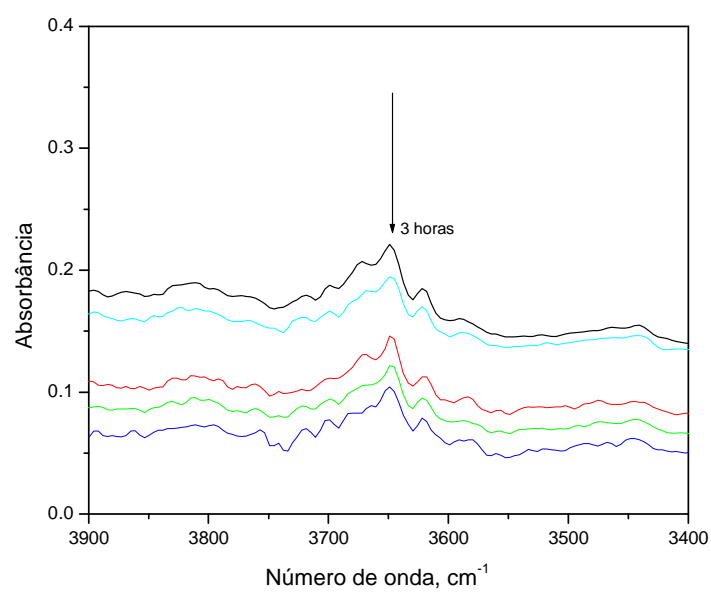

B

Figura 17. Espectro de FTIR do filme PS/TX antes e após 20 horas de irradiação com luz visível em atmosfera inerte. (A) 1800 a $1600 \mathrm{~cm}^{-1}$ e (B) 3900 a $3400 \mathrm{~cm}^{-1}$.

As mudanças causadas pela irradiação com luz visível na presença de ar e em atmosfera inerte foram observadas em algumas bandas características na região do IR.

As curvas da Figura 18A (diferença da absorbância em $1740 \mathrm{~cm}^{-1}$ versus tempo de irradiação) indicam a formação do grupo carbonila $(\mathrm{C}=\mathrm{O})$. Estes fotoprodutos são gerados mais rapidamente nos PS/TX na presença de $\mathrm{O}_{2}$ do que em atmosfera inerte, isto propõe que o polímero ao ser irradiado em ar está mais propício a formação da carbonila quando comparado ao polímero em atmosfera inerte.

A Figura 18B indica que os polímeros PS/TX irradiados na presença de ar sofrem degradação oxidativa, isto é, levam a formação de grupos -OH/-OOH. Já os polímeros irradiados em atmosfera inerte não apresentaram nenhuma variação na absorbância. 


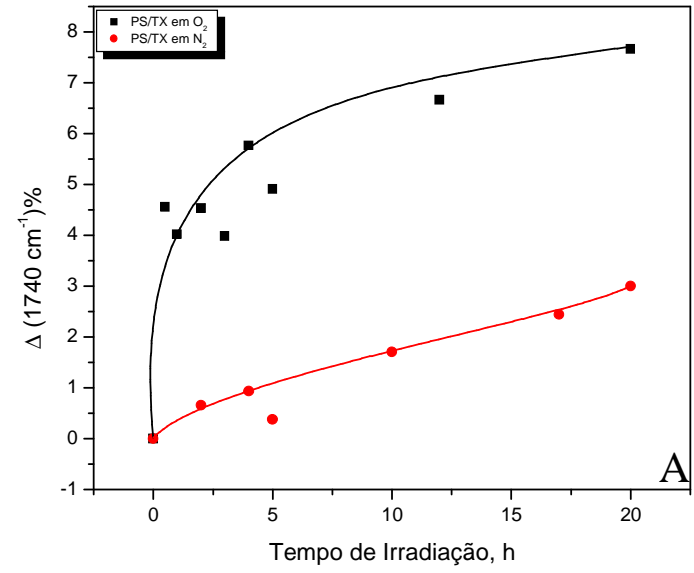

A

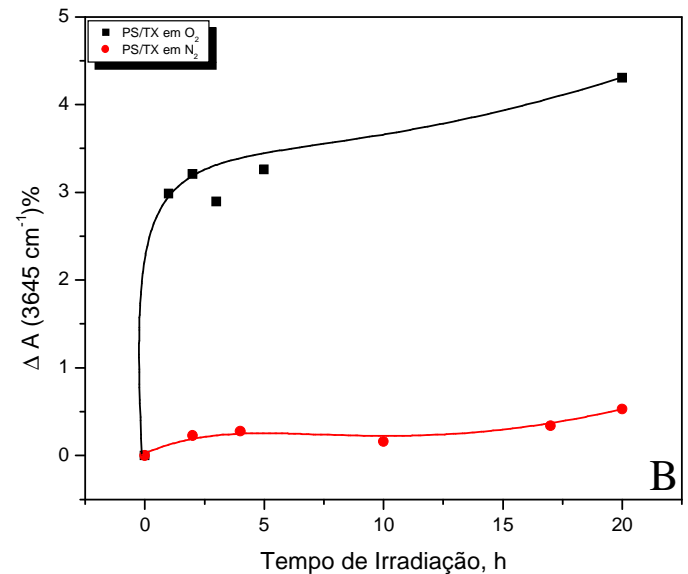

B

Figura 18. Mudança na absorbância em (A) $1740 \mathrm{~cm}^{-1}$ e (B) em $3645 \mathrm{~cm}^{-1}$, ocorridas nos filmes PS/TX em ar e PS/TX, sob atmosfera $\mathrm{N}_{2}$.

\subsubsection{Fotodegradação do Poliestireno na Presença do Sensibilizador Benzofenona}

A fotodegradação do poliestireno na presença de benzofenona (BP) foi estudada por Torikai, Takeuchi e Fueki (1983) em diferentes atmosferas sob irradiação UV-Vis. Chegou-se a conclusão que a benzofenona age como um sensibilizador em fotodegradação ${ }^{13}$. A benzofenona é um sensibilizador bastante conhecido em reações fotoquímicas o qual forma o radical cetila pela seguinte reação:

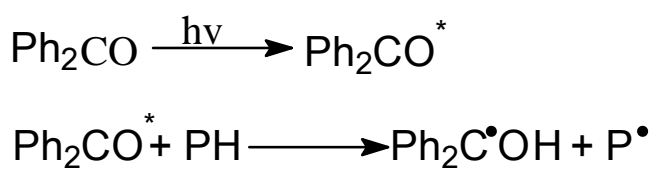

Portanto, esse sistema já conhecido mecanisticamente foi escolhido para comparação com os resultados obtidos do sistema PS/TX.

Análise dos Espectros de Absorção na região UV-vis

A Figura 19 ilustra o espectro de absorção do filme PS na presença do sensibilizador benzofenona $\left(5 \times 10^{-3} \mathrm{~mol} \mathrm{~L}^{-1}\right)$ antes da irradiação. A banda da BP aparece entre 320 e $400 \mathrm{~nm}$. 


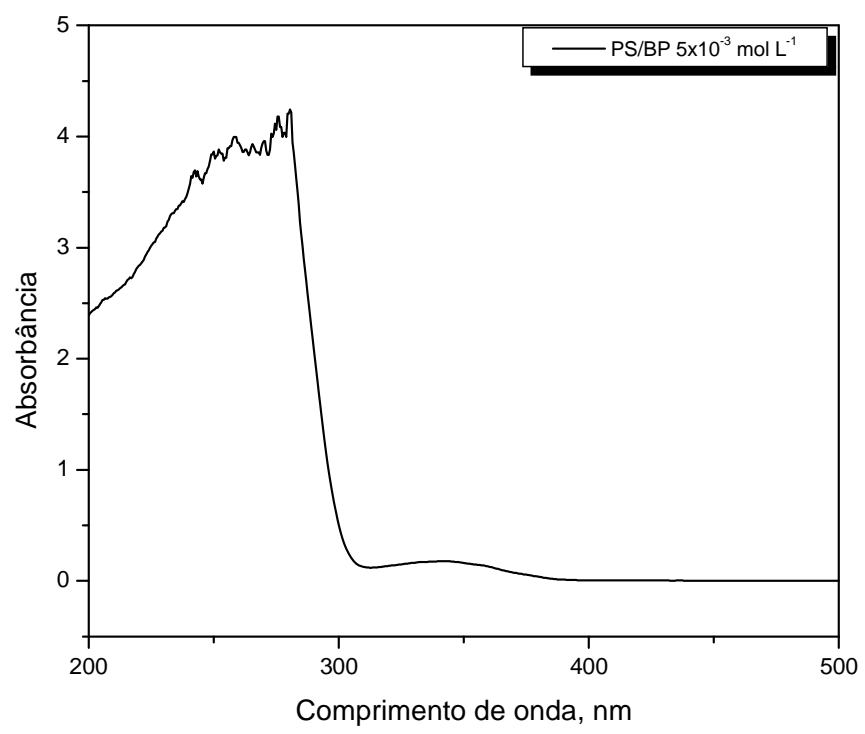

Figura 19. Espectro de absorção do PS na presença de benzofenona $\left(5,0 \times 10^{-3} \mathrm{~mol} \mathrm{~L}^{-1}\right)$ antes da irradiação.

A Figura 20 ilustra os espectros da absorção do filme PS/BP em diferentes tempos de irradiação (A) em ar, e (B) em atmosfera inerte. Inicialmente, observa-se o aparecimento de novas bandas em 310, 331 e $361 \mathrm{~nm}$ referentes aos subprodutos formados pela interação entre o fotossensibilizador BP e o polímero PS presentes nos dois sistemas. O aumento da absorbância em $310 \mathrm{~nm}$ pode ser explicado pela formação de grupos insaturados combinados com as carbonilas ${ }^{24}$.

Também é observada uma mudança na banda em $250 \mathrm{~nm}$. Não houve ponto isosbéstico na fotodegradação do filme PS/BP, tanto em ar como também em atmosfera inerte, provavelmente devido à ausência de produtos de oxidação, ou porque estão presentes em baixa concentração. 


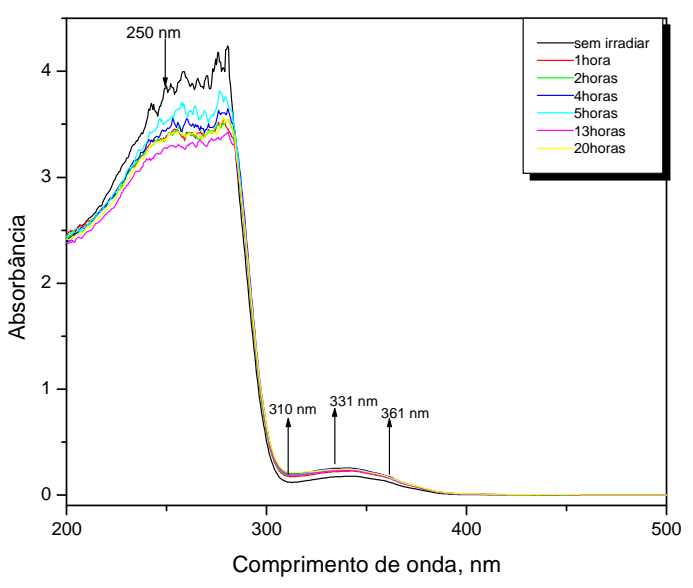

A

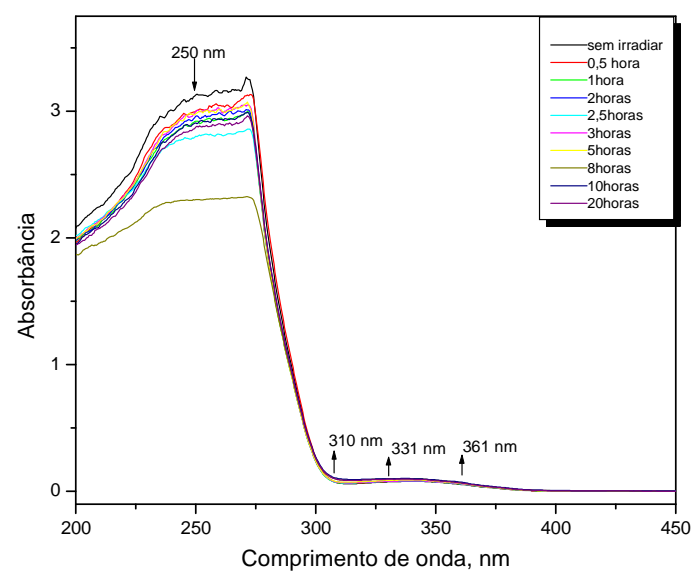

B

Figura 20. Espectro de absorção do filme PS/BP antes e após 20 horas de irradiação com luz visível, em ar (A), e em atmosfera inerte (B).

A irradiação do poliestireno com luz visível na presença do sensibilizador benzofenona provocou um aumento da absorbância em $250 \mathrm{~nm}$, quando irradiado em ar, Figura 21A. Tal efeito pode ser atribuído ao aumento de duplas ligações conjugadas ao longo da cadeia polimérica, isto é, a degradação oxidativa leva à formação de dienos ${ }^{3}$. Já em atmosfera inerte é observada uma diminuição da absorbância neste mesmo comprimento de onda o qual pode ser atribuído ao consumo de cromóforo e ao rearranjo da cadeia polimérica.

Na Figura 21B é ilustrado o aumento da absorbância em 310 nm, que independe da presença de $\mathrm{O}_{2}$, pois se verifica um aumento da absorbância nos dois sistemas, em ar e em atmosfera inerte. 


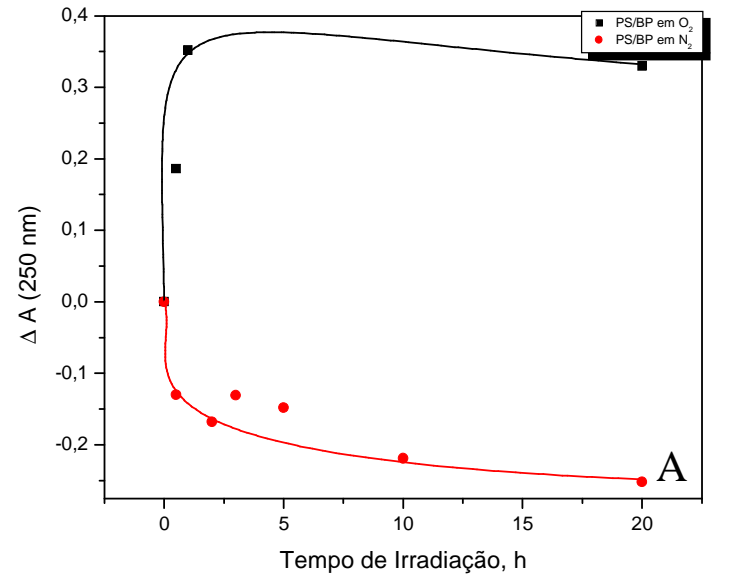

A

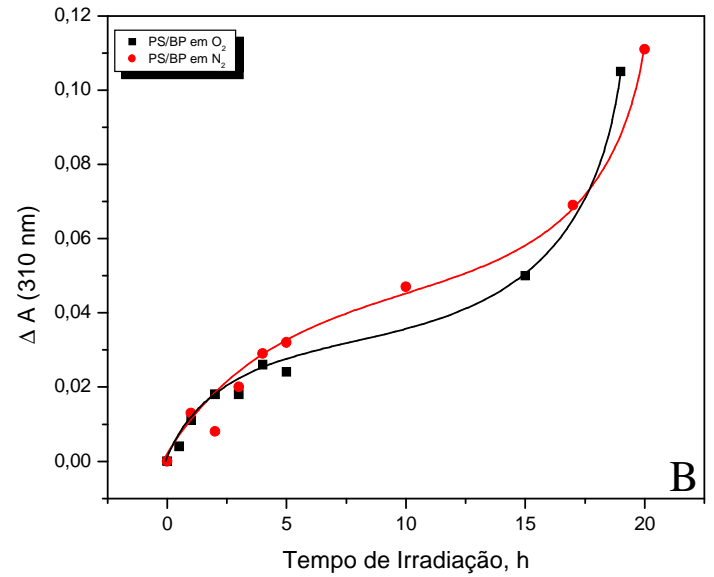

B

Figura 21. Mudança na absorbância em (A) 250 nm e em (B) 310 nm, ocorridas nos filmes PS/BP sob ar e PS/BP sob $\mathrm{N}_{2}$.

A Figura 22 ilustrada as variações de absorbância em 331 e 361 nm, que podem ser atribuídas a fotoprodutos formados a partir da irradiação dos filmes poliméricos na presença de benzofenona. A Figura 22A mostra uma dependência com a atmosfera em que o sistema está exposto, isto pode ser observado pelo aumento da absorbância em $331 \mathrm{~nm}$ em ar e pela absorbância permanecer praticamente inalterada em atmosfera inerte.

Já em atmosfera inerte, Figura 22B, é observado um aumento da absorbância em $361 \mathrm{~nm}$ indicando que independe do $\mathrm{O}_{2}$.

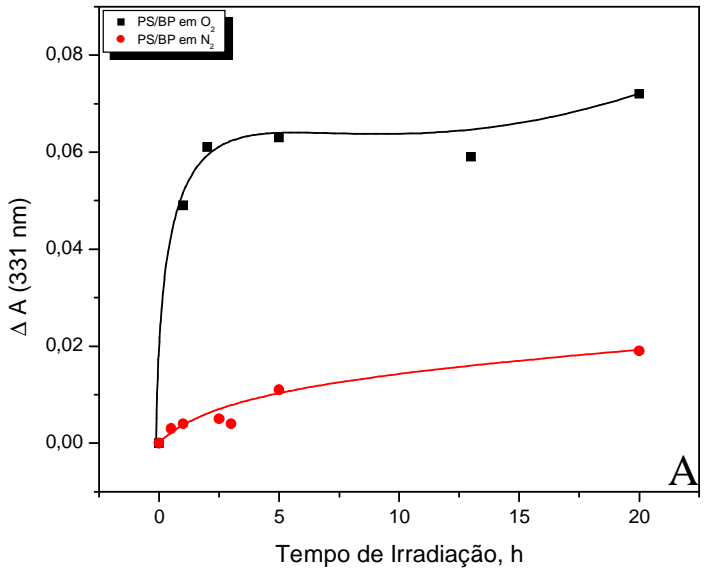

A

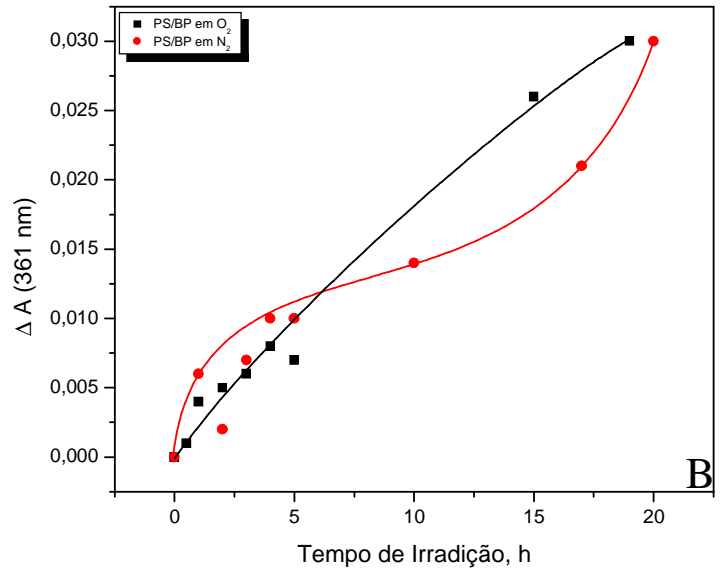

B

Figura 22. Mudança na absorbância em (A) $331 \mathrm{~nm}$ e em (B) $361 \mathrm{~nm}$ ocorridas nos filmes PS/BP sob ar e PS/BP sob $\mathrm{N}_{2}$. 


\section{Análise dos Espectros de FTIR}

As mudanças químicas provocadas pela irradiação dos filmes PS/BP foram monitoradas pelas medidas de FTIR. A Figura 23 ilustra as mudanças ocorridas nas principais bandas de absorção IR durante a fotodegradação do PS na presença do sensibilizador benzofenona $\left(5 \times 10^{-3} \mathrm{~mol} \mathrm{~L}^{-1}\right)$ em ar.

As principais modificações, provavelmente causadas por mudanças estruturais ocorridas no filme polimérico, foram:

Aumento progressivo da banda carbonila $(\mathrm{C}=\mathrm{O}) \mathrm{em} 1740 \mathrm{~cm}^{-1}$;

Aumento progressivo da absorção na região da hidroxila/hidroperóxido (-OH/-OOH) em $3645 \mathrm{~cm}^{-1}$.

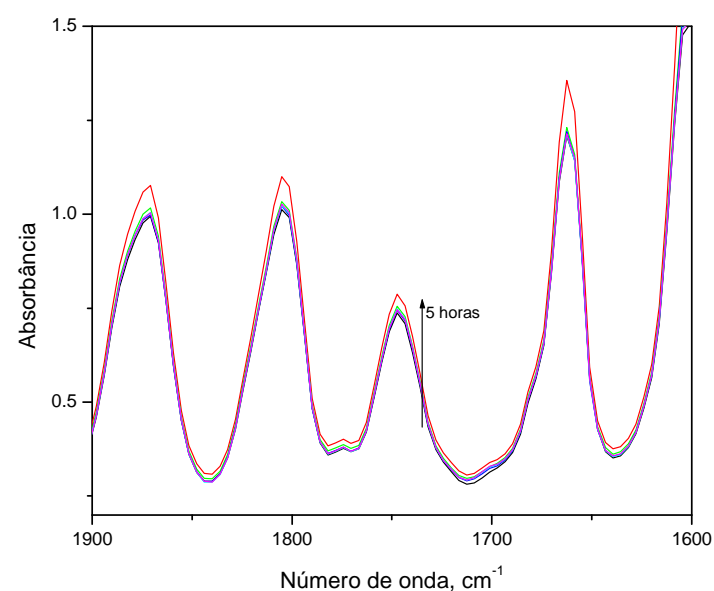

A

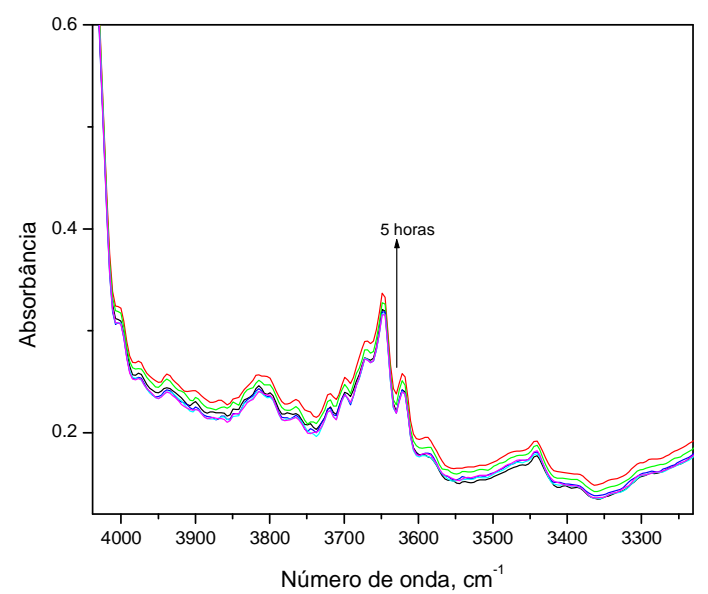

B

Figura 23. Espectro de FTIR do filme PS/BP antes e após 5 horas de irradiação com luz visível, sob ar. (A) 1900 a $1600 \mathrm{~cm}^{-1} 1$ e (B) 4000 a $3200 \mathrm{~cm}^{-1}$.

A Figura 24 ilustra as mudanças ocorridas nas principais bandas de absorção IR para o sistema em atmosfera de $\mathrm{N}_{2}$ :

Aumento da banda da carbonila em $1740 \mathrm{~cm}^{-1}$;

$>$ Diminuição da absorção na região da hidroxila/hidroperóxido (-OH/-OOH) em $3645 \mathrm{~cm}^{-1}$. 


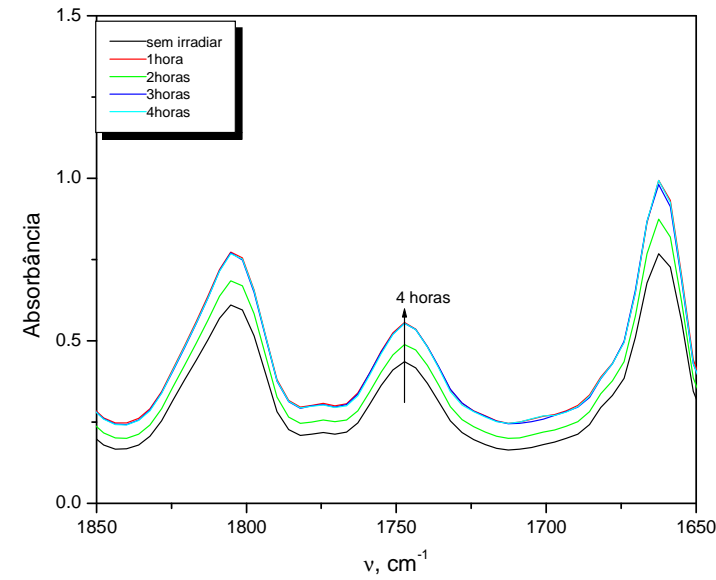

A

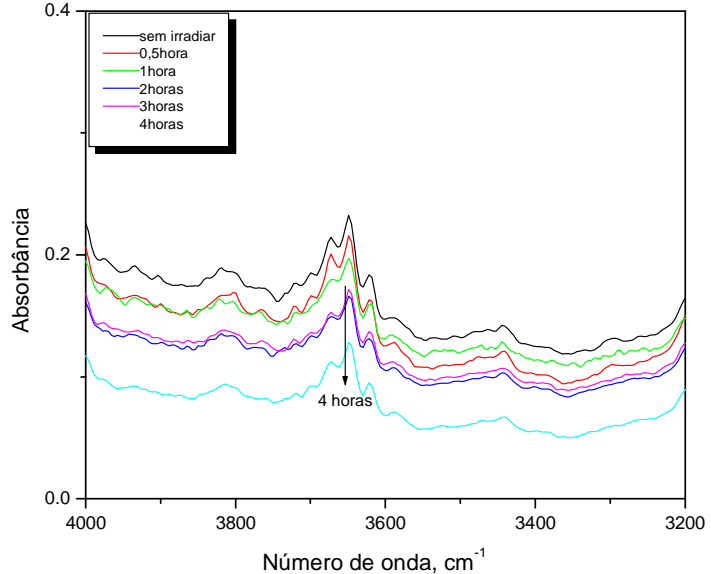

B

Figura 24. Espectro de absorção do filme PS/BP antes e após 4 horas de irradiação com luz visível em atmosfera inerte. (A) 1850 a $1650 \mathrm{~cm}^{-1} \mathrm{e}$ (B) 4000 a $3200 \mathrm{~cm}^{-1}$.

A Figura 25 ilustra as mudanças ocorridas na absorbância em $1740 \mathrm{~cm}^{-1}$ e em $3645 \mathrm{~cm}^{-1}$ no filme polimérico PS/BP comparando os sistemas de irradiação em ar e em

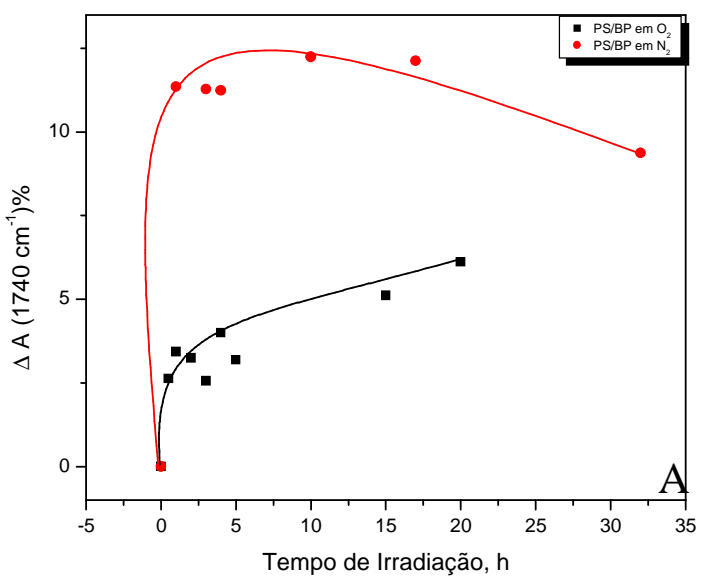

A

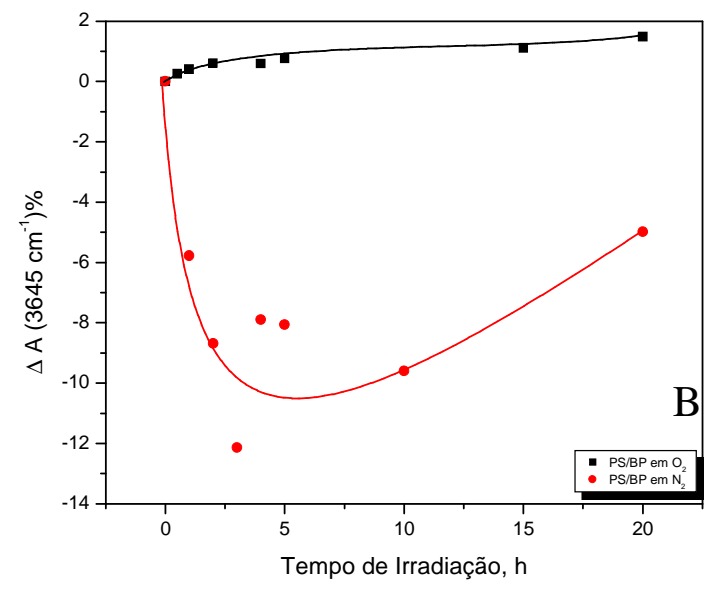

B

Figura 25. Mudança na absorbância (A) em $1740 \mathrm{~cm}^{-1}$ e (B) em $3645 \mathrm{~cm}^{-1}$ ocorridas nos filmes PS/BP na presença de $\mathrm{O}_{2}$ e PS/BP em atmosfera inerte.

atmosfera inerte.

A Figura 25A indica um aumento da absorbância em $1740 \mathrm{~cm}^{-1}$ quando o sistema PS/BP é irradiado em atmosfera inerte.

Na Figura 25B, é ilustrada a variação da absorbância em $3645 \mathrm{~cm}^{-1}$, que indica uma diminuição na absorbância em atmosfera inerte, quando comparado a irradiação sob ar, que 
permanece praticamente inalterada. O PS na presença de benzofenona mostra uma competição entre o ataque do oxigênio para formação de fotoprodutos e a recombinação de radicais (entrecruzamentos de cadeias) ${ }^{13}$. A diminuição observada pode ser resultado desses mecanismos competitivos no qual em atmosfera de nitrogênio prevaleceria o mecanismo de ligações cruzadas.

\subsubsection{Fotodegradação do Poliestireno}

Análise dos Espectros de Absorção na região UV-vis

A Figura 26 ilustra o espectro de absorção do filme PS antes da irradiação com luz ultravioleta.

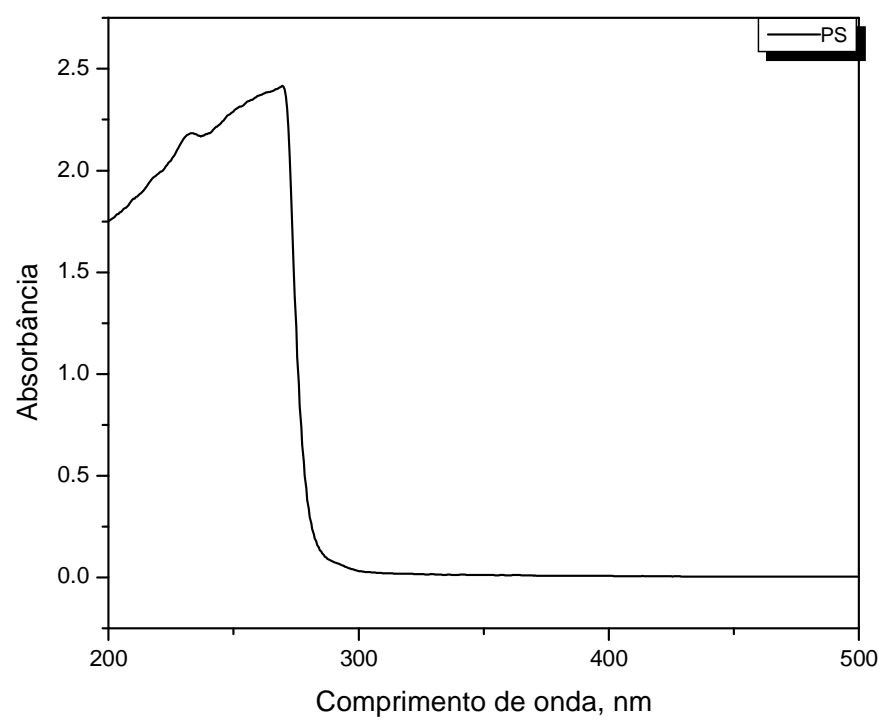

Figura 26. Espectro de absorção do filme PS antes da irradiação com luz ultravioleta.

A Figura 27 ilustra o espectro de absorbância do filme PS nos diferentes tempos de irradiação em ar e em atmosfera de $\mathrm{N}_{2}$. Inicialmente, observa-se o aparecimento de uma nova banda na região entre 300 e $400 \mathrm{~nm}$. Para este estudo serão monitoradas as bandas em 318 e em $250 \mathrm{~nm}$. 


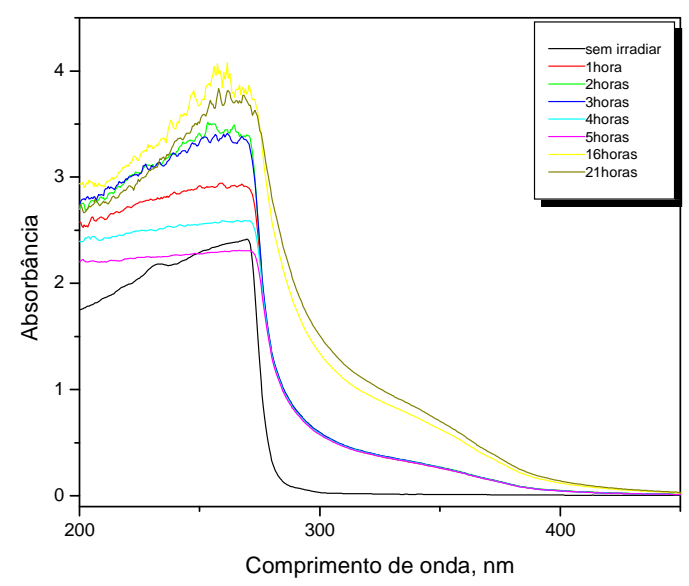

A

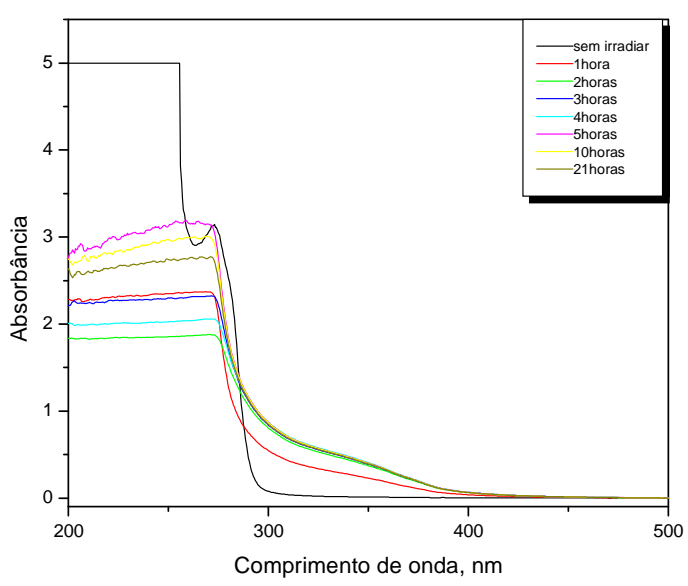

B

Figura 27. Espectro de absorbância do filme PS antes e após 21 horas de irradiação com luz ultravioleta, (A) em ar, (B) sob atmosfera de $\mathrm{N}_{2}$.

É observado na Figura 28A, um aumento da absorbância em 250 nm quando na presença de $\mathrm{O}_{2}$ que pode ser atribuída ao aumento de duplas ligações conjugadas ao longo da cadeia polimérica ${ }^{3}$, porém é observada uma diminuição da mesma banda $(250 \mathrm{~nm})$ de absorbância quando em atmosfera inerte, que pode estar relacionado ao consumo de cromóforo e também a um possível rearranjo da cadeia polimérica.

Na Figura 28B nota-se que a dependência com atmosfera não é significativa, pois não há grande diferença na intensidade de absorção entre os dois sistemas avaliados.

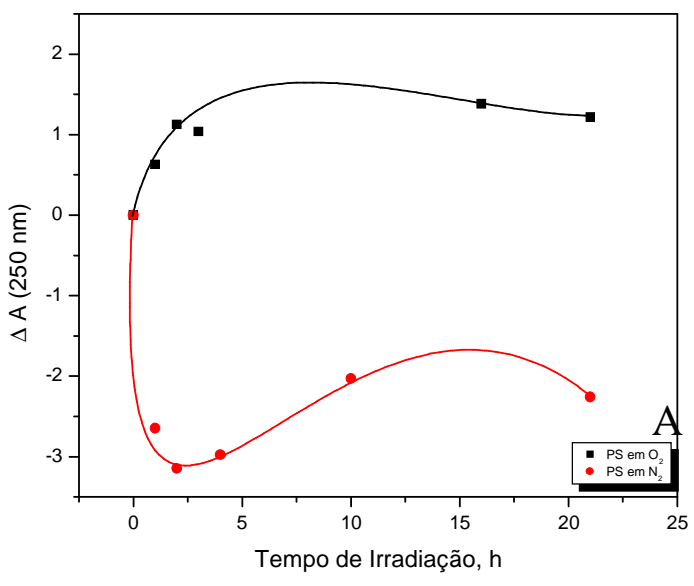

A

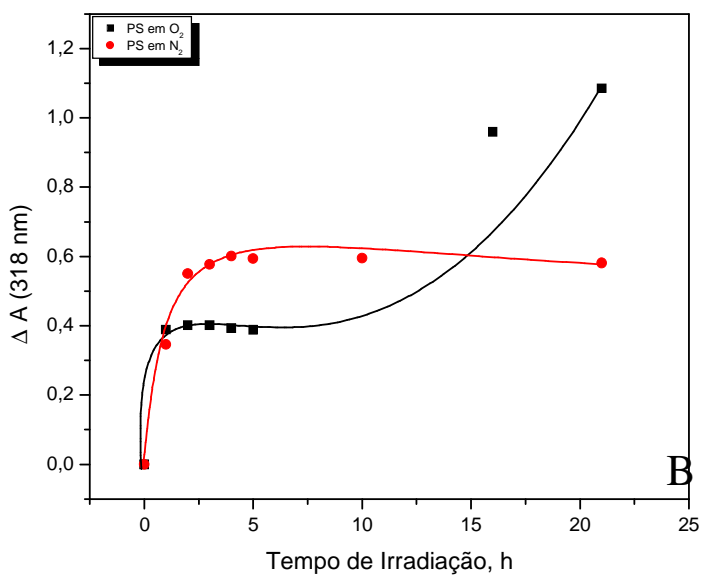

B

Figura 28. Mudança na absorbância em (A) $250 \mathrm{~nm}$ e (B) em $318 \mathrm{~nm}$ ocorridas nos filmes PS em ar e PS em atmosfera inerte. 
Análise dos Espectros de FTIR

Os filmes puros de PS foram irradiados por 21 horas com luz ultravioleta em dois sistemas distintos de atmosfera proporcionando o acompanhamento da degradação por FTIR.

A Figura 29 ilustra o espectro de FTIR do filme de PS antes da irradiação.

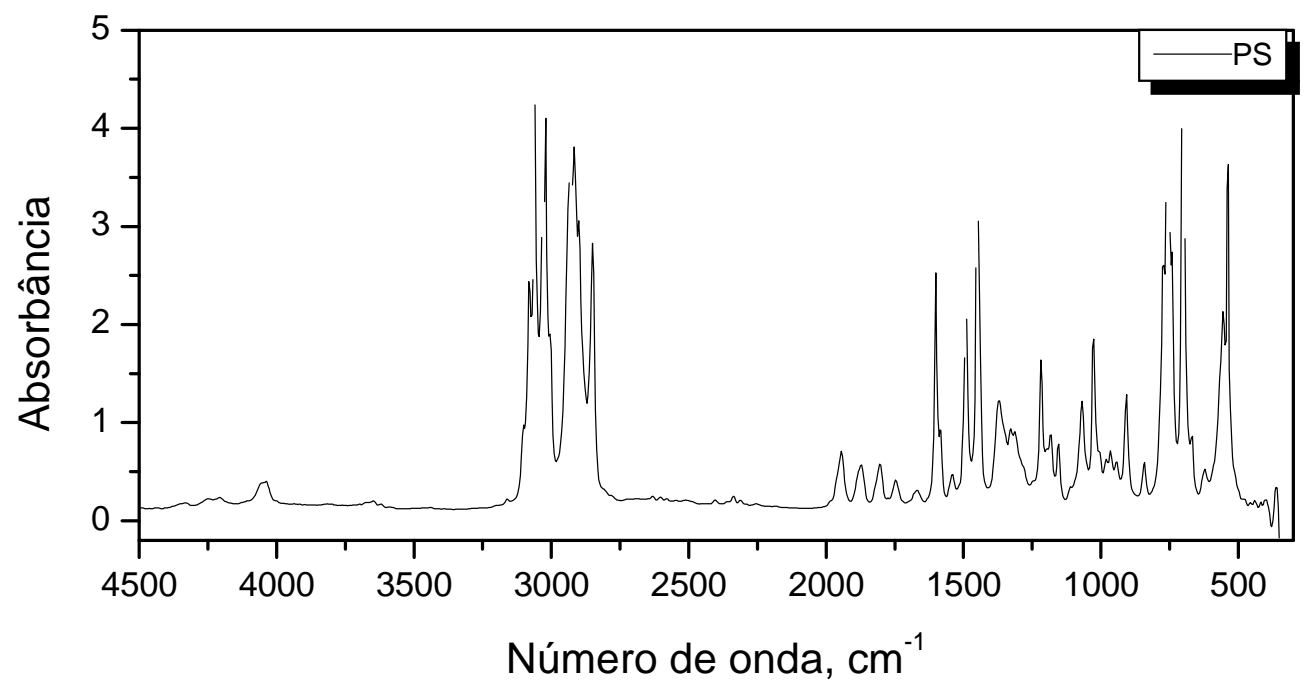

Figura 29. Espectro de FTIR do PS antes da irradiação com luz ultravioleta.

A Figura 30 ilustra as mudanças ocorridas nas principais bandas de absorção IR durante a fotodegradação do PS puro em ar, a $40{ }^{\circ} \mathrm{C}$. 


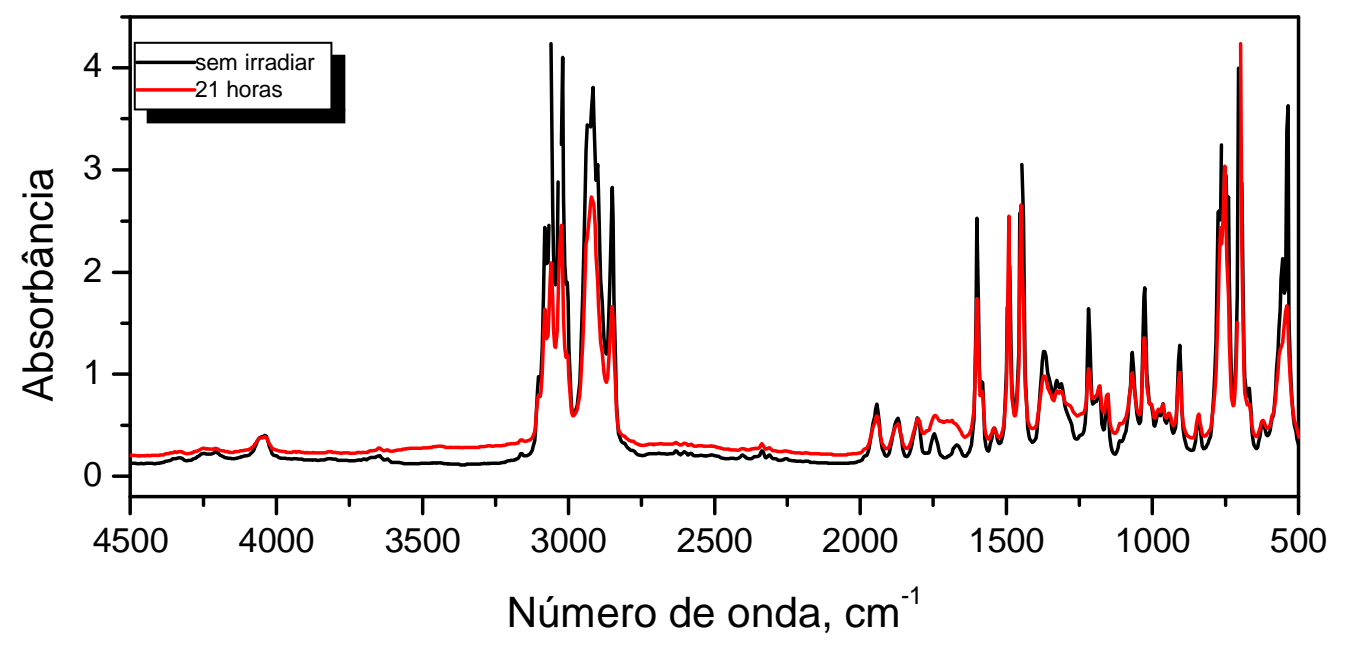

Figura 30. Espectro de FTIR do filme PS antes e após 21 horas de irradiação com luz ultravioleta, sob ar.

O espectro de FTIR do filme PS nos diferentes tempos de irradiação, Figura 31 mostra as seguintes modificações provavelmente causadas pela irradiação:

Aumento progressivo da banda da carbonila $(\mathrm{C}=\mathrm{O}) \mathrm{em} 1740 \mathrm{~cm}^{-1}$;

Aumento da absorção na região da hidroxila/hidroperóxido (-OH/-OOH) em $3645 \mathrm{~cm}^{-1}$.

A Figura 31 ilustra as mudanças ocorridas nas principais bandas de absorção IR durante a irradiação do PS em atmosfera inerte, a $40{ }^{\circ} \mathrm{C}$. As principais modificações foram:

Aumento da banda da carbonila $(\mathrm{C}=\mathrm{O})$ em $1740 \mathrm{~cm}^{-1}$;

Aumento da absorção na região da hidroxila/hidroperóxido (-OH/-OOH) em $3645 \mathrm{~cm}^{-1}$. 


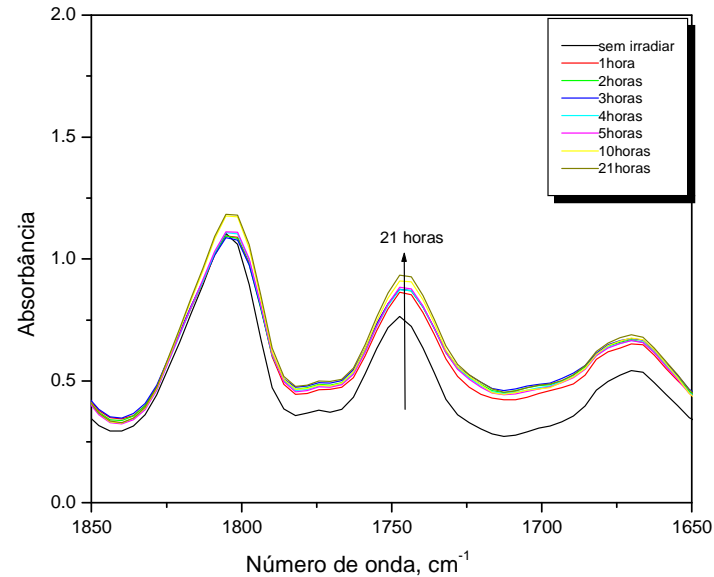

A

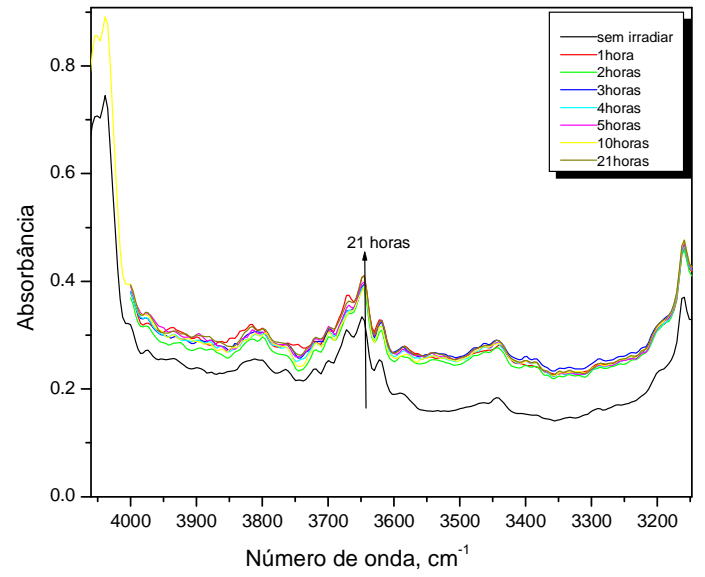

B

Figura 31. Espectro de FTIR do filme PS antes e após 21 horas de irradiação com luz ultravioleta em atmosfera inerte. (A) 1850 a $1650 \mathrm{~cm}^{-1}$ e (B) 4000 a $3200 \mathrm{~cm}^{-1}$.

A Figura 32 ilustra a comparação da irradiação do poliestireno nos dois sistemas estudados. Em atmosfera inerte, não há variação da absorbância em $1740 \mathrm{~cm}^{-1}$, permanecendo constante. Quando na presença de ar, é observado um aumento significativo da absorbância, indicando a degradação fotoxidativa. Em $3645 \mathrm{~cm}^{-1}$, o aumento da absorbância é mais significativo em ar, porém em atmosfera inerte observa-se um comportamento mais estável.

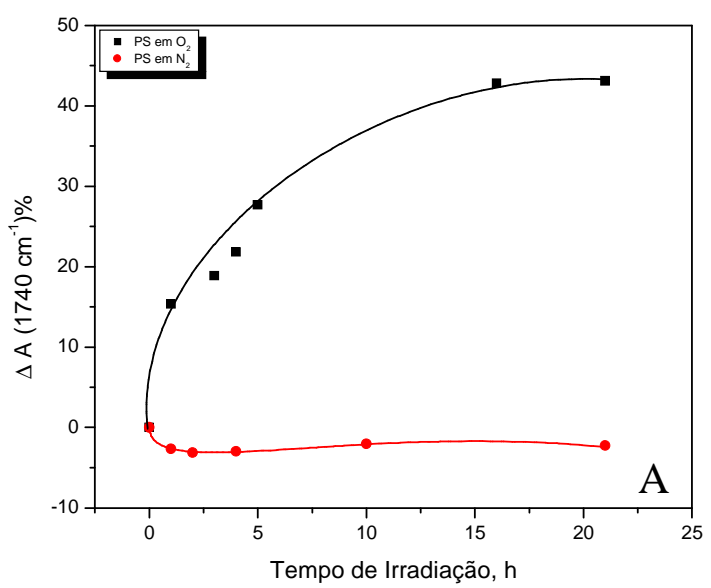

A

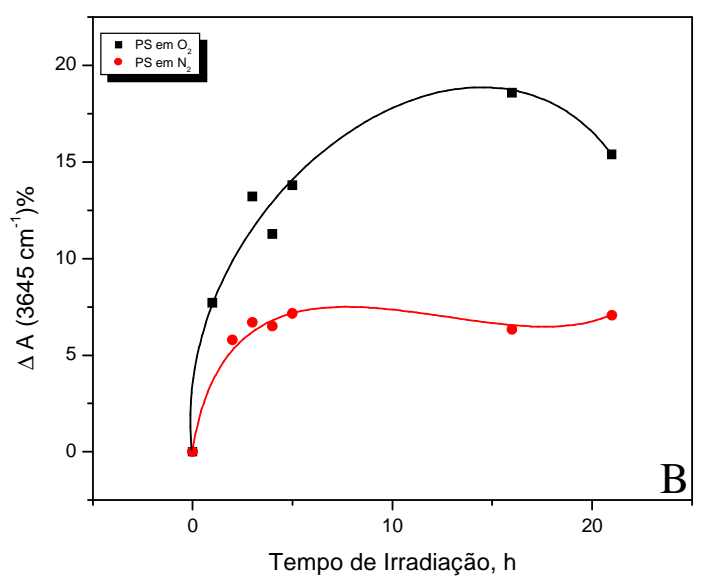

B

Figura 32. Mudança na absorbância em (A) $1740 \mathrm{~cm}^{-1}$ e em (B) $3645 \mathrm{~cm}^{-1}$ ocorridas nos filmes PS na presença de $\mathrm{O}_{2}$ e PS em atmosfera inerte. 


\subsubsection{Comparação da Fotodegradação do Poliestireno Puro e na Presença dos Sensibilizadores Tioxantona e Benzofenona em ar}

As reações fotoquímicas no poliestireno foram acompanhadas por FTIR e por espectroscopia de UV-vis. É importante salientar que nesta parte do estudo serão comparados os resultados obtidos pela irradiação dos filmes de poliestireno por irradiação UV e dos filmes de poliestireno com os fotossensibilizadores benzofenona e tioxantona por irradiação visível.

Comparação dos Resultados obtidos por UV-Vis

A Figura 33 ilustra as mudanças ocorridas nos filmes PS, PS/TX e PS/BP na presença de ar em $250 \mathrm{~nm}$. Observa-se que o filme polimérico sensibilizado com BP em ar não apresentou um aumento significativo da absorbância. Já os filmes de poliestireno na ausência e presença do sensibilizador TX apresentaram um aumento da absorbância.

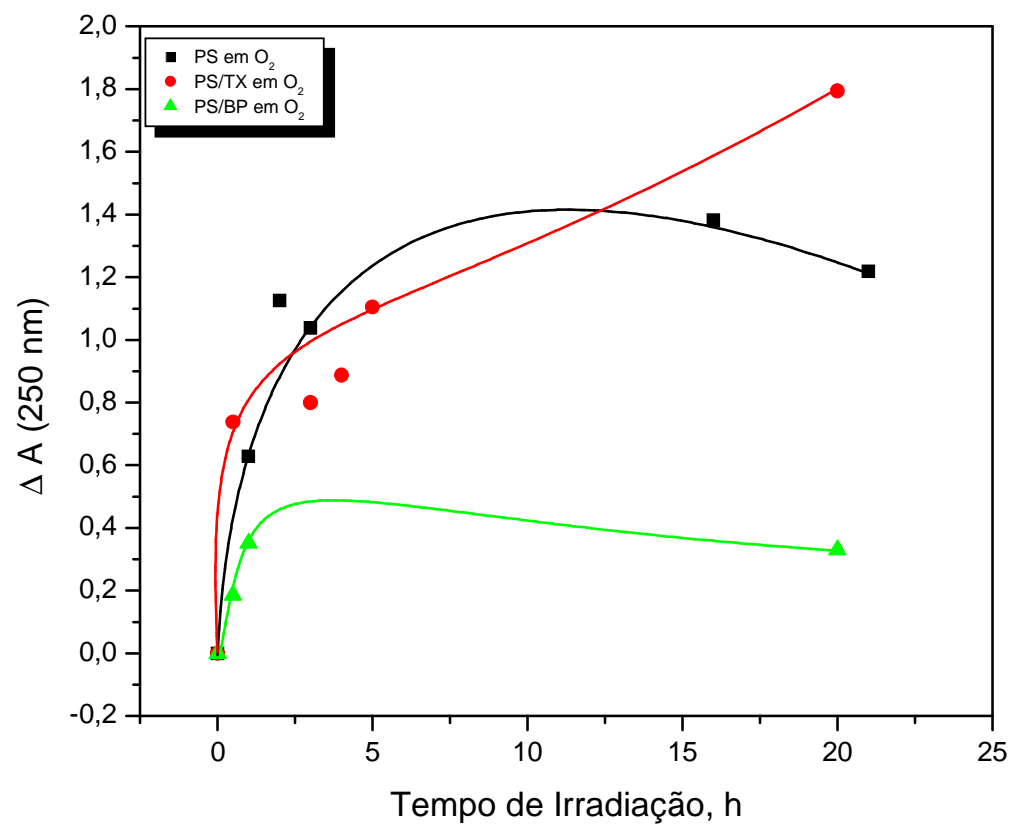

Figura 33. Mudança na absorbância em $250 \mathrm{~nm}$ ocorridas nos filmes PS, PS/TX e PS/BP em ar.

A tioxantona seguiu o mecanismo de produção de compostos com duplas ligações.

A Figura 34 ilustra a mudança na absorbância em $318 \mathrm{~nm}$ nos sistemas estudados na presença de ar. Pode-se observar que o filme com TX tende a um valor constante nas primeiras horas de irradiação. 


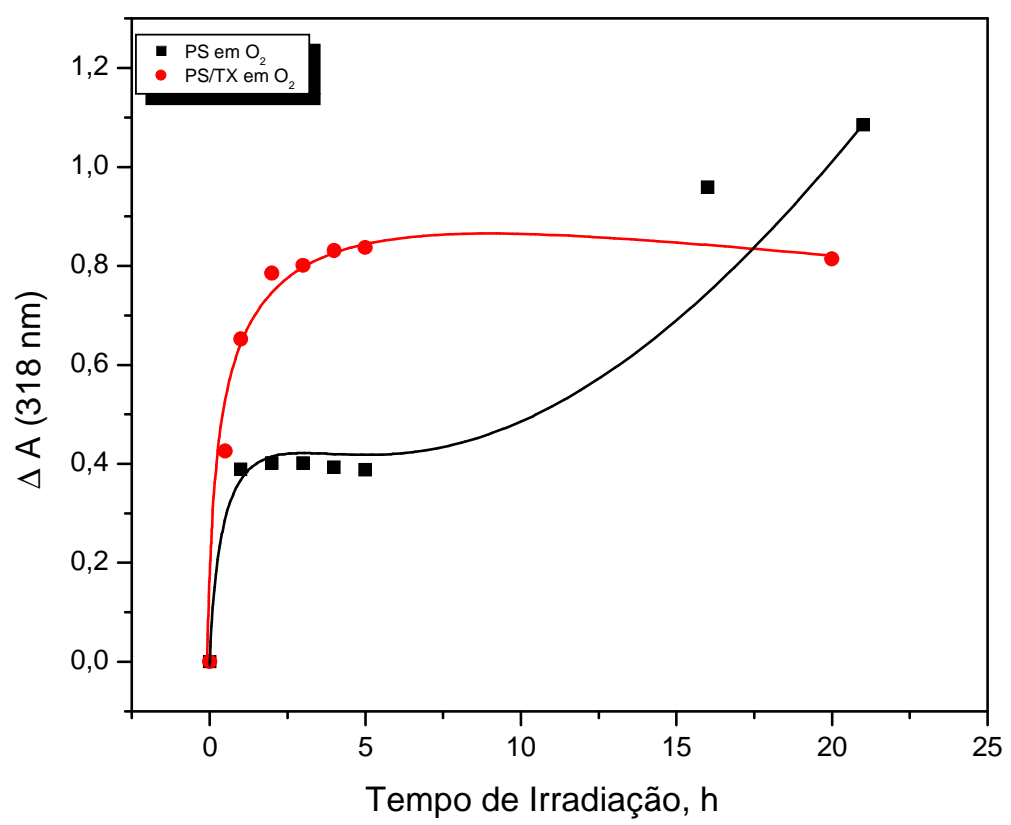

Figura 34. Mudança na absorbância em 318 nm ocorridas nos filmes PS e PS/TX na presença de ar.

Comparação dos Resultados obtidos por FTIR

A Figura 35 ilustra as mudanças na absorbância em $1740 \mathrm{~cm}^{-1}$ dos filmes de poliestireno puro e poliestireno na presença dos fotossensibilizadores. Observa-se um aumento da absorbância para os sistemas estudados indicando que os sistemas fotosensibilizados utilizando-se radiação visível também são efetivos na degradação do poliestireno. As reações fotosensibilizadas no visível mostram ter uma menor contribuição na geração de carbonilas e produtos de oxidação quando comparados aos filmes de PS irradiados no UV. 


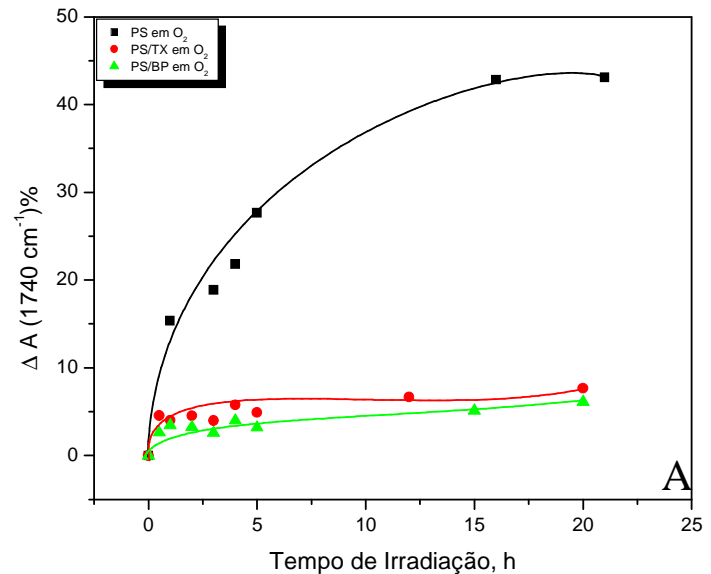

A

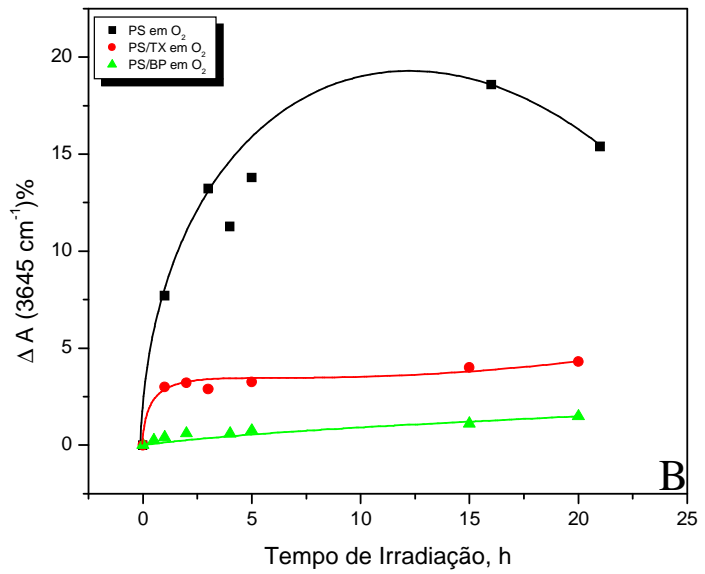

B

Figura 35. Mudança na absorbância em $1740 \mathrm{~cm}^{-1}$ (A) e em $3645 \mathrm{~cm}^{-1}$ (B) ocorridas nos filmes PS, PS/TX e PS/BP na presença de ar.

\subsubsection{Comparação da Fotodegradação do Poliestireno puro e na presença dos sensibilizadores Tioxantona e Benzofenona em Atmosfera Inerte}

Comparação dos Resultados obtidos por UV-vis

A Figura 36 ilustra as mudanças nos filmes PS, PS/TX e PS/BP em $250 \mathrm{~nm}$. Observase que o poliestireno com os sensibilizadores, benzofenona e tioxantona, não apresentou mudanças significativas na absorbância. No entanto, na ausência dos sensibilizadores houve uma diminuição na absorbância nas primeiras horas de irradiação e também um aumento após 5 horas de irradiação, podendo estar relacionado à formação de fotoprodutos. 


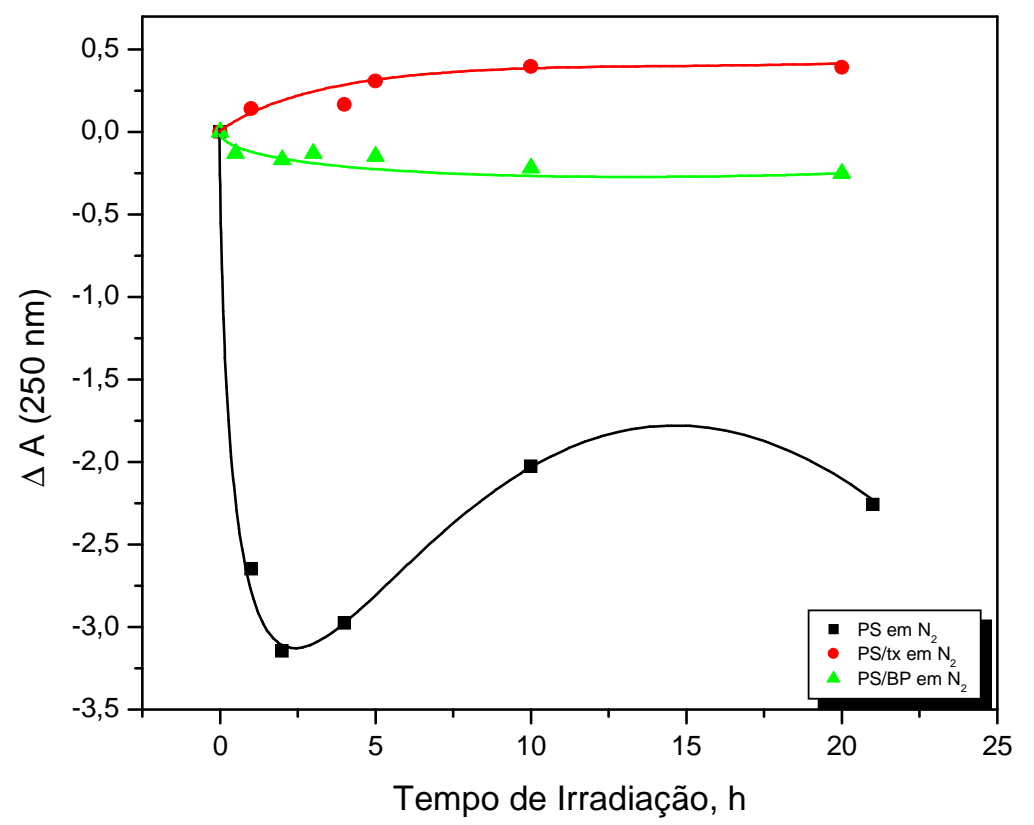

Figura 36. Mudança na absorbância em 250 nm ocorridas nos filmes PS, PS/TX e PS/BP em atmosfera inerte.

A Figura 37 ilustra as mudanças em $318 \mathrm{~nm}$ dos filmes PS e PS/TX em atmosfera inerte. É possível verificar a tendência a um valor constante nas primeiras horas de irradiação. 


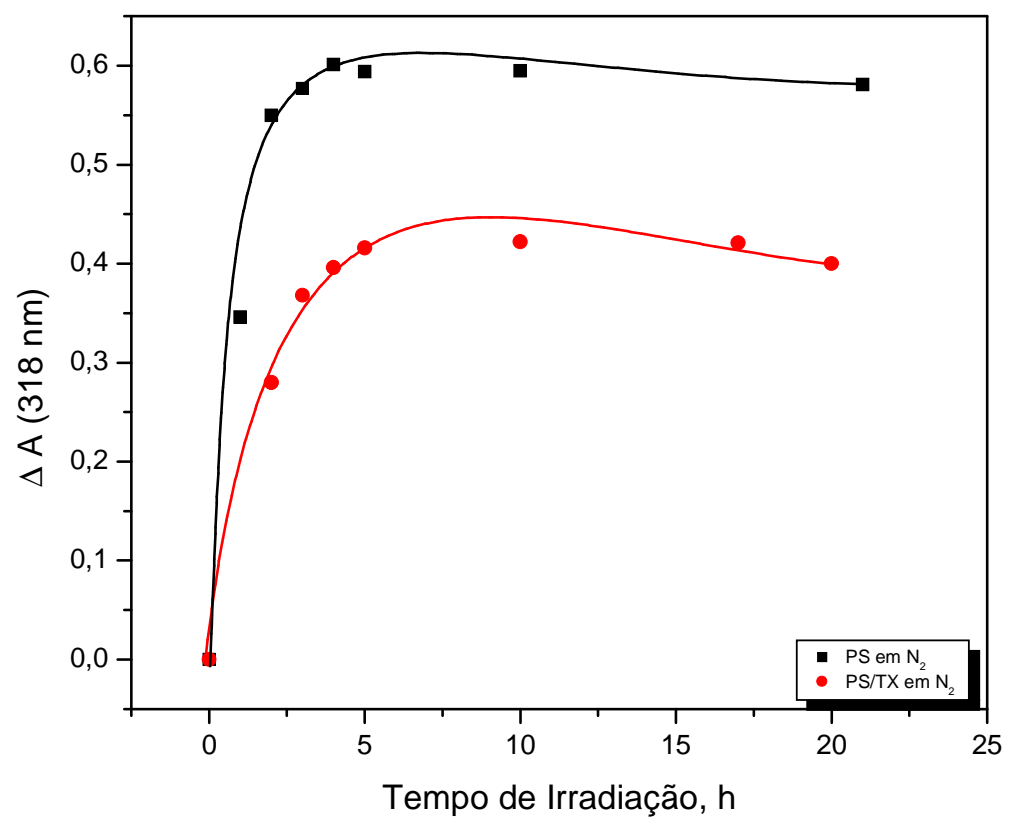

Figura 37. Mudança na absorbância em 318 nm ocorridas nos filmes PS, PS/TX em atmosfera inerte.

Comparação dos Resultados obtidos por FTIR

A Figura 38 compara as mudanças em $1740 \mathrm{~cm}^{-1} \mathrm{e} \mathrm{em} 3645 \mathrm{~cm}^{-1}$ ocorridas nos filmes PS, PS/TX e PS/BP em atmosfera inerte.

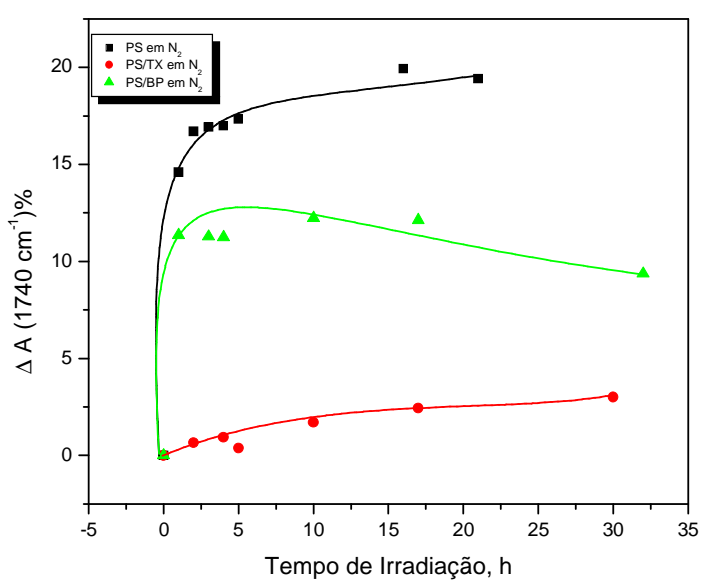

A

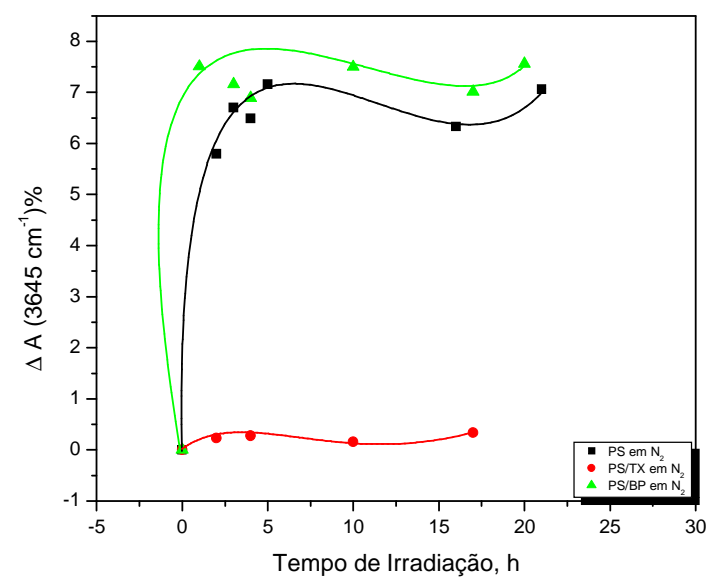

B

Figura 38. Mudança na absorbância em $1740 \mathrm{~cm}^{-1}$ (A) e em $3645 \mathrm{~cm}^{-1}$ (B) ocorridas nos filmes PS, PS/TX e PS/BP em atmosfera inerte. 
A baixa variação da intensidade de absorbância em $1740 \mathrm{~cm}^{-1}$ encontrada nos filmes de poliestireno contendo tioxantona pode indicar que está ocorrendo uma inibição no mecanismo de produção de carbonilas quando comparado aos demais sistemas investigados.

\subsubsection{Resultados da Cromatografia de Exclusão por Tamanho, SEC}

As massas molares foram obtidas com o propósito de se avaliar a fotodegradação dos filmes poliméricos sensibilizados por tioxantona e benzofenona. Os polímeros de poliestireno foram irradiados com luz visível na presença de ar e também sob atmosfera de nitrogênio, posteriormente foram solubilizados em THF para as medidas de SEC. De maneira geral, observou-se uma diminuição da massa molar ponderal média o que caracteriza a degradação do poliestireno. Os resultados obtidos estão resumidos na Tabela 3.

Tabela 3. Mudanças na massa molar ponderal média $\left(\overline{\mathrm{M}}_{\mathrm{w}}\right)$ provocadas pela irradiação com luz visível do filme de poliestireno sensibilizado por tioxantona e benzofenona, em ar ou nitrogênio nos diferentes tempos de irradiação

\begin{tabular}{llll}
\hline Sistema & Atmosfera & Tempo irrad. / h & $\overline{\mathbf{M}}_{\mathrm{w}}$ \\
\hline \hline \multirow{3}{*}{ PS/TX } & & 0 & 410.000 \\
& ar & 80 & 380.000 \\
& & 132 & 275.000 \\
\cline { 2 - 4 } & \multirow{2}{*}{$\mathrm{N}_{2}$} & 0 & 421.000 \\
& & 20 & 411.000 \\
& & 38 & 370.000 \\
\hline \multirow{3}{*}{ PS/BP } & & 0 & 600.000 \\
& & 80 & 340.000 \\
& & 132 & 278.000 \\
\hline & \multirow{2}{*}{$\mathrm{N}_{2}$} & 0 & 582.000 \\
& & 20 & 500.000 \\
& & 38 & 405.000 \\
\hline
\end{tabular}

Alguns estudos anteriores ${ }^{13}$ propuseram o seguinte esquema reacional para o sistema PS/BP irradiado com a lâmpada de mercúrio em ar e sob vácuo:

Com base no mecanismo da Figura 3, os resultados de SEC indicam que tanto os filmes irradiados com benzofenona quanto com tioxantona em ar e nitrogênio levam a quebra de cadeias (degradação). 


\subsection{CARACTERIZAÇÃO DO COPOLÍMERO SINTETIZADO ESTIRENO-CO- TIOXANTONA (PS-TX I)}

O copolímero estireno-co-tioxantona (PS-TX I) foi sintetizado pela modificação do poliestireno e em seguida caracterizado por espectroscopia UV-Vis, Infravermelho, RMN ${ }^{1} \mathrm{H}$ e análise elementar. O copolímero PS-TX I apresentou uma banda de absorção na região entre 350-450 nm. Essa banda de absorção quando comparada a da tioxantona, que possui o máximo de absorção em $380 \mathrm{~nm}$, apresenta um deslocamento para o vermelho. Esse deslocamento pode ser atribuído a estrutura macromolecular do PS-TX I ${ }^{22,25}$. A Figura 39 ilustra o espectro de absorção do copolímero PS-TX I.

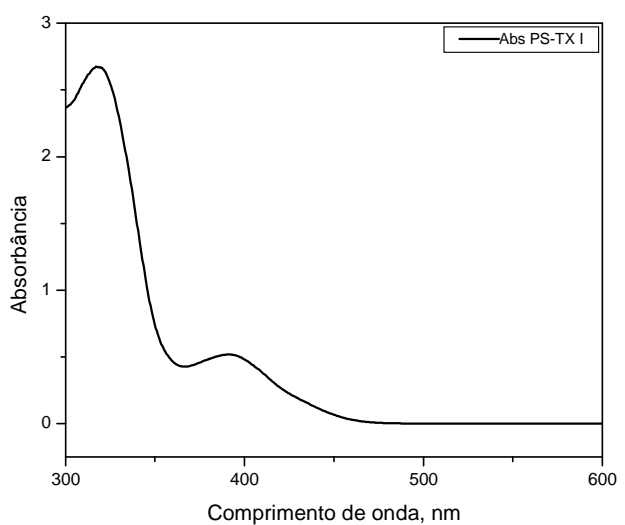

A

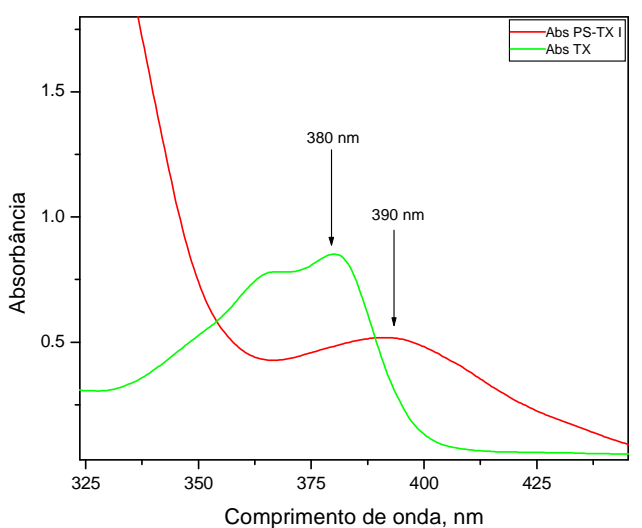

B

Figura 39. Espectro de absorção (A) do copolímero PS-TX I em dimetilformamida e (B) espectro de absorção do copolímero PS-TX comparada a absorção da tioxantona livre.

A Figura 40 ilustra o espectro de infravermelho do copolímero PS-TX I, o pico em $1629 \mathrm{~cm}^{-1}$, correspondente ao sinal do grupo carbonila indica que houve a formação do copolímero PS-TX I.

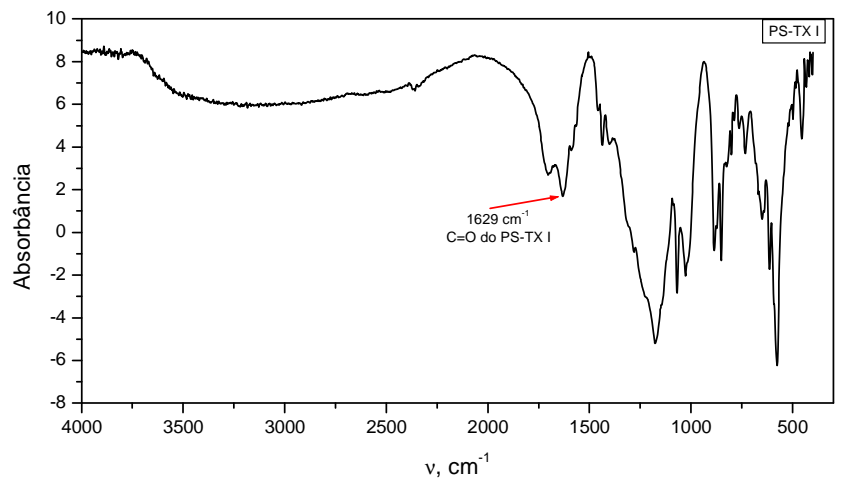

Figura 40. Espectro de infravermelho do copolímero PS-TX I. 
Por outro lado, através dos resultados obtidos pela análise elementar pôde-se avaliar somente a porcentagem do elemento enxofre $(\mathrm{S})$. A porcentagem calculada para este elemento presente no reagente de partida ácido tiosalicílico foi de $20,8 \%$. Já o valor encontrado na análise do copolímero PS-TX I foi de 17,9 \% para o elemento enxofre. A reação de copolimerização foi satisfatória.

O espectro de ${ }^{1} \mathrm{H}-\mathrm{NMR}$ pode ser considerado como uma evidência complementar da reação de adição, uma vez que um novo sinal relacionado aos prótons da tioxantona é encontrado na região de $\delta$ 6-8 $\mathrm{ppm}^{22}$. A Figura 41 ilustra o espectro de ${ }^{1} \mathrm{H}-\mathrm{NMR}$ do copolímero PS-TX I na região de $\delta$ 7-9 ppm.

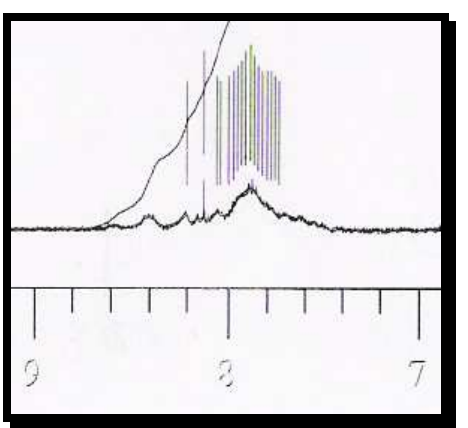

Figura 41. Região característica do espectro de ${ }^{1} \mathrm{H}-\mathrm{NMR}$ para o copolímero PS-TX I.

\subsection{ESTUDO DA FOTOESTABILIDADE DA TIOXANTONA E DOS COPOLÍMEROS PS-TX I E PS-TX II EM SOLUÇÃO}

\section{Tioxantona livre em solução de benzeno (TX)}

O estudo da fotoestabilidade da tioxantona foi realizado em uma câmara de irradiação com luz visível, à temperatura de $25^{\circ} \mathrm{C}$. As mudanças provocadas pela irradiação foram monitoradas através da técnica de espectroscopia de absorção UV-Vis. A Figura 42 ilustra os espectros de absorção da tioxantona em diferentes tempos de irradiação. Observa-se na região entre 330 e $400 \mathrm{~nm}$ a diminuição da banda de absorção da TX a qual é atribuída ao seu consumo ("photobleaching”). 


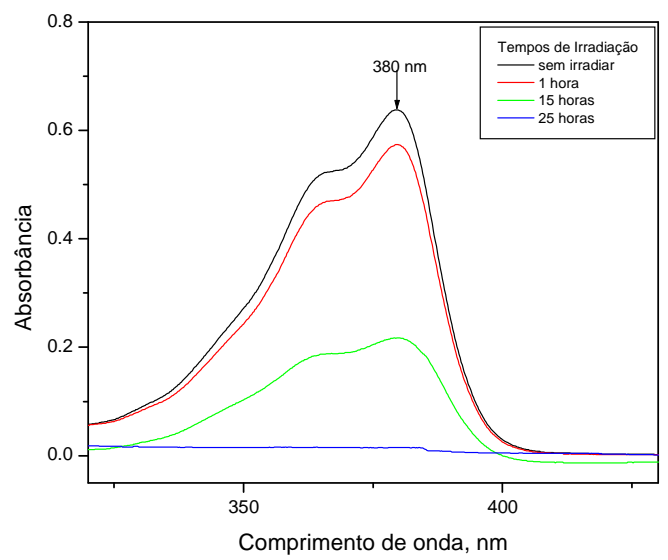

Figura 42. Espectros de absorção da tioxantona livre em solução de benzeno antes e após 25 horas de irradiação com luz visível na presença de ar.

\section{Tioxantona na presença de poliestireno em solução de benzeno (PS+TX)}

A Figura 43 ilustra os espectros de absorção da tioxantona livre na presença de poliestireno em solução de benzeno. É observado nesta figura, que antes e após 150 horas de irradiação não houve mudança significativa na absorção em $380 \mathrm{~nm}$ referente à tioxantona.

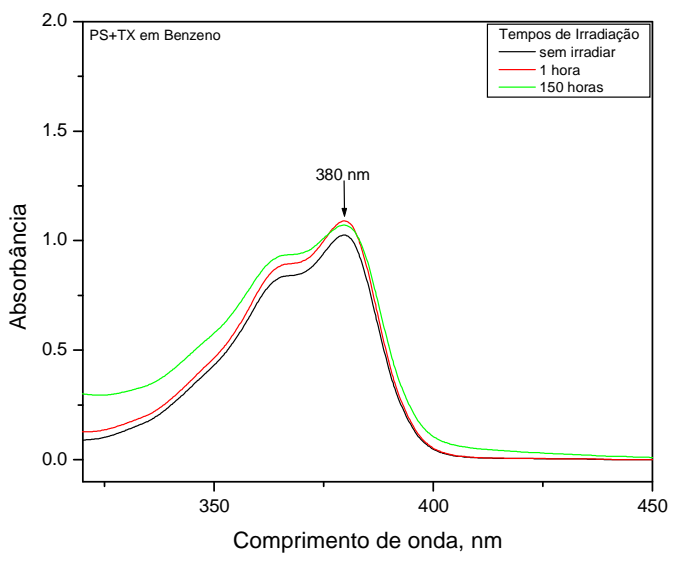

Figura 43. Espectros de absorção da tioxantona na presença de poliestireno em solução de benzeno antes e após 150 horas de irradiação com luz visível na presença de ar.

Pode-se dizer através da Figura 43 que a tioxantona (Figura 42) mostrou-se mais fotoestável na presença de poliestireno, já que a diminuição da absorbância em $380 \mathrm{~nm}$ foi muito menor na ausência do polímero PS. 


\section{>Copolímero PS-TX I em dimetilformamida}

A Figura 44 ilustra o espectro de absorbância do copolímero PS-TX I irradiado por diferentes tempos em dimetilformamida. Observa-se uma diminuição da absorbância na região entre 360 e $420 \mathrm{~nm}$. A diferença de absorbância $390 \mathrm{~nm}$ em função do tempo de irradiação (Figura 44B) mostra que a variação é praticamente constante até 15 horas e após esse tempo diminui rapidamente. Esse resultado indica que o consumo da tioxantona presente no copolímero PS-TX I só ocorre após 15 horas de irradiação.

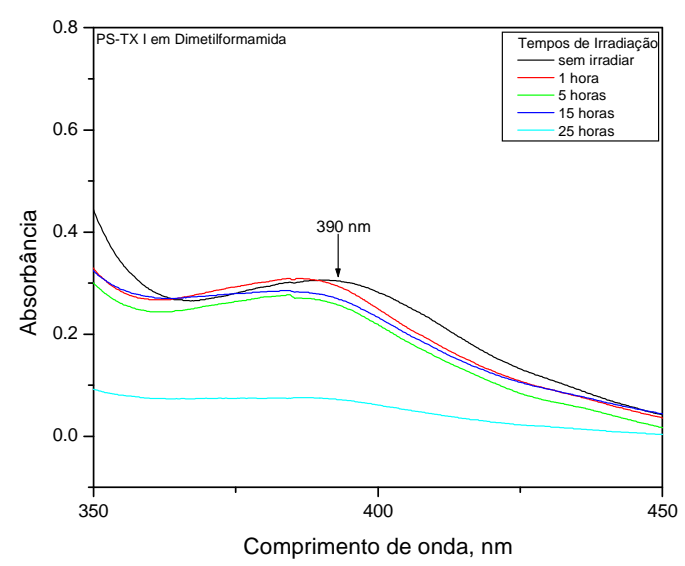

A

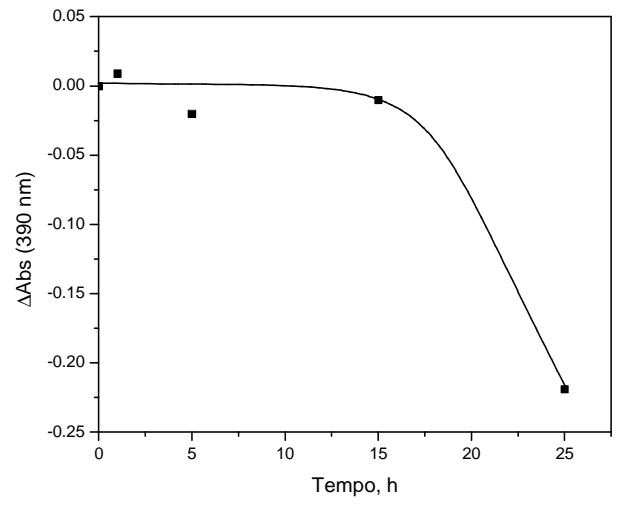

B

Figura 44. (A) Espectros de absorção do copolímero PS-TX I em solução de dimetilformamida antes e após 25 horas de irradiação. (B) Variação da absorção em 380 nm do copolímero PS-TX I.

\section{Copolímero PS-TX II em benzeno}

As modificações nos espectros de absorção do copolímero PS-TX II em solução de benzeno estão ilustrados na Figura 45A. As mudanças mostram a diminuição da absorbância entre 350 e 420 nm. Já a Figura 45B ilustra a variação da absorbância em $380 \mathrm{~nm}$ em função do tempo de irradiação, observa-se nesse caso que o consumo da tioxantona é quase total nos primeiros 30 minutos. 


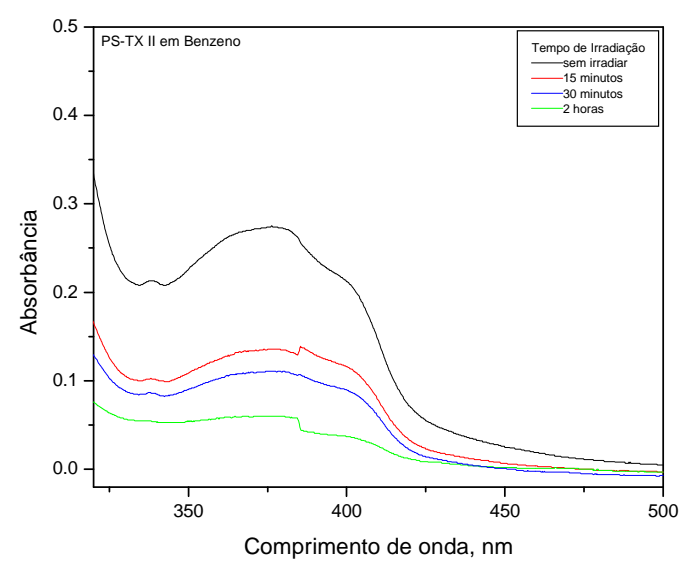

A

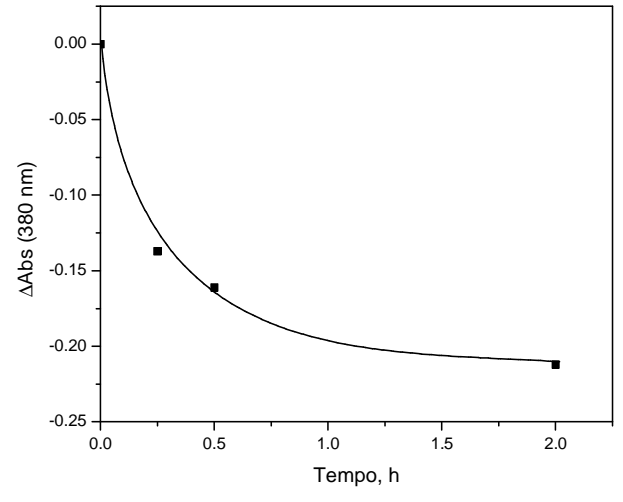

B

Figura 45. (A) Espectros de absorção do copolímero PS-TX II antes e após 2 horas de irradiação com luz visível em ar. (B) Variação da absorção em $380 \mathrm{~nm}$ do copolímero PSTX II.

Quando se compara os copolímeros PS-TX I e PS-TX II pode-se dizer que o consumo da tioxantona presente no copolímero II é mais rápido que no copolímero I. Tal resultado pode estar relacionado com a estrutura dos copolímeros, ou seja, no copolímero II a tioxantona está mais livre que no copolímero I. E também pode estar relacionado aos diferentes solventes utilizados, dimetilformamida para PS-TX I e benzeno para PS-TX II.

\subsection{ESTUDOS DAS REAÇÕES ELEMENTARES ("Flash Photolysis")}

A técnica de fotólise por pulso de laser é uma excelente ferramenta para determinar velocidades de reação de estados excitados e medir o tempo de vida de intermediários formados com tempos de vida na ordem de $\mu \mathrm{s}^{26}$.

Assim, a fim de se obter um melhor entendimento das reações elementares envolvidos nos processos de fotodegradação foi investigado através da técnica de fotólise por pulso de laser os radicais e tripletes de tioxantona ${ }^{27}$.

Inicialmente investigou-se o comportamento espectral da tioxantona em diferentes solventes a fim de se comparar com os sistemas contendo poliestireno. Por um lado, foi investigado o comportamento espectral da tioxantona quando adicionado a uma solução de polímero e por outro quando a tioxantona está ligado covalentemente ao polímero. 
Os estudos de radicais e tripletes de tioxantona foram realizados para quatro sistemas diferentes: tioxantona livre $(T X)$, tioxantona na presença de poliestireno $(P S+T X)$, copolímero estireno-co-tioxantona (PS-TXI) e copolímero estireno-co-tioxantona 4,9\% (PS-TX II).

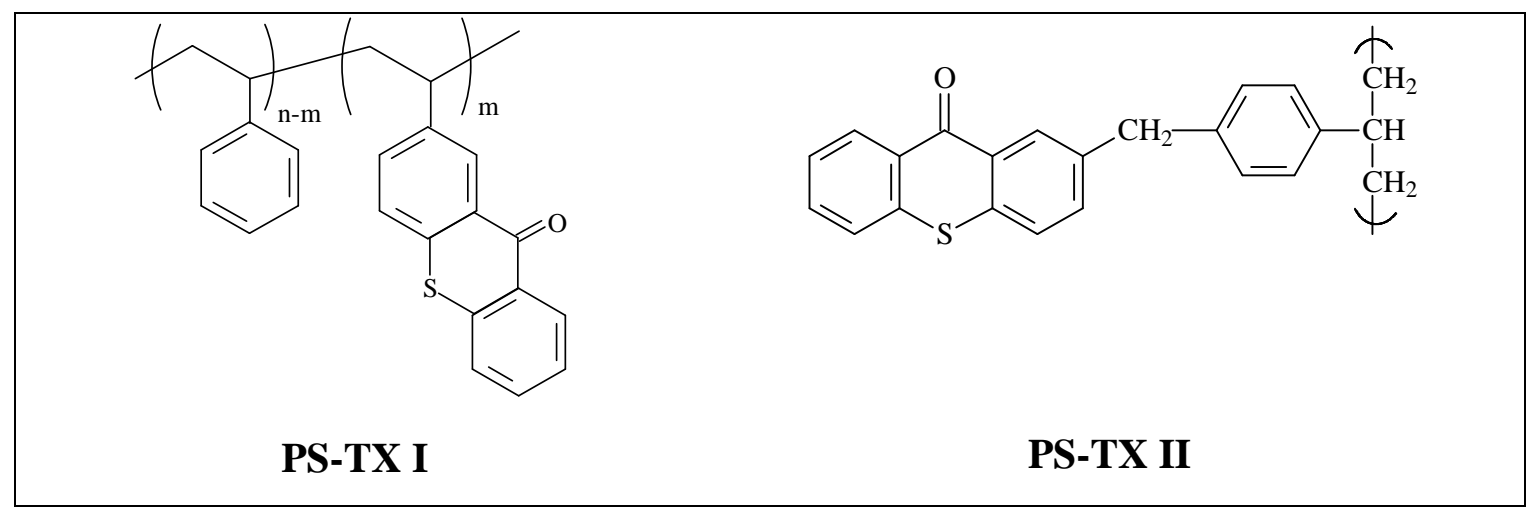

\subsubsection{Estudo dos Transientes da Tioxantona Livre (TX)}

O estudo das reações elementares da tioxantona livre foi realizado através de técnica de fotólise por pulso de laser para investigar o comportamento da tioxantona em diferentes solventes e em diferentes atmosferas. Os solventes utilizados para o estudo foram dimetilformamida, tetrahidrofurano, acetonitrila e benzeno.

\section{$>$ TX em dimetilformamida}

A Figura 46A ilustra o espectro de absorção do transiente de TX em dimetilformamida, em atmosfera de $\mathrm{N}_{2}$. $\mathrm{O}$ espectro é caracterizado por uma banda de absorção com máximo em $650 \mathrm{~nm}$ e um ombro na região de $430 \mathrm{~nm}$. A absorção em $650 \mathrm{~nm}$ é muito mais intensa quando comparado a aquela na região de $430 \mathrm{~nm}$. O pico em $650 \mathrm{~nm}$ tem sido atribuído ao triplete de tioxantona (TX) e em $430 \mathrm{~nm}$ é devido ao radical cetila da tioxantona (TXH ) formado pela abstração de hidrogênio.

A Figura 46B ilustra o decaimento do estado triplete de TX em 660 nm na ausência de supressor. Os tempos de vida obtidos estão resumidos na Tabela 4. 


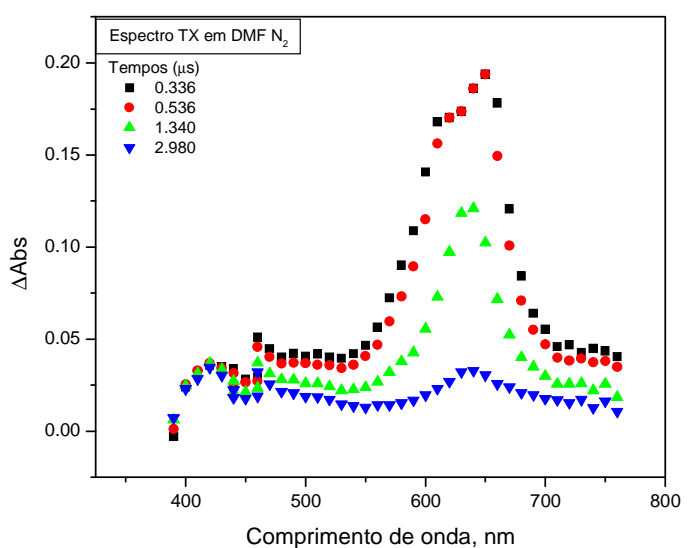

A

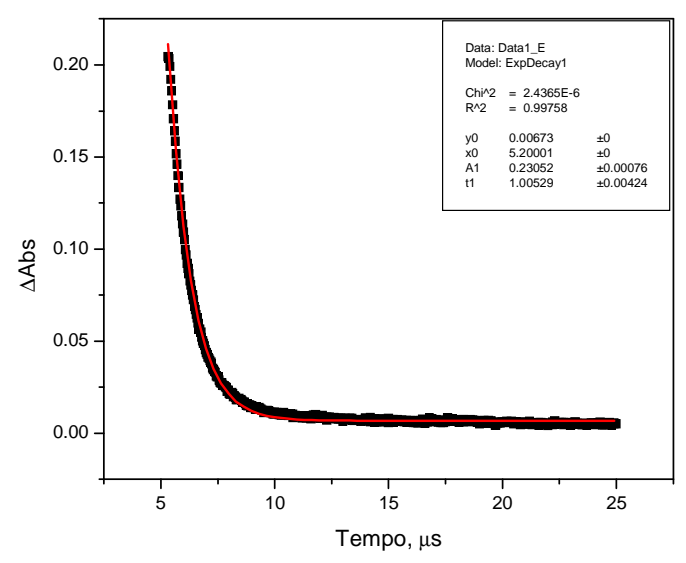

B

Figura 46. (A) Espectro de absorção do transiente de TX em dimetilformamida em atmosfera de $\mathrm{N}_{2}$, de 390 a $760 \mathrm{~nm}$. (B) Decaimento de absorção do transiente de TX em dimetilformamida, em $660 \mathrm{~nm}, \mathrm{t}_{\mathrm{d}}=2,5 \mu \mathrm{s}$, em atmosfera de $\mathrm{N}_{2}$.

A Figura 47A ilustra o espectro de absorção do transiente de TX em dimetilformamida, em ar. O espectro é caracterizado por uma banda de absorção com máximo em $650 \mathrm{~nm}$ atribuída a absorção triplete-triplete $(T-T)$.

A Figura 47B ilustra o decaimento do estado triplete de TX em $660 \mathrm{~nm}$. Os tempos de vida obtidos estão resumidos na Tabela 4.

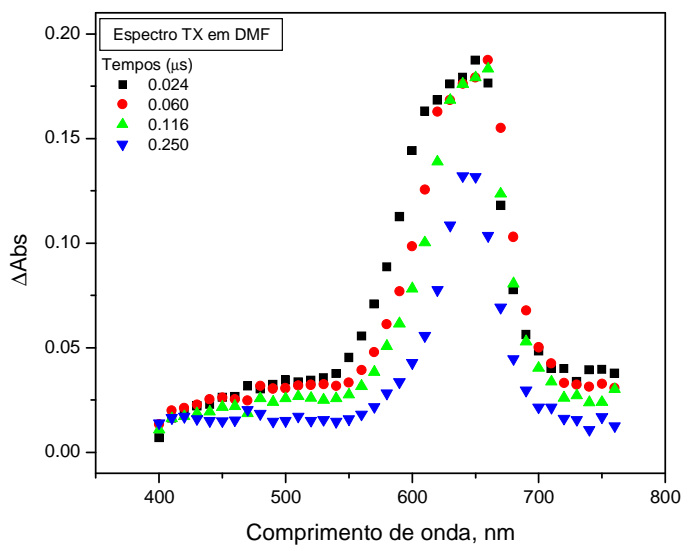

A

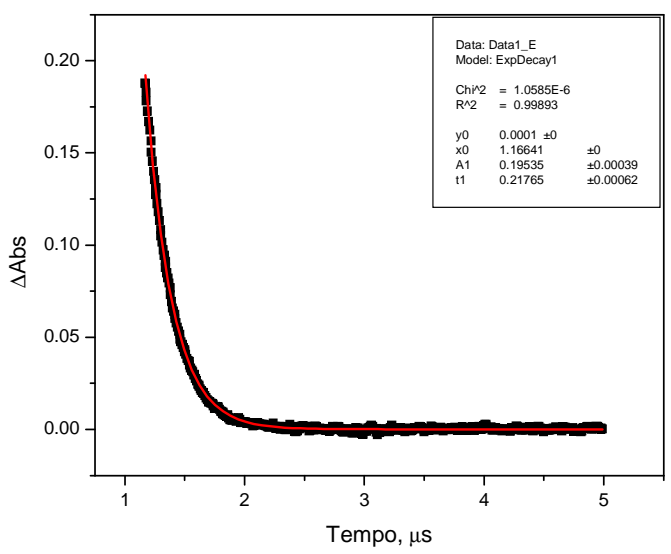

B

Figura 47. (A) Espectro de absorção de transiente de TX em dimetilformamida, em ar, de 400 a $760 \mathrm{~nm}$. (B) Decaimento de absorção do transiente de TX em dimetilformamida, em 660 $\mathrm{nm}, \mathrm{t}_{\mathrm{d}}=500 \mathrm{~ns}$, em ar. 


\section{$>$ TX em tetrahidrofurano}

A Figura 48A ilustra o espectro de absorção do transiente de TX em tetrahidrofurano e em atmosfera de $\mathrm{N}_{2}$. $\mathrm{O}$ espectro é caracterizado por uma banda de absorção com máximo em $642 \mathrm{~nm}$ atribuída a absorção triplete-triplete $(T-T)$. A Figura 48B ilustra o decaimento do estado triplete de TX em $660 \mathrm{~nm}$ na ausência de supressor. Os tempos de vida obtidos estão resumidos na Tabela 4.

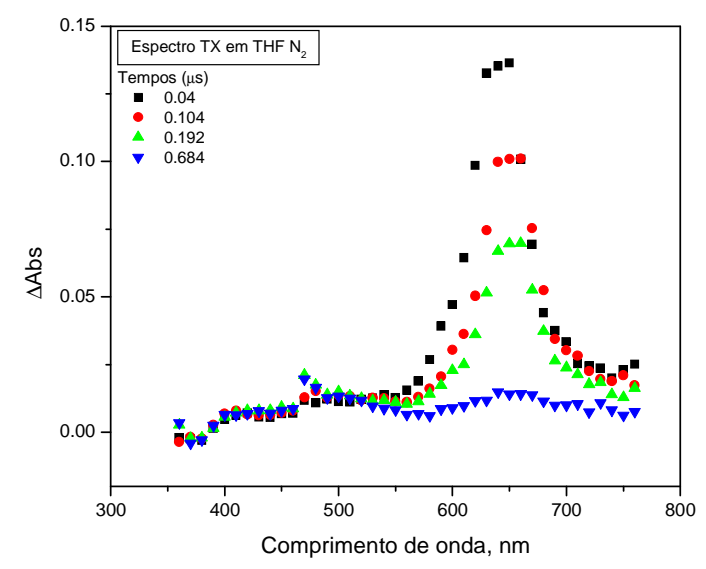

A

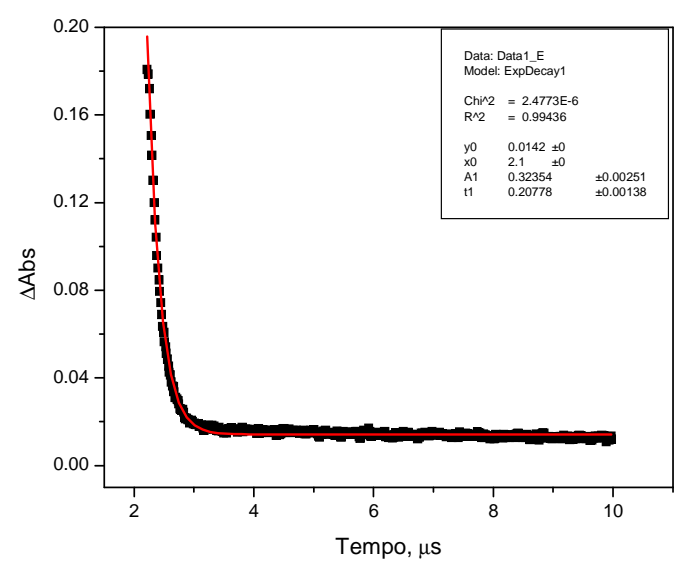

B

Figura 48. (A) Espectro de absorção de transiente de TX em tetrahidrofurano, em atmosfera de $\mathrm{N}_{2}$, de 360 a $760 \mathrm{~nm}$. (B) Decaimento de absorção do transiente de TX em tetrahidrofurano, em $660 \mathrm{~nm}, \mathrm{t}_{\mathrm{d}}=1 \mu \mathrm{s}$, em atmosfera de $\mathrm{N}_{2}$.

A Figura 49A ilustra o espectro de absorção do transiente de TX em tetrahidrofurano na presença de ar. O espectro é caracterizado por uma banda de absorção com máximo em $640 \mathrm{~nm}$ atribuída a absorção triplete-triplete $(T-T)$. A Figura 49B ilustra o decaimento do estado triplete de TX em $660 \mathrm{~nm}$. Os tempos de vida obtidos estão resumidos na Tabela 4. 


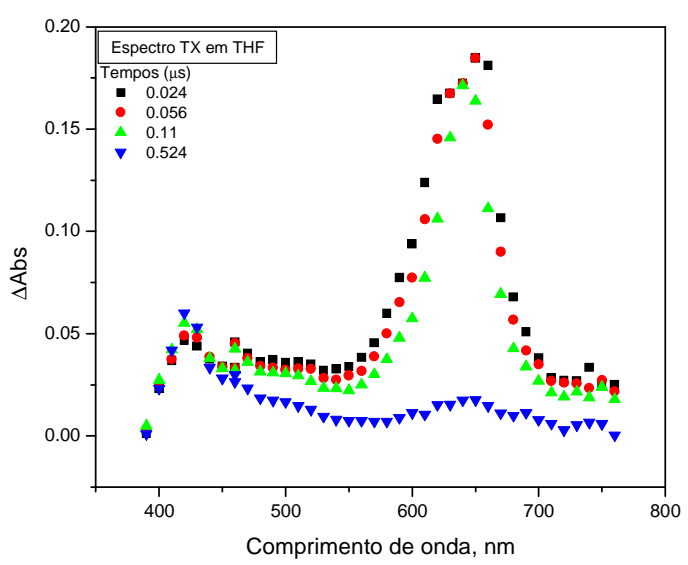

A

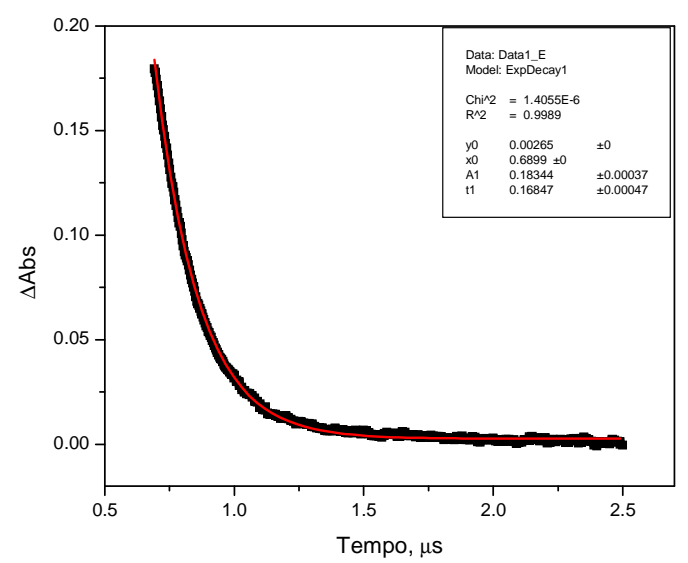

B

Figura 49. (A) Espectro de absorção de transiente de TX em tetrahidrofurano, em ar, de 390 a 760 nm. (B) Decaimento de absorção do transiente de TX em tetrahidrofurano, em 660 nm, $\mathrm{t}_{\mathrm{d}}=250 \mathrm{~ns}$, em ar.

\section{$>$ TX em acetonitrila}

A Figura 50A ilustra o espectro de absorção do transiente de TX em acetonitrila e em atmosfera de $\mathrm{N}_{2}$. $\mathrm{O}$ espectro é caracterizado por uma banda de absorção com máximo em $625 \mathrm{~nm}$ atribuída a absorção triplete-triplete $(T-T)$. A Figura 50B ilustra o decaimento do estado triplete de TX em $660 \mathrm{~nm}$ na ausência de supressor. Os tempos de vida obtidos estão resumidos na Tabela 4.

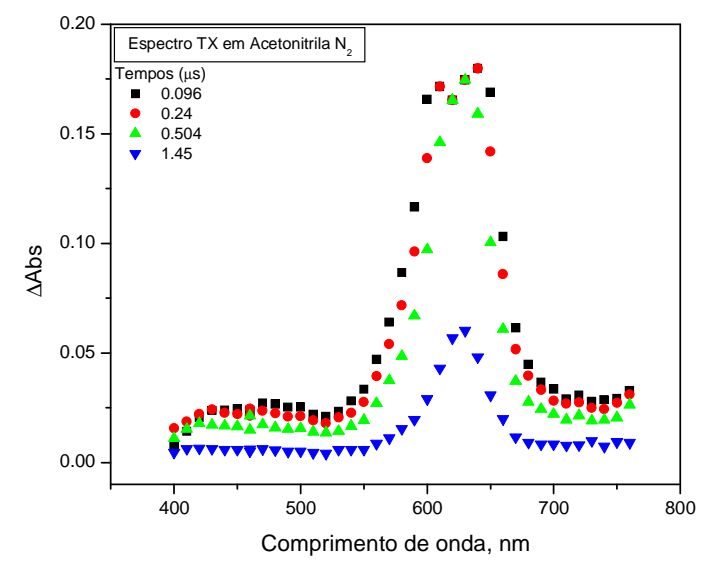

A

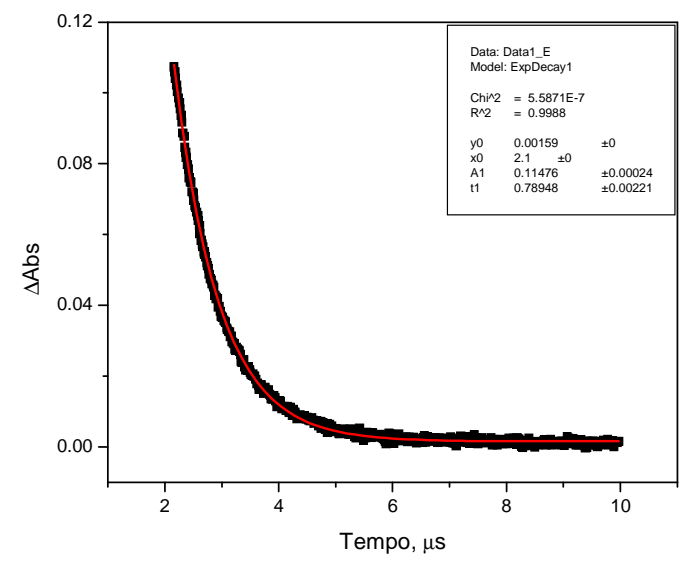

B

Figura 50. (A) Espectro de absorção de transiente de TX em acetonitrila, em atmosfera de $\mathrm{N}_{2}$, de 400 a 760 nm. (B) Decaimento de absorção do transiente de TX em acetonitrila, em 660 $\mathrm{nm}, \mathrm{t}_{\mathrm{d}}=1 \mu \mathrm{s}$, em atmosfera de $\mathrm{N}_{2}$. 
A Figura 51A ilustra o espectro de absorção do transiente de TX em acetonitrila, em ar. O espectro é caracterizado por uma banda de absorção com máximo em $625 \mathrm{~nm}$ atribuída a absorção triplete-triplete (T-T). A Figura 51B ilustra o decaimento do estado triplete de TX em $660 \mathrm{~nm}$. Os tempos de vida obtidos estão resumidos na Tabela 4.

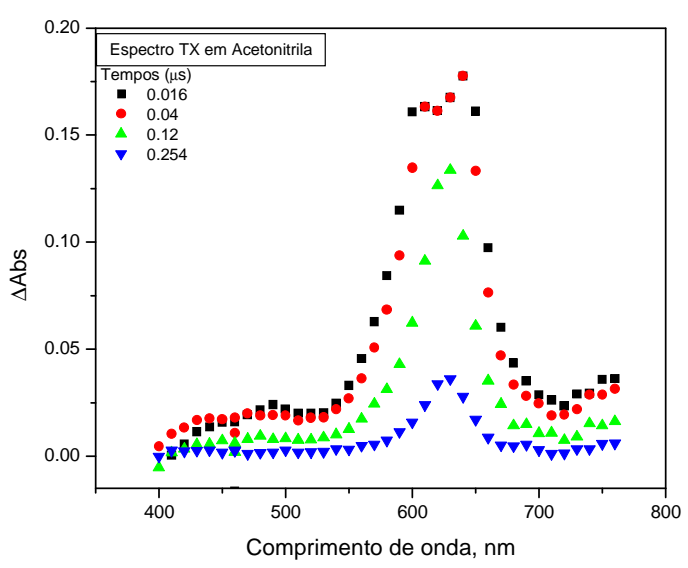

A

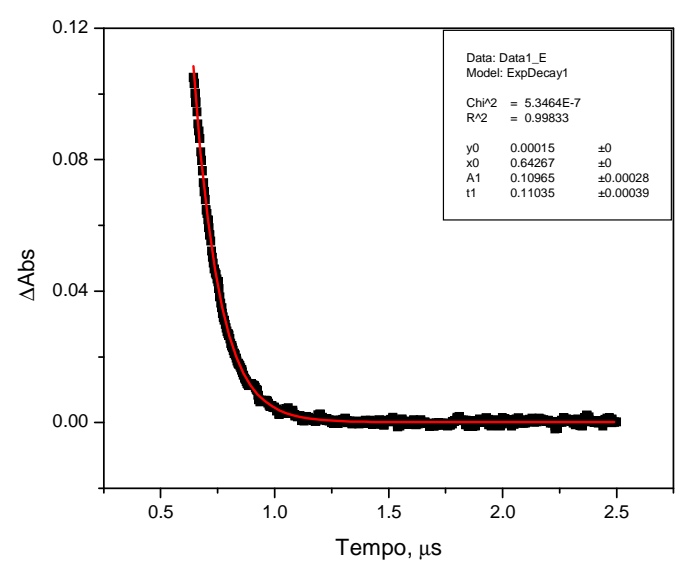

B

Figura 51. (A) Espectro de absorção de transiente de TX em acetonitrila, em ar, de 400 a 760 nm. (B) Decaimento de absorção do transiente de TX em acetonitrila, em $660 \mathrm{~nm}, \mathrm{t}_{\mathrm{d}}=250 \mathrm{~ns}$, em ar.

\section{$>$ TX em benzeno}

$\mathrm{O}$ espectro de absorção do transiente de TX em benzeno e em atmosfera de $\mathrm{N}_{2}$ é ilustrado pela Figura 52A. O espectro é caracterizado por uma banda de absorção com máximo em $655 \mathrm{~nm}$ atribuída a absorção triplete-triplete (T-T). A Figura 52B ilustra o decaimento do estado triplete de TX em $660 \mathrm{~nm}$ na ausência de supressor. Os tempos de vida obtidos estão resumidos na Tabela 4. 


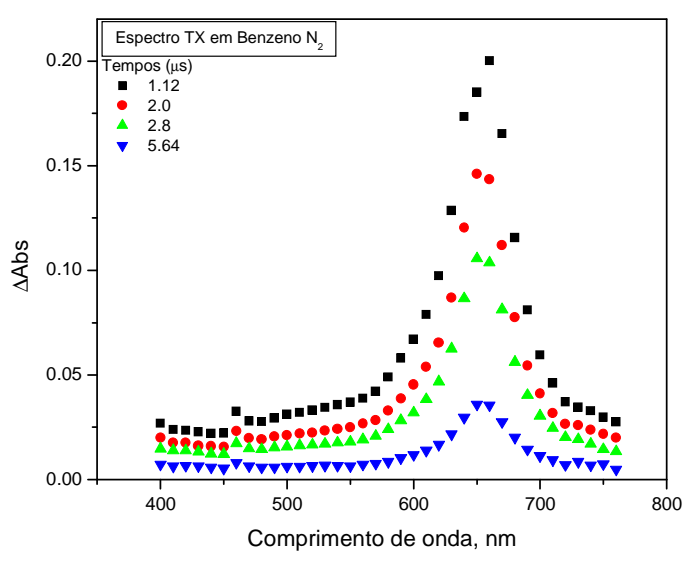

A

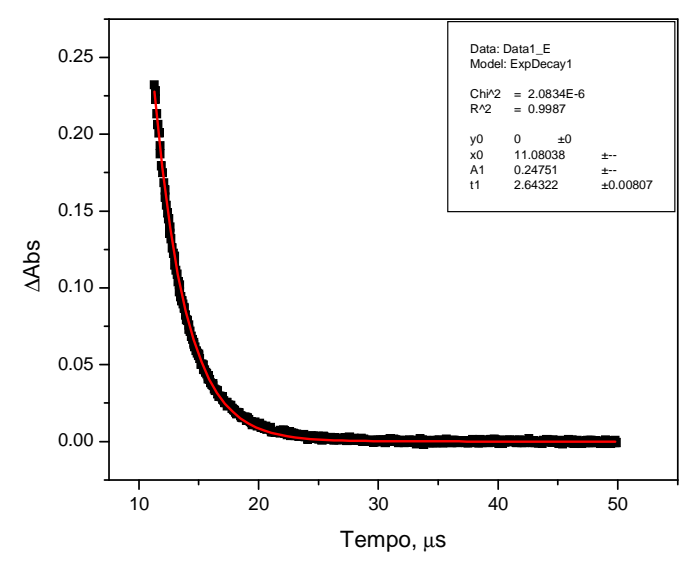

B

Figura 52. (A) Espectro de absorção de transiente de TX em benzene, em atmosfera de $\mathrm{N}_{2}$, de 400 a $760 \mathrm{~nm}$. (B) Decaimento de absorção do transiente de TX em benzeno, em $660 \mathrm{~nm}, \mathrm{t}_{\mathrm{d}}=$ $5 \mu$ s, em atmosfera de $\mathrm{N}_{2}$.

O espectro de absorção do transiente de TX em benzeno, na presença de ar, é ilustrado pela Figura 53. O espectro é caracterizado por uma banda de absorção com máximo em $655 \mathrm{~nm}$ atribuída a absorção triplete-triplete $(T-T)$. A Figura 53B ilustra o decaimento do estado triplete de TX em $660 \mathrm{~nm}$. Os tempos de vida obtidos estão resumidos na Tabela 4.

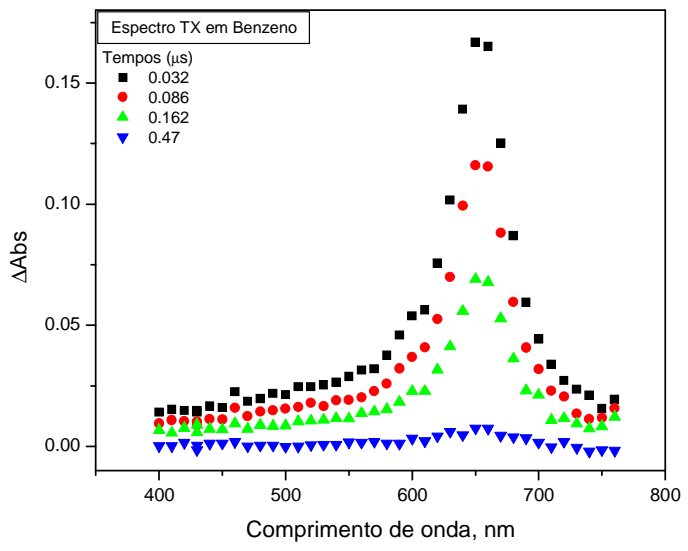

A

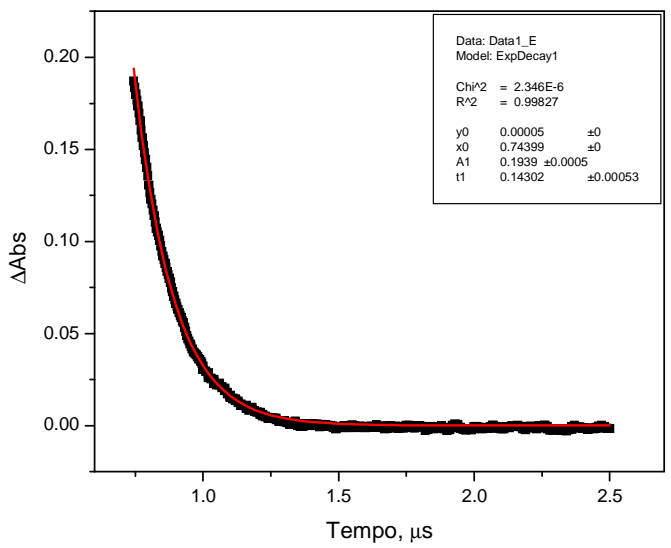

B

Figura 53. (A) Espectro de absorção de transiente de TX em benzeno, em ar, de 400 a 760 nm. (B) Decaimento de absorção do transiente de TX em benzeno, em $660 \mathrm{~nm}, \mathrm{t}_{\mathrm{d}}=250 \mathrm{~ns}$, em ar. 
Tabela 4. Tempos de vida do estado triplete em $660 \mathrm{~nm}$ para o sistema TX

\begin{tabular}{|c|c|}
\hline Sistema TX/ar & $\tau_{1}(\mu s)$ \\
\hline dimetilformamida & 0.22 \\
\hline tetrahidrofurano & 0.17 \\
\hline acetonitrila & 0.11 \\
\hline benzeno & 0.14 \\
\hline Sistema TX/N $\mathbf{N}_{2}$ & $\tau_{1}(\mu s)$ \\
\hline dimetilformamida & 1.00 \\
\hline tetrahidrofurano & 0.21 \\
\hline acetonitrila & 0.79 \\
\hline benzeno & 2.64 \\
\hline
\end{tabular}

Os resultados apresentados anteriormente da tioxantona nos diferentes solventes (dimetilformamida, tetrahidrofurano, acetonitrila e benzeno) mostram um deslocamento no máximo de absorção na região entre 600 e $700 \mathrm{~nm}(T-T)$. Tais resultados podem estar relacionados com a polaridade do solvente. Estudos anteriores demonstram que há uma influência da polaridade do solvente nas energias dos estados eletrônicos da tioxantona, como também em outros sistemas carbonílicos ${ }^{28,29}$.

Para se comprovar a influência da polaridade do solvente, construiu-se um gráfico do máximo de absorção do triplete na região de $600 \mathrm{~nm}$ em função do parâmetro de polaridade do solvente $\left(\mathrm{E}_{\mathrm{T}}(30)\right)^{30}$. A Figura 54 apresenta o resultado obtido. Os dados utilizados na construção dessa figura encontram-se na Tabela 5.

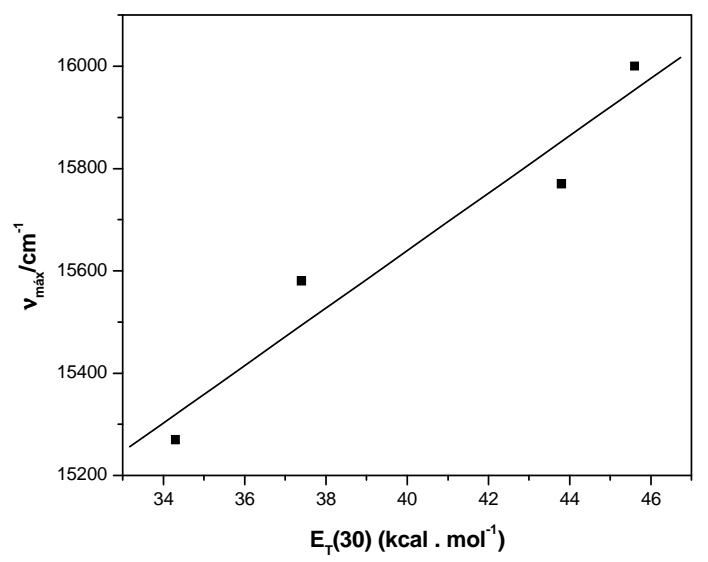

Figura 54. Máximos de absorção na região de $600 \mathrm{~nm}$ em função do parâmetro de polaridade $\mathrm{E}_{\mathrm{T}}(30)$. 
Tabela 5. Solvente utilizado, $\mathrm{E}_{\mathrm{T}}(30)$, máximo de absorção na região de $600 \mathrm{~nm}$ e $v\left(\mathrm{~cm}^{-1}\right)$

\begin{tabular}{cccc}
\hline Solvente & $\mathbf{E}_{\mathbf{T}}(\mathbf{3 0})\left({\mathbf{k c a l} . \mathbf{m o l}^{-1}}^{\mathbf{1}}\right)$ & $\boldsymbol{\lambda}_{\text {máx }}$ na região de 600 $\mathbf{~ n m}$ & $\boldsymbol{v}\left(\mathbf{c m}^{-\mathbf{1}}\right)$ \\
\hline Dimetilformamida & 43,8 & $634 \mathrm{~nm}$ & 15770 \\
Tetrahidrofurano & 37,4 & $642 \mathrm{~nm}$ & 15580 \\
Acetonitrila & 45,6 & $625 \mathrm{~nm}$ & 16000 \\
Benzeno & 34,3 & $655 \mathrm{~nm}$ & 15270 \\
\hline
\end{tabular}

Observa-se uma dependência linear entre o número de onda ( $\lambda$ na região de $600 \mathrm{~nm}$ ) e o parâmetro de polaridade. De forma geral, para um soluto com estado excitado muito mais polar que o estado fundamental, um aumento na polaridade do solvente irá estabilizar o estado excitado mais que o estado fundamental, diminuindo a energia da transição e levando a um deslocamento para a região do vermelho. $\mathrm{O}$ deslocamento para a região do azul associado com as transições $n \rightarrow \pi^{*}$, tem sido bastante estudado. A respeito de cetonas alifáticas há uma pequena redução do momento de dipolo na excitação levando geralmente para um deslocamento para o azul.

Os solventes polares estabilizam os estados $\pi \rightarrow \pi^{*}$, e desestabilizam os estados $n \rightarrow \pi^{*}$. Portanto, as tioxantonas são um exemplo de como o solvente pode afetar as propriedades fotoquímicas e fotofísicas ${ }^{31}$.

\subsubsection{Estudo dos Transientes de Tioxantona na Presença de Poliestireno (PS+TX)}

Os espectros de absorção de transientes e os tempos de decaimento do estado triplete da tioxantona na presença de poliestireno (PS+TX) em solução foram medidos utilizando a técnica de fotólise por pulso de laser. As medidas foram realizadas em solução de dimetilformamida e também em solução de tetrahidrofurano, em atmosfera controlada de $\mathrm{N}_{2}$ e também na presença de ar.

\section{$>P S+T X$ em dimetilformamida}

A Figura 55A ilustra o espectro de absorção do transiente de PS+TX em dimetilformamida e em atmosfera de $\mathrm{N}_{2}$. $\mathrm{O}$ espectro é caracterizado por uma banda de absorção máxima em $634 \mathrm{~nm}$ atribuída a absorção triplete-triplete (T-T).

A Figura 55B ilustra o decaimento do estado triplete de PS+TX em $660 \mathrm{~nm}$ na ausência de supressor. Os tempos de vida obtidos estão resumidos na Tabela 6 . 


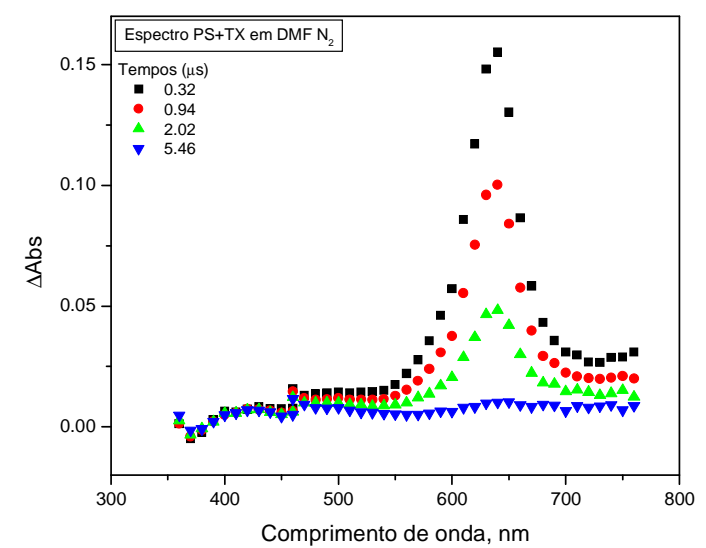

A

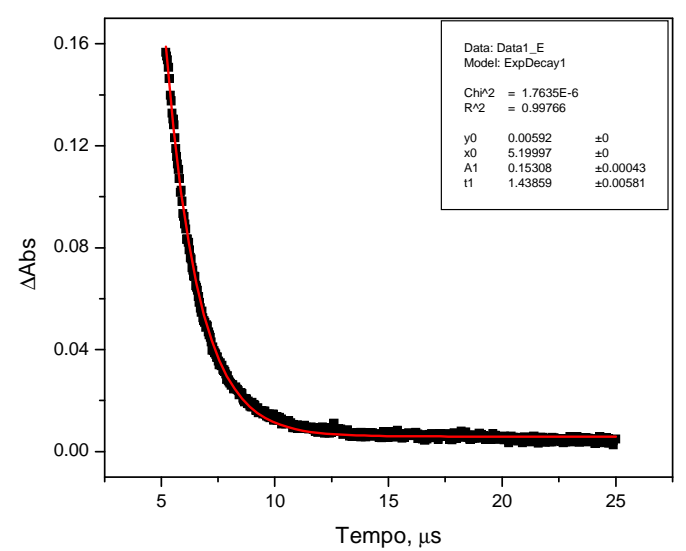

B

Figura 55. (A) Espectro de absorção de transiente de PS+TX em dimetilformamida, em atmosfera de $\mathrm{N}_{2}$, de 360 a $760 \mathrm{~nm}$. (B) Decaimento de absorção do transiente de PS+TX em dimetilformamida, em $660 \mathrm{~nm}, \mathrm{t}_{\mathrm{d}}=2,5 \mu \mathrm{s}$, em atmosfera de $\mathrm{N}_{2}$.

A Figura 56A ilustra o espectro de absorção do transiente de PS+TX em dimetilformamida e na presença de ar. O espectro é caracterizado por uma banda de absorção com máximo em $634 \mathrm{~nm}$ atribuída a absorção triplete-triplete $(T-T)$.

A Figura 56B ilustra o decaimento do estado triplete de PS+TX em $660 \mathrm{~nm}$. Os tempos de vida obtidos estão resumidos na Tabela 6 .

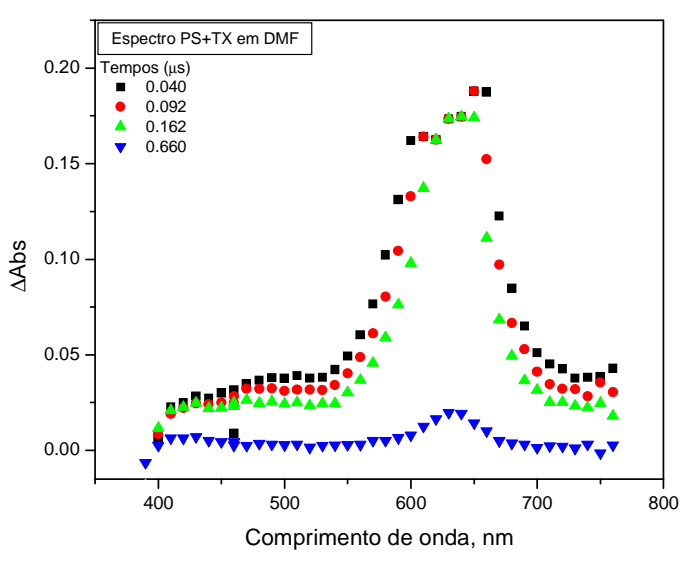

A

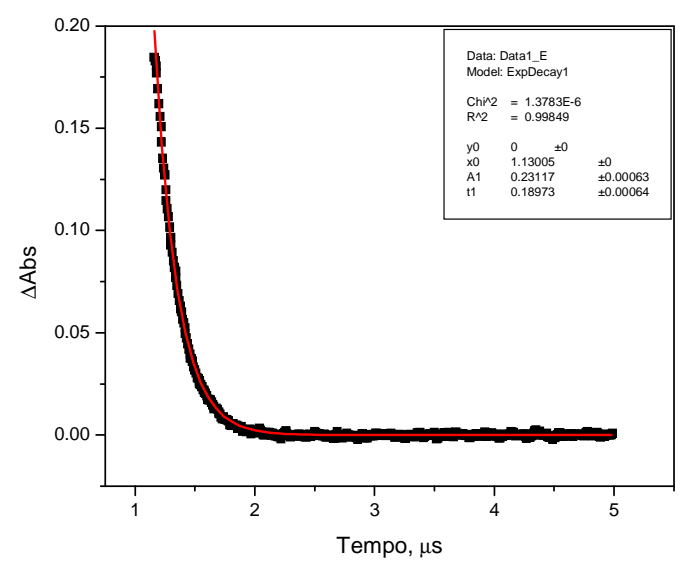

B

Figura 56. (A) Espectro de absorção de transiente de PS+TX em dimetilformamida, em ar, de 390 a $760 \mathrm{~nm}$. (B) Decaimento de absorção do transiente de PS+TX em dimetilformamida, em $660 \mathrm{~nm}, \mathrm{t}_{\mathrm{d}}=500 \mathrm{~ns}$, em ar. 


\section{$>P S+T X$ em tetrahidrofurano}

A Figura 57A ilustra o espectro de absorção do transiente de PS+TX em tetrahidrofurano e em atmosfera de $\mathrm{N}_{2}$. O espectro é caracterizado por uma banda de absorção com máximo em $642 \mathrm{~nm}$ atribuída a absorção triplete-triplete $(T-T)$.

A Figura 57B ilustra o decaimento do estado triplete de PS+TX em $660 \mathrm{~nm}$ na ausência de supressor. Os tempos de vida obtidos estão resumidos na Tabela 6.

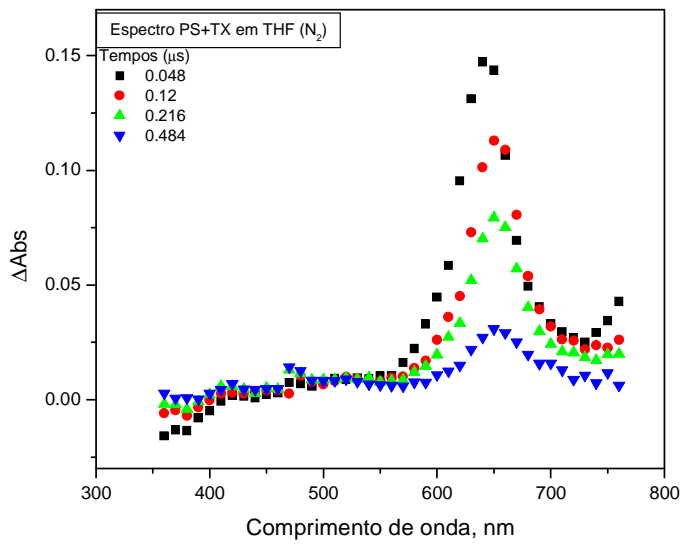

A

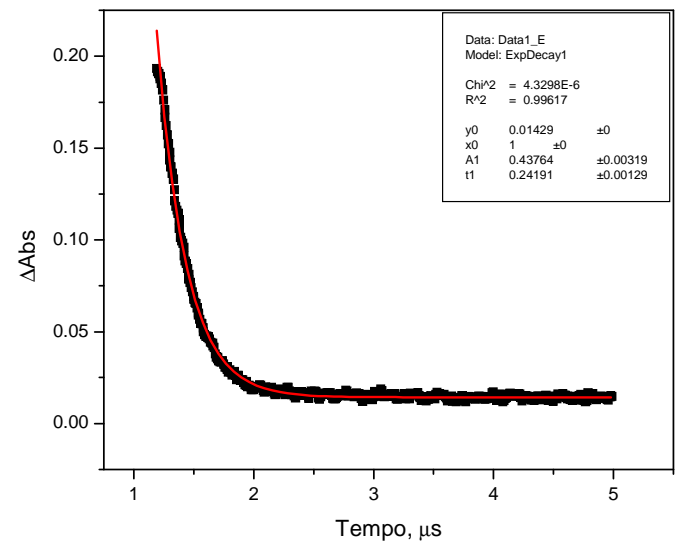

B

Figura 57. (A) Espectro de absorção de transiente de PS+TX em tetrahidrofurano, em atmosfera de $\mathrm{N}_{2}$, de 360 a $760 \mathrm{~nm}$. (B) Decaimento de absorção do transiente de PS+TX em tetrahidrofurano, em $660 \mathrm{~nm}, \mathrm{t}_{\mathrm{d}}=500 \mathrm{~ns}$, em atmosfera de $\mathrm{N}_{2}$.

O espectro de absorção do transiente de PS+TX em tetrahidrofurano é ilustrado na Figura 58A, em ar. O espectro é caracterizado por uma banda de absorção com máximo em $642 \mathrm{~nm}$ atribuída a absorção triplete-triplete $(T-T)$.

A Figura 58B ilustra o decaimento do estado triplete de PS+TX em $660 \mathrm{~nm}$. Os tempos de vida obtidos estão resumidos na Tabela 6. 


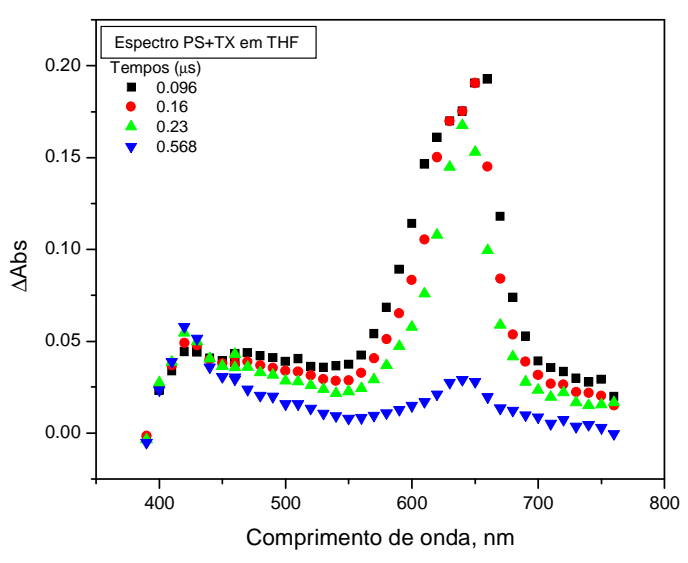

A

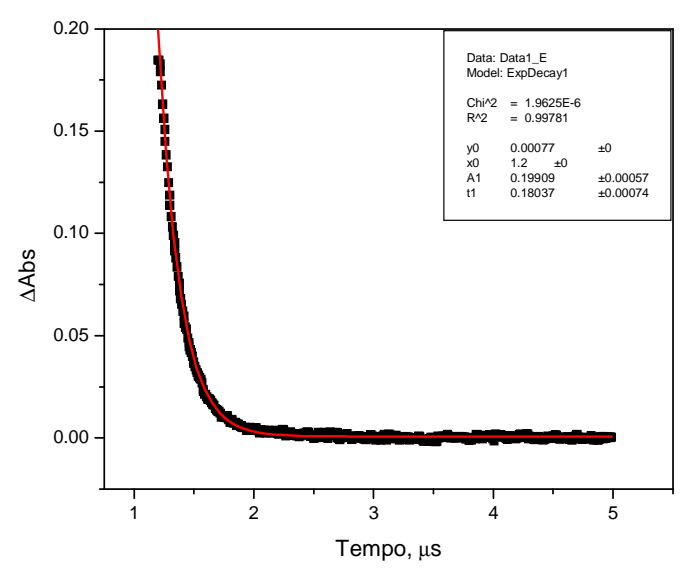

B

Figura 58. (A) Espectro de absorção de transiente de PS+TX em tetrahidrofurano, em ar, de 360 a 760 nm. (B) Decaimento de absorção do transiente de PS+TX em tetrahidrofurano, em $660 \mathrm{~nm}, \mathrm{t}_{\mathrm{d}}=500 \mathrm{~ns}$, em ar.

Analisando os gráficos anteriores pode-se dizer que a adição do poliestireno às soluções de tioxantona nos diferentes solventes (dimetilformamida e tetrahidrofurano) não deslocou o máximo de absorção na região de $600 \mathrm{~nm}$. Ou seja, os valores de máximo encontrados foram os mesmos que nos sistemas da tioxantona livre. Os tempos de vida do triplete em $660 \mathrm{~nm}$ encontrados para a tioxantona na presença de poliestireno foram praticamente os mesmos que os da tioxantona livre nos diferentes solventes, isto mostra que a presença do poliestireno não alterou os tempos de vida do estado triplete da tioxantona.

Tabela 6. Tempos de vida do estado triplete em $660 \mathrm{~nm}$ para o sistema PS+TX

\begin{tabular}{|c|c|}
\hline Sistema PS+TX/ar & $\overline{\tau_{1}(\mu s)}$ \\
\hline dimetilformamida & 0.19 \\
\hline tetrahidrofurano & 0.18 \\
\hline Sistema PS+TX/N $\mathbf{N}_{2}$ & $\tau_{1}(\mu s)$ \\
\hline dimetilformamida & 1.44 \\
\hline tetrahidrofurano & 0.24 \\
\hline
\end{tabular}

\subsubsection{Estudo dos Transientes do Copolímero PS-TX I}

Os espectros de absorção de transientes e os tempos de decaimento do estado triplete do copolímero PS-TX I em solução foram medidos utilizando a técnica de fotólise por pulso 
de laser. As medidas foram realizadas em solução de dimetilformamida e também em solução de tetrahidrofurano, em atmosfera controlada de $\mathrm{N}_{2}$ e na presença de ar.

\section{$>P S-T X$ I em dimetilformamida}

A Figura 59 A ilustra o espectro de absorção do transiente do copolímero PS-TX I em dimetilformamida e em atmosfera de $\mathrm{N}_{2}$. $\mathrm{O}$ espectro é caracterizado por uma banda de absorção com máximo em $665 \mathrm{~nm}$ atribuída a absorção triplete-triplete $(T-T)$. A Figura $59 \mathrm{~B}$ ilustra o decaimento do estado triplete do copolímero PS-TX I em 660 nm na ausência de supressor. Os tempos de vida obtidos estão resumidos na Tabela 7.

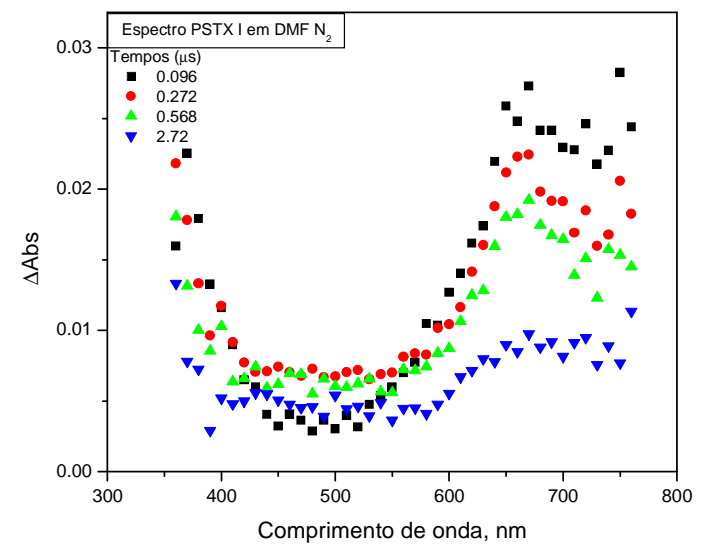

A

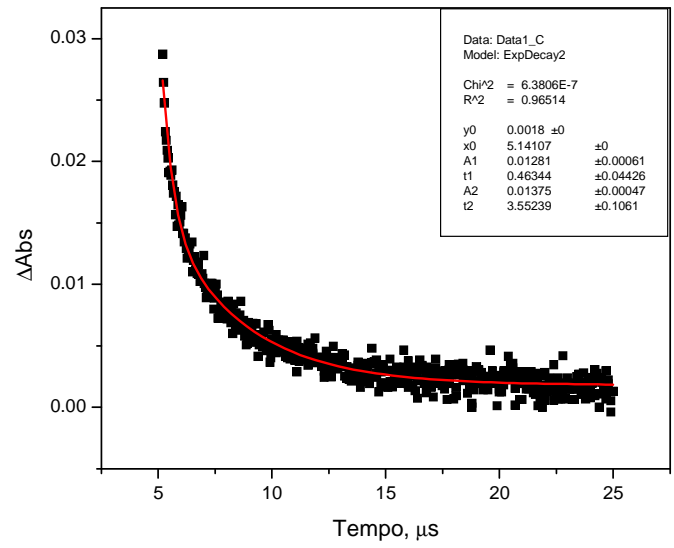

B

Figura 59. (A) Espectro de absorção de transiente de PS-TX I em dimetilformamida, em atmosfera de $\mathrm{N}_{2}$, de 360 a $760 \mathrm{~nm}$. (B) Decaimento de absorção do transiente de PS-TX I em dimetilformamida, em $660 \mathrm{~nm}, \mathrm{t}_{\mathrm{d}}=2,5 \mu \mathrm{s}$, em atmosfera de $\mathrm{N}_{2}$.

Na Figura 60 A é ilustrado o espectro de absorção do transiente do copolímero PS-TX I em dimetilformamida, na presença de ar. O espectro é caracterizado por uma banda de absorção com máximo em $670 \mathrm{~nm}$ atribuída a absorção triplete-triplete $(T-T)$. A Figura $60 \mathrm{~B}$ ilustra o decaimento do estado triplete do copolímero PS-TX I em $670 \mathrm{~nm}$. Os tempos de vida obtidos estão resumidos na Tabela 7. 


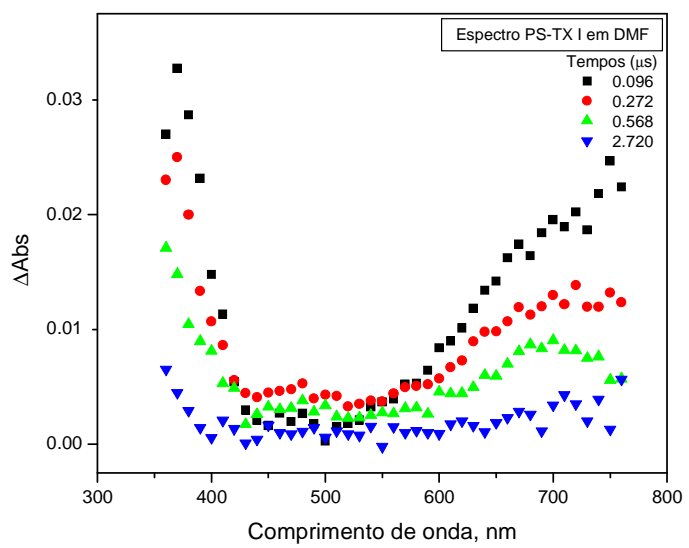

A

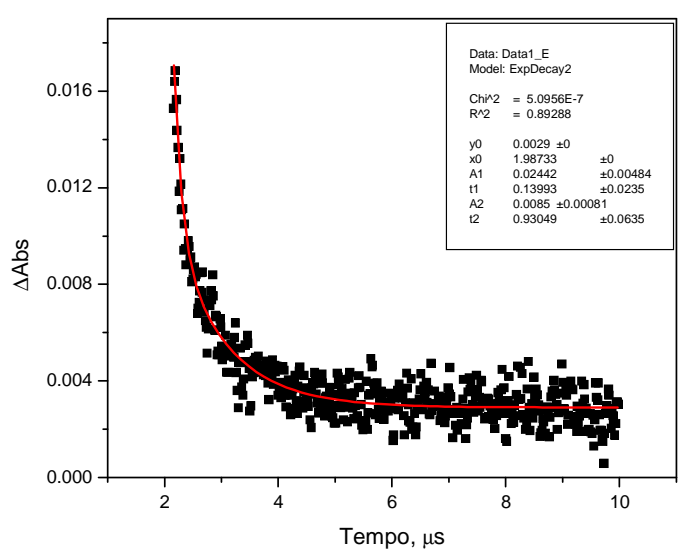

B

Figura 60. (A) Espectro de absorção de transiente de PS-TX I em dimetilformamida, em ar, de 360 a $760 \mathrm{~nm}$. (B) Decaimento de absorção do transiente de PS-TX I em dimetilformamida, em $660 \mathrm{~nm}, \mathrm{t}_{\mathrm{d}}=1 \mu \mathrm{s}$, em ar.

\section{$>$ PS-TX I em tetrahidrofurano}

A Figura 61 A ilustra o espectro de absorção do transiente do copolímero PS-TX I em tetrahidrofurano, sob atmosfera de $\mathrm{N}_{2}$. $\mathrm{O}$ espectro é caracterizado por uma banda de absorção com máximo em $650 \mathrm{~nm}$ atribuída a absorção triplete-triplete $(T-T)$. A Figura $61 \mathrm{~B}$ ilustra o decaimento do estado triplete do copolímero PS-TX I em $660 \mathrm{~nm}$ na ausência de supressor, os tempos de vida obtidos estão resumidos na Tabela 7.

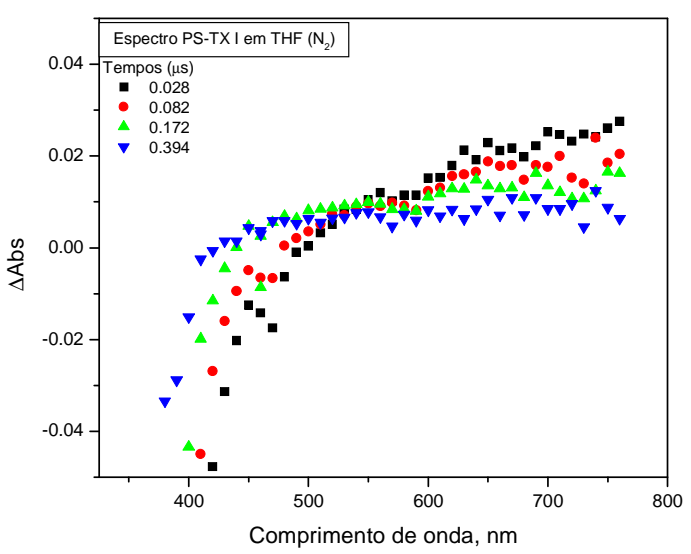

A

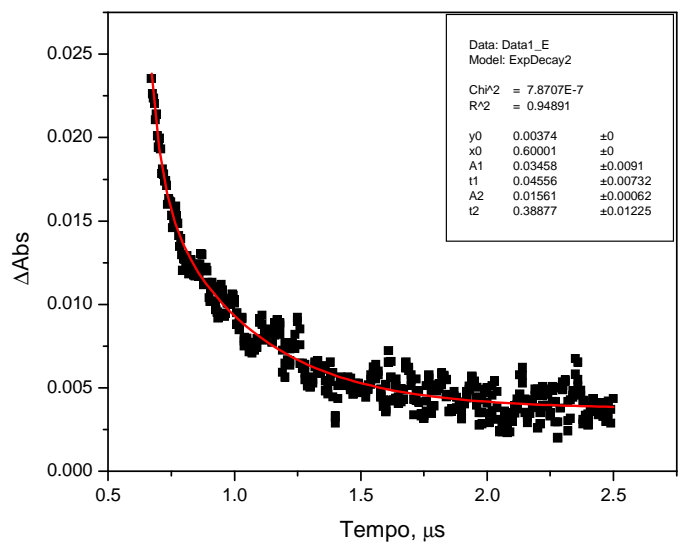

B

Figura 61. (A) Espectro de absorção de transiente de PS-TX I em tetrahidrofurano, em atmosfera de $\mathrm{N}_{2}$, de 360 a $760 \mathrm{~nm}$. (B) Decaimento de absorção do transiente de PS-TX I em tetrahidrofurano, em $660 \mathrm{~nm}, \mathrm{t}_{\mathrm{d}}=250 \mathrm{~ns}$, em atmosfera de $\mathrm{N}_{2}$. 
Na Figura 62 A é ilustrado o espectro de absorção do transiente do copolímero PS-TX I em tetrahidrofurano na presença de ar. O espectro é caracterizado por uma banda de absorção com máximo em $660 \mathrm{~nm}$ atribuída a absorção triplete-triplete $(T-T)$. A Figura $62 \mathrm{~B}$ ilustra o decaimento do estado triplete do copolímero PS-TX I em $660 \mathrm{~nm}$. A Tabela 7 resume os tempos de vida.

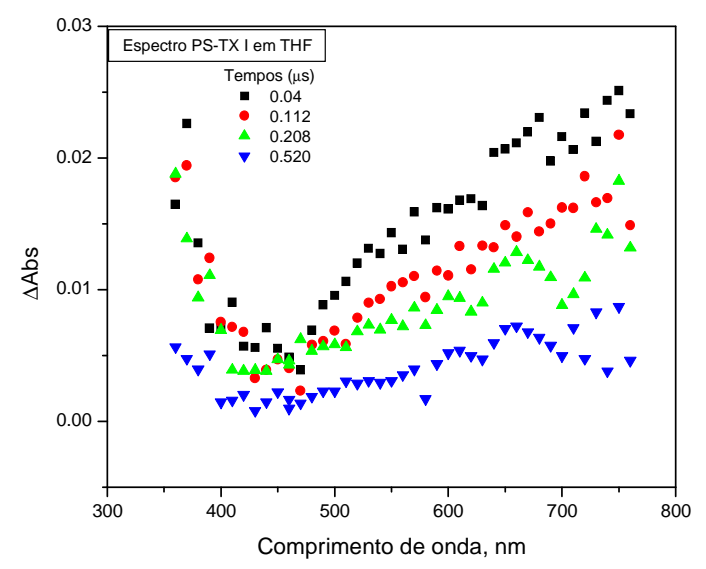

A

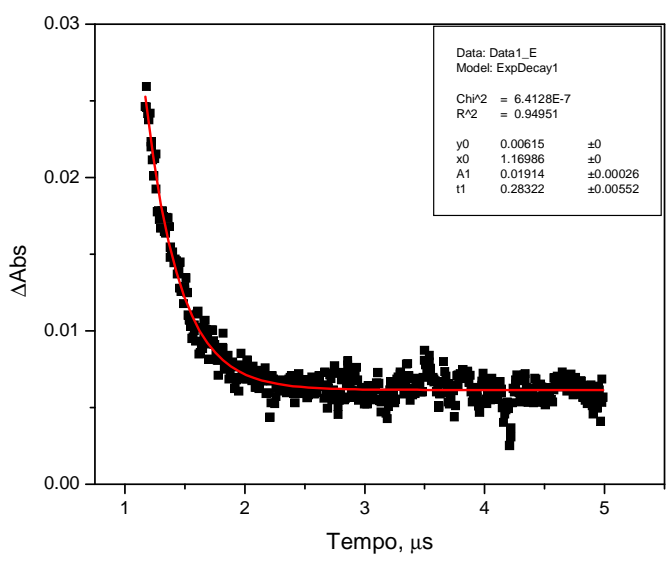

B

Figura 62. (A) Espectro de absorção de transiente de PS-TX I em tetrahidrofurano, em ar, de 360 a 760 nm. (B) Decaimento de absorção do transiente de PS-TX I em tetrahidrofurano, em $660 \mathrm{~nm}, \mathrm{t}_{\mathrm{d}}=500 \mathrm{~ns}$, em ar.

Analisando os espectros de absorção $T-T$ do copolímero PS-TX I em dimetilformamida e em tetrahidrofurano pode-se dizer que houve um pequeno deslocamento do máximo de absorção na região de $600 \mathrm{~nm}$. Já em comparação com a tioxantona livre, o deslocamento em ambos os solventes foi em torno de $30 \mathrm{~nm}$. Isto pode estar relacionado também com a estrutura do copolímero PS-TX I.

Tabela 7. Tempos de vida do estado triplete em $660 \mathrm{~nm}$ para o sistema PS-TX I

\begin{tabular}{lll}
\hline Sistema PS-TX I/ar & $\boldsymbol{\tau}_{\mathbf{1}}(\boldsymbol{\mu s})$ & $\boldsymbol{\tau}_{\mathbf{2}}(\boldsymbol{\mu s})$ \\
\hline dimetilformamida & 0.14 & 0.93 \\
tetrahidrofurano & 0.28 & - \\
\hline Sistema PS-TX I/N $\mathbf{N}_{\mathbf{2}}$ & $\boldsymbol{\tau}_{\mathbf{1}}(\boldsymbol{\mu s})$ & $\boldsymbol{\tau}_{\mathbf{2}}(\boldsymbol{\mu} \mathbf{s})$ \\
\hline dimetilformamida & 0.46 & 3.55 \\
tetrahidrofurano & 0.05 & 0.39 \\
\hline
\end{tabular}




\subsubsection{Estudo dos transientes do copolímero PS-TX II}

Os estudos das reações elementares do copolímero PS-TX II foram realizados através da técnica de fotólise por pulso de laser, em solução de dimetilformamida e também em solução de tetrahidrofurano.

\section{PPS-TX II em dimetilformamida}

A Figura 63 A ilustra o espectro de absorção do transiente do copolímero PS-TX II em dimetilformamida e em atmosfera de $\mathrm{N}_{2}$. $\mathrm{O}$ espectro é caracterizado por uma banda de absorção com máximo em $640 \mathrm{~nm}$ atribuída a absorção triplete-triplete $(T-T)$. A Figura $63 \mathrm{~B}$ ilustra o decaimento do estado triplete do copolímero PS-TX II em 660 nm na ausência de supressor. Os tempos de vida obtidos estão resumidos na Tabela 8.

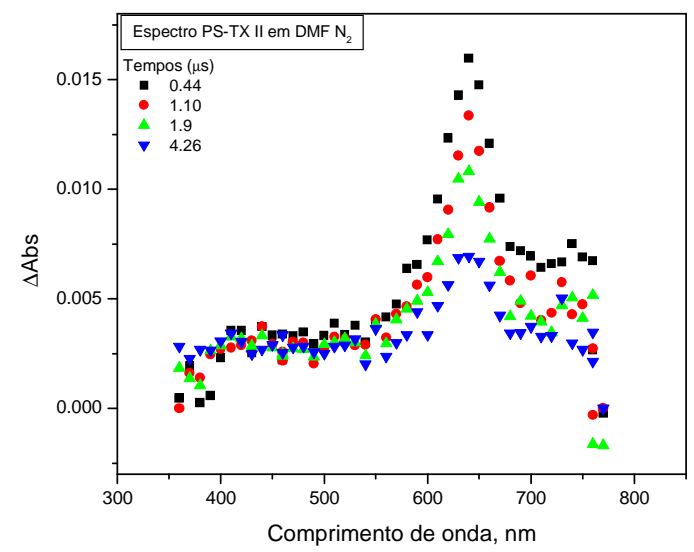

A

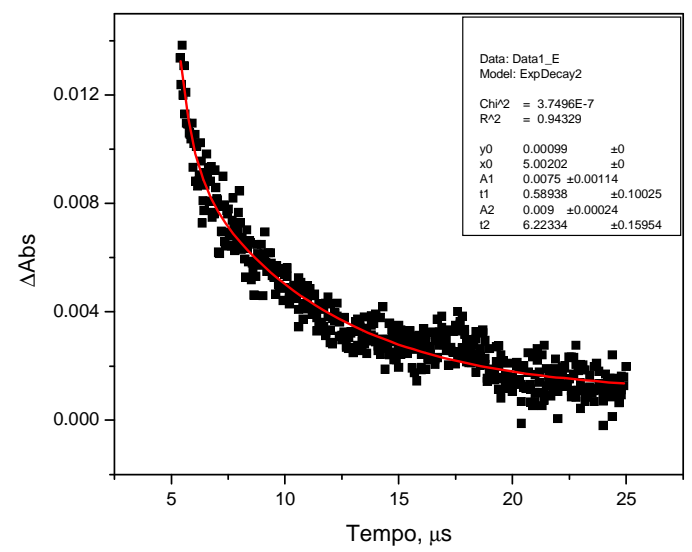

B

Figura 63. (A) Espectro de absorção de transiente de PS-TX II em dimetilformamida, em atmosfera de $\mathrm{N}_{2}$, de 360 a $760 \mathrm{~nm}$. (B) Decaimento de absorção do transiente de PS-TX II em dimetilformamida, em $660 \mathrm{~nm}, \mathrm{t}_{\mathrm{d}}=2,5 \mu \mathrm{s}$, em atmosfera de $\mathrm{N}_{2}$.

A Figura 64 A ilustra o espectro de absorção do transiente do copolímero PS-TX II em dimetilformamida, em ar. O espectro é caracterizado por uma banda de absorção com máximo em $640 \mathrm{~nm}$ atribuída a absorção triplete-triplete $(T-T)$. A Figura 64 B ilustra o decaimento do estado triplete do copolímero PS-TX II em $660 \mathrm{~nm}$. Os tempos de vida obtidos estão resumidos na Tabela 8 . 


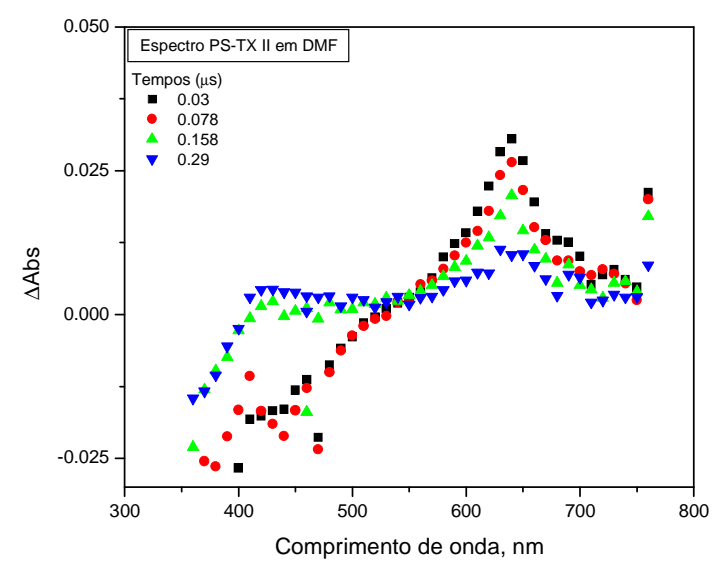

A

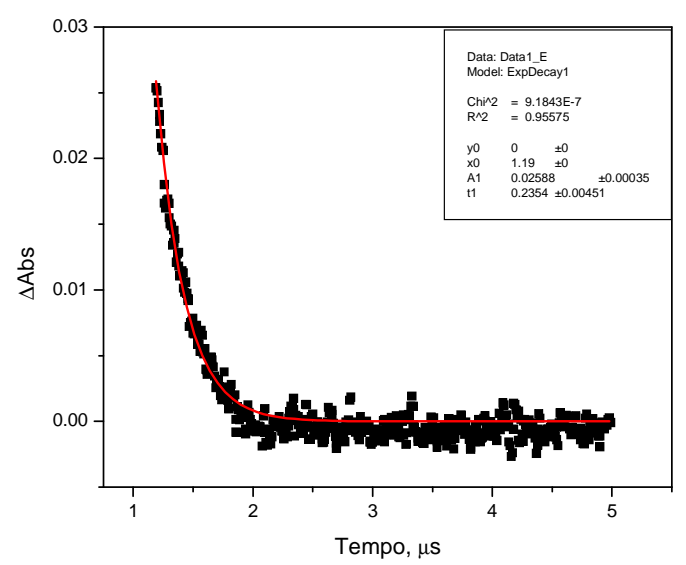

B

Figura 64. (A) Espectro de absorção de transiente de PS-TX II em dimetilformamida, em ar, de 360 a $760 \mathrm{~nm}$. (B) Decaimento de absorção do transiente de PS-TX II em dimetilformamida, em $660 \mathrm{~nm}, \mathrm{t}_{\mathrm{d}}=500 \mathrm{~ns}$, em ar.

\section{$>$ PS-TX II em tetrahidrofurano}

A Figura 65 A ilustra o espectro de absorção do transiente do copolímero PS-TX II em tetrahidrofurano, sob atmosfera de $\mathrm{N}_{2}$. O espectro é caracterizado por uma banda de absorção com máximo em $645 \mathrm{~nm}$ atribuída a absorção triplete-triplete $(T-T)$. A Figura 65B ilustra o decaimento do estado triplete do copolímero PS-TX II em 660 nm na ausência de supressor. Os tempos de vida obtidos estão resumidos na Tabela 8.

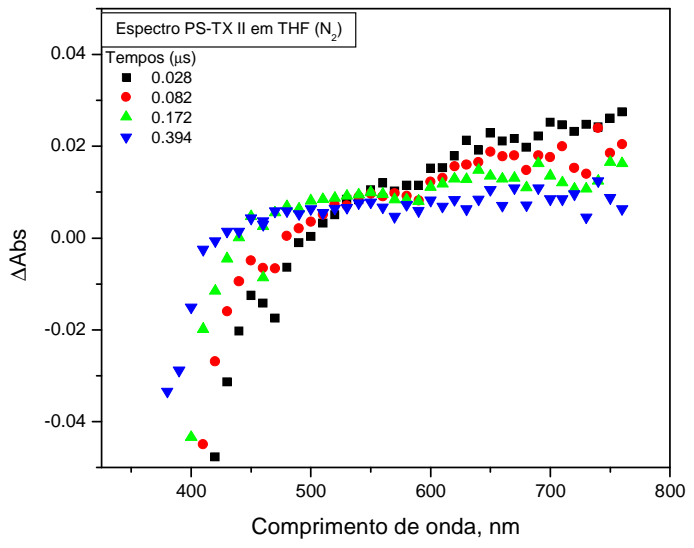

A

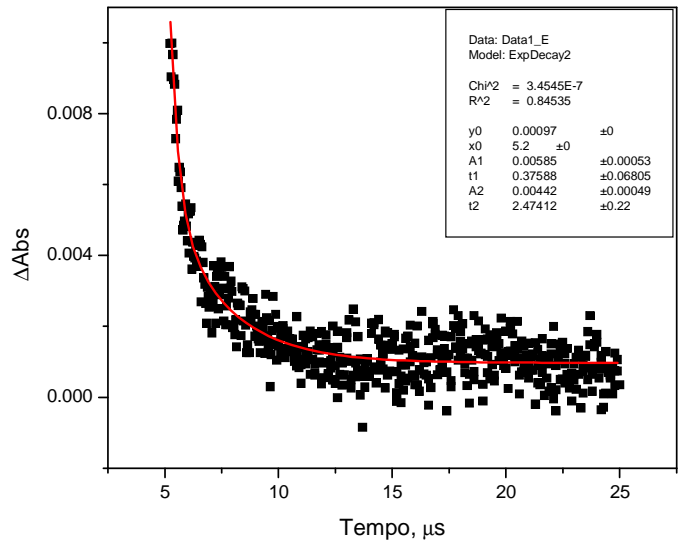

B

Figura 65. (A) Espectro de absorção de transiente de PS-TX II em tetrahidrofurano, em atmosfera de $\mathrm{N}_{2}$, de 360 a $760 \mathrm{~nm}$. (B) Decaimento de absorção do transiente de PS-TX II em tetrahidrofurano, em $660 \mathrm{~nm}, \mathrm{t}_{\mathrm{d}}=2,5 \mu \mathrm{s}$, em atmosfera de $\mathrm{N}_{2}$. 
A Figura 66A ilustra o espectro de absorção do transiente do copolímero PS-TX II em tetrahidrofurano, em ar. $\mathrm{O}$ espectro é caracterizado por uma banda de absorção com máximo em $640 \mathrm{~nm}$ atribuída a absorção triplete-triplete $(T-T)$.

A Figura 66B ilustra o decaimento do estado triplete do copolímero PS-TX II em $660 \mathrm{~nm}$. Os tempos de vida obtidos estão resumidos na Tabela 8.

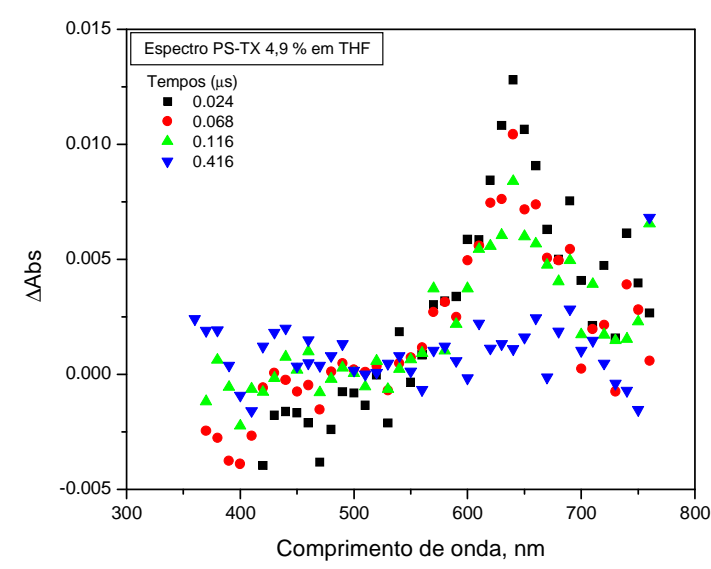

A

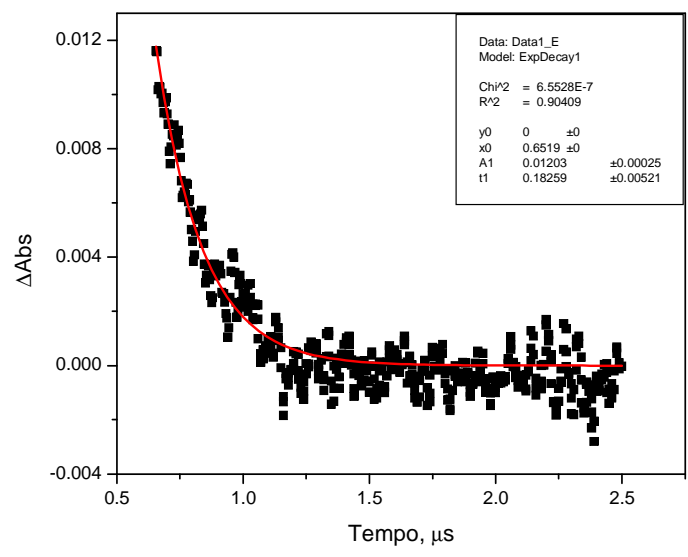

B

Figura 66. (A) Espectro de absorção de transiente de PS-TX II em tetrahidrofurano, em ar, de 360 a $760 \mathrm{~nm}$. (B) Decaimento de absorção do transiente de PS-TX II em tetrahidrofurano, em $660 \mathrm{~nm}, \mathrm{t}_{\mathrm{d}}=250 \mathrm{~ns}$, em ar.

Analisando os espectros de absorção $T-T$ do copolímero PS-TX II em dimetilformamida e em tetrahidrofurano pode-se dizer que houve um pequeno deslocamento do máximo de absorção na região de $600 \mathrm{~nm}$. Já em comparação com a tioxantona livre, o deslocamento em ambos os solventes foi menor que o ocorrido com o copolímero PS-TX I, em torno de $5 \mathrm{~nm}$. Isto pode estar relacionado também com a estrutura do copolímero PS-TX II, ou seja, a tioxantona está mais livre nessa estrutura, igualando-se ao comportamento da tioxantona.

Tabela 8. Tempos de vida do estado triplete em $660 \mathrm{~nm}$ para o sistema PS-TX II

\begin{tabular}{lll}
\hline Sistema PS-TX II/ar & $\boldsymbol{\tau}_{\mathbf{1}}(\boldsymbol{\mu} \mathbf{s})$ & $\boldsymbol{\tau}_{\mathbf{2}}(\boldsymbol{\mu} \mathbf{s})$ \\
\hline dimetilformamida & 0.24 & - \\
tetrahidrofurano & 0.18 & - \\
\hline Sistema PS-TX II/ $\mathbf{N}_{\mathbf{2}}$ & $\boldsymbol{\tau}_{\mathbf{1}}(\boldsymbol{\mu} \mathbf{s})$ & $\boldsymbol{\tau}_{\mathbf{2}}(\boldsymbol{\mu} \mathbf{s})$ \\
\hline dimetilformamida & 0.59 & 6.22 \\
tetrahidrofurano & 0.38 & 2.47 \\
\hline
\end{tabular}


Os tempos de vida nos diferentes solventes apresentados nas Tabelas 4, 67 e 8 mostram que existe uma dependência entre o tempo de vida do triplete da tioxantona em função da polaridade do solvente. Assim, observou-se que em solventes mais polares o tempo de vida aumenta. Isso ocorre porque os estados tripletes ${ }^{3} \pi \pi^{*}$ e ${ }^{3} n \pi^{*}$ estão próximos em energia em solventes não polares, o acoplamento vibrônico entre os estados degenerados aumenta a velocidade de cruzamento entresistemas para o estado fundamental $\mathrm{S}_{0}$ diminuindo o tempo de vida do triplete. Por outro lado, em solventes polares o estado ${ }^{3} \pi \pi^{*}$ é estabilizado enquanto o estado ${ }^{3} \mathrm{n}^{*}$ é desestabilizado resultando no descréscimo do acoplamento vibrônico que diminue a velocidade de cruzamento entre sistemas aumentado o tempo de vida do estado triplete ${ }^{32}$.

\subsubsection{Estudo de Supressão do Estado Triplete Utilizando Trietanolamina (TEOHA)}

O estudo de supressão do estado excitado triplete de tioxantonas foi investigado com base em resultados anteriores. Alguns autores observaram que o estado triplete $\mathrm{n} \Pi^{*}$ de cetonas aromáticas é mais reativo do que $\pi \pi^{*}$ em reações de abstração de hidrogênio ${ }^{33,34}$. Além disso, os autores procuraram esclarecer como as diferenças nas configurações eletrostáticas afetam a constante de velocidade para a supressão por transferência de carga ${ }^{35}$. Assim, procurou-se estudar a influência do solvente sobre a constante de velocidade de supressão por uma amina alifática terciária com a finalidade de se obter informações sobre o possível efeito de proximidade nos estados tripletes excitados. A partir disso, foi investigada a supressão da tioxantona em diferentes solventes bem como a supressão na presença de poliestireno e dos copolímeros PS-TX I e PS-TX II.

\section{Tioxantona livre em diferentes solventes (TX)}

O comportamento da supressão da tioxantona (TX) no estado excitado triplete por trietanolamina (TEOHA), um eficiente doador de elétrons, foi investigado usando um laser de Nd-YAG com comprimento de onda de excitação em $355 \mathrm{~nm}$. A absorção do triplete-triplete $(T-T)$ nos diferentes solventes foi monitorada em $660 \mathrm{~nm}$. Em todos os experimentos manteve-se a absorbância em torno de 0,3 para comprimento de onda $355 \mathrm{~nm}$, a fim de se minimizar o processo de auto-supressão.

O decaimento da absorbância do estado triplete da tioxantona foi acompanhado pela variação da concentração de supressor, [TEOHA]. O inverso do tempo de vida observado foi 
graficado em função da concentração da amina (supressor) de acordo com as equações 18 e 19:

$$
\begin{aligned}
\left(\tau_{\mathrm{T}}\right)^{-1} & =\left(\tau_{\mathrm{T}}^{0}\right)^{-1}+\mathrm{k}_{\mathrm{q}}[\text { TEOHA }] \times \tau_{\mathrm{T}}^{0} \\
\tau_{\mathrm{T}}{ }^{0} / \tau_{\mathrm{T}} & =1+\mathrm{k}_{\mathrm{q}} \tau_{\mathrm{T}}[\text { TEOHA }]
\end{aligned}
$$

A Figura 67A ilustra os decaimentos de absorção do transiente de TX em 660 nm no solvente dimetilformamida, em diferentes concentrações de TEOHA. A Figura 67B ilustra o gráfico de Stern-Volmer da supressão do tempo de vida do estado triplete da TX pela adição de TEOHA. $\mathrm{O}$ valor econtrado para a constante de velocidade de supressão $\left(\mathrm{k}_{\mathrm{q}}\right)$ está resumido na Tabela 9.

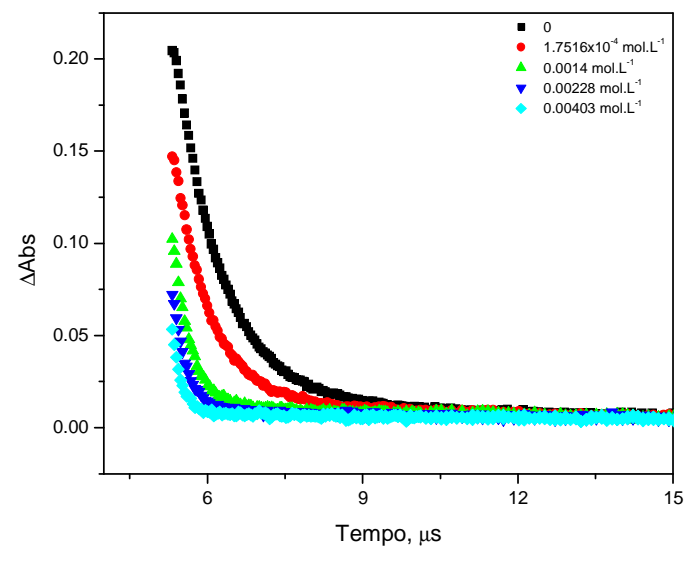

A

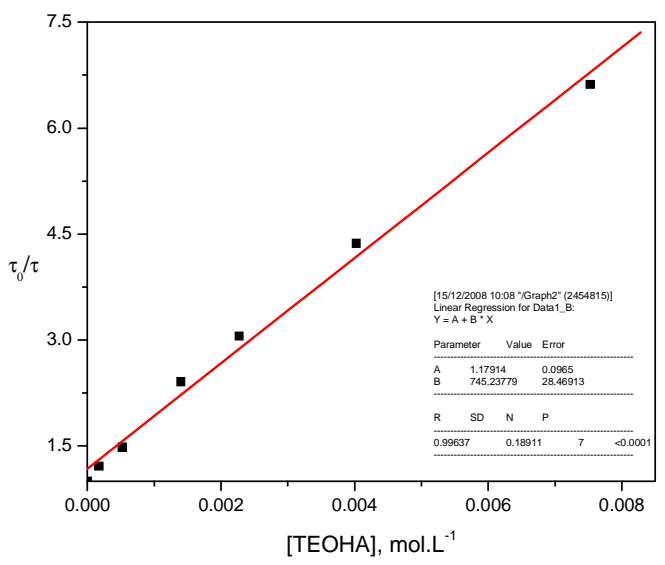

B

Figura 67. (A) Decaimentos de absorção do transiente de TX em $660 \mathrm{~nm}$ no solvente dimetilformamida, em diferentes concentrações de TEOHA. (B) Gráfico de Stern-Volmer da supressão de TX em dimetilformamida por diferentes concentrações de TEOHA.

A Figura 68A ilustra os decaimentos de absorção do transiente de TX em 660 nm no solvente tetrahidrofurano, em diferentes concentrações de TEOHA. A Figura 68B ilustra o gráfico de Stern-Volmer da supressão do tempo de vida do estado triplete da TX pela adição de TEOHA. O valor econtrado para a constante de velocidade de supressão $\left(\mathrm{k}_{\mathrm{q}}\right)$ está resumido na Tabela 9. 


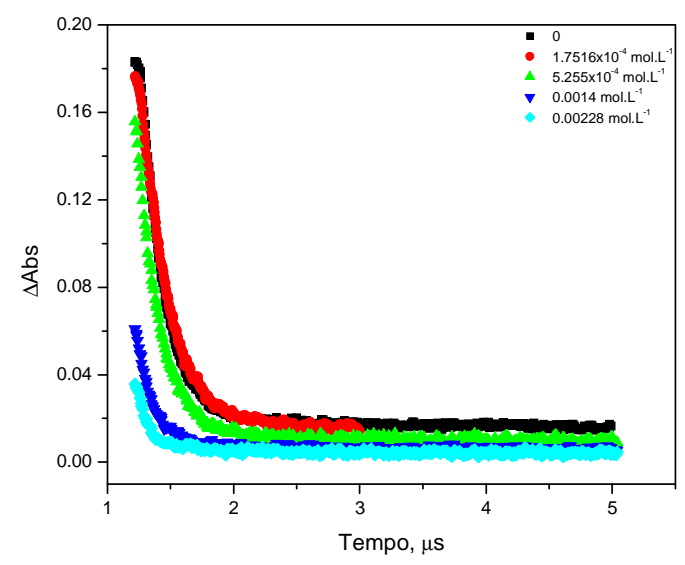

A

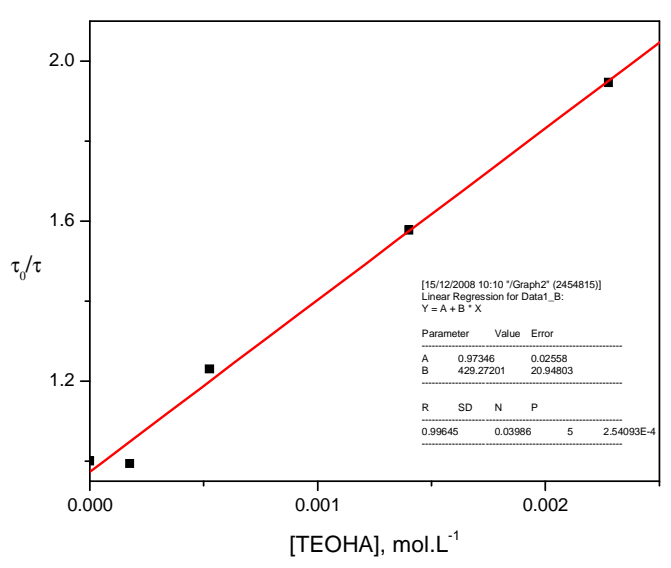

B

Figura 68. (A) Decaimentos de absorção do transiente de $\mathrm{TX}$ em $660 \mathrm{~nm}$ no solvente tetrahidrofurano, em diferentes concentrações de TEOHA. (B) Gráfico de Stern-Volmer da supressão de TX em tetrahidrofurano por diferentes concentrações de TEOHA.

A Figura 69A ilustra os decaimentos de absorção do transiente de TX em 660 nm no solvente acetonitrila, em diferentes concentrações de TEOHA. A Figura 69B ilustra o gráfico de Stern-Volmer da supressão do tempo de vida do estado triplete da TX em acetonitrila por diferentes concentrações de TEOHA. O valor econtrado para a constante de velocidade de supressão $\left(\mathrm{k}_{\mathrm{q}}\right)$ está resumido na Tabela 9.

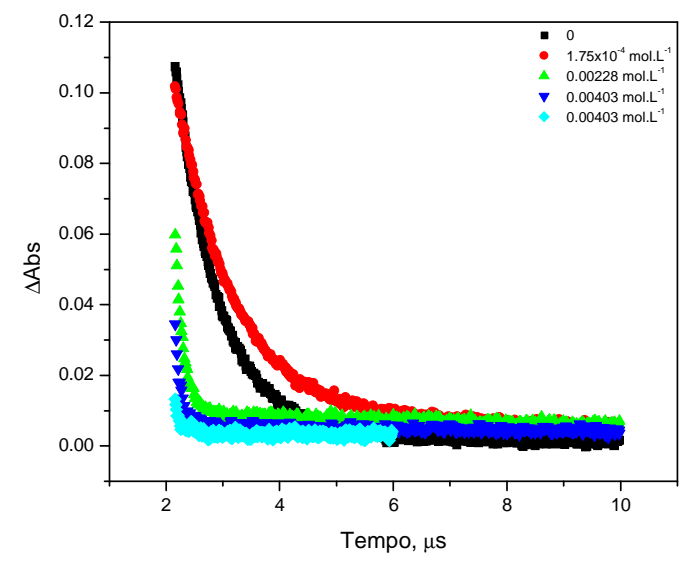

A

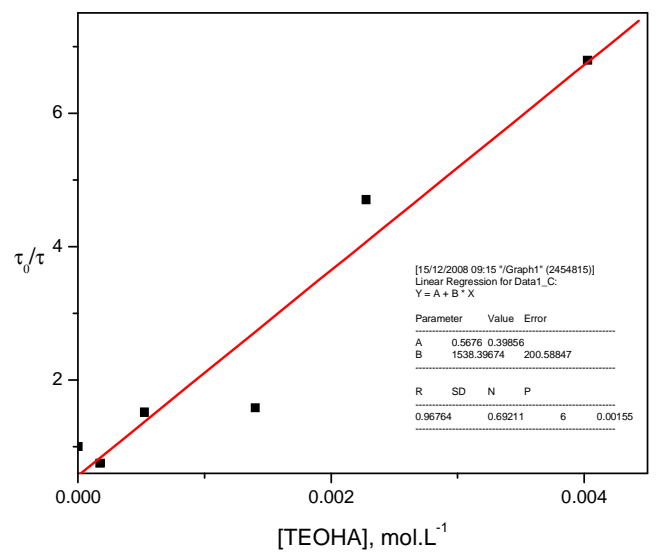

B

Figura 69. (A) Decaimentos de absorção do transiente de $\mathrm{TX}$ em $660 \mathrm{~nm}$ no solvente acetonitrila, em diferentes concentrações de TEOHA. (B) Gráfico de Stern-Volmer da supressão de TX em acetonitrila por diferentes concentrações de TEOHA. 
A Figura 70A ilustra os decaimentos de absorção do transiente de TX em 660 nm no solvente benzeno, em diferentes concentrações de TEOHA. A Figura 70B ilustra o gráfico de Stern-Volmer da supressão do tempo de vida do estado triplete da TX em benzeno por diferentes concentrações de TEOHA. O valor econtrado para a constante de velocidade de supressão $\left(\mathrm{k}_{\mathrm{q}}\right)$ está resumido na Tabela 9.

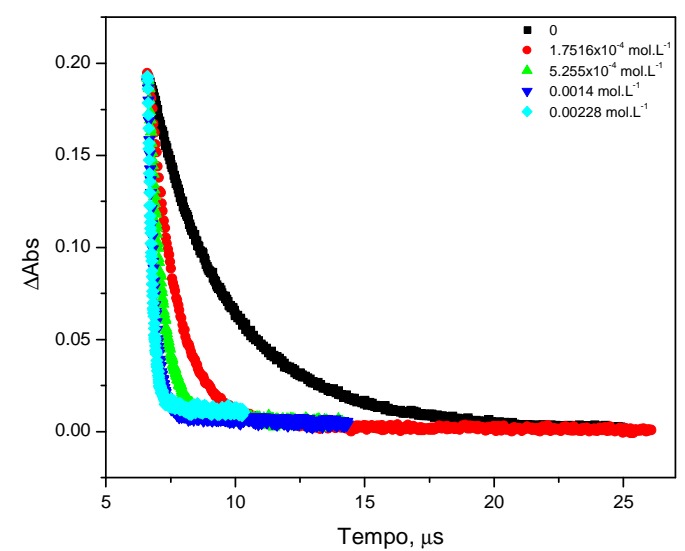

A

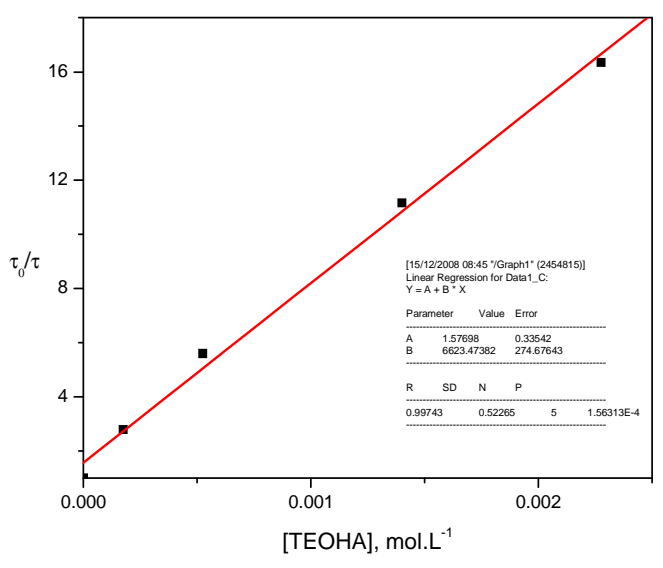

B

Figura 70. (A) Decaimentos de absorção do transiente de TX em 660 nm no solvente benzeno, em diferentes concentrações de TEOHA. (B) Gráfico de Stern-Volmer da supressão de TX em benzeno por diferentes concentrações de TEOHA.

\section{Tioxantona com o polímero poliestireno (PS+TX)}

A Figura 71A ilustra os decaimentos de absorção do transiente de PS+TX em $660 \mathrm{~nm}$ no solvente dimetilformamida, em diferentes concentrações de TEOHA. A Figura 71B ilustra o gráfico de Stern-Volmer da supressão do tempo de vida do estado triplete de PS+TX em dimetilformamida por diferentes concentrações de TEOHA. O valor econtrado para a constante de velocidade de supressão $\left(\mathrm{k}_{\mathrm{q}}\right)$ está resumido na Tabela 9 . 


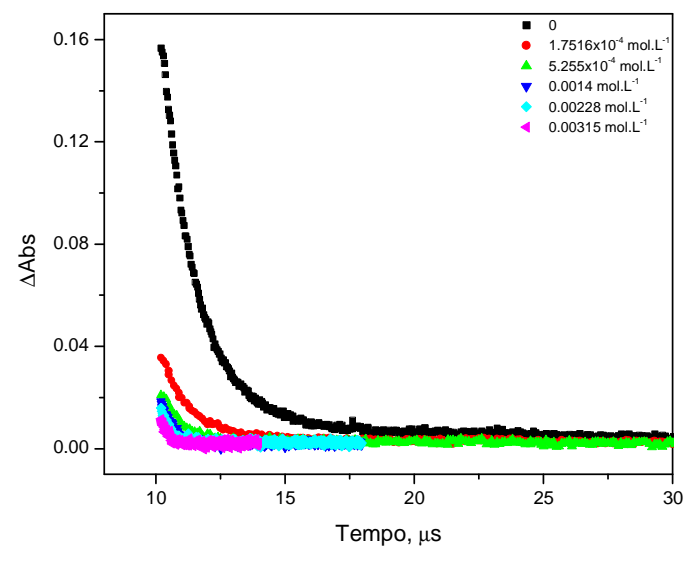

A

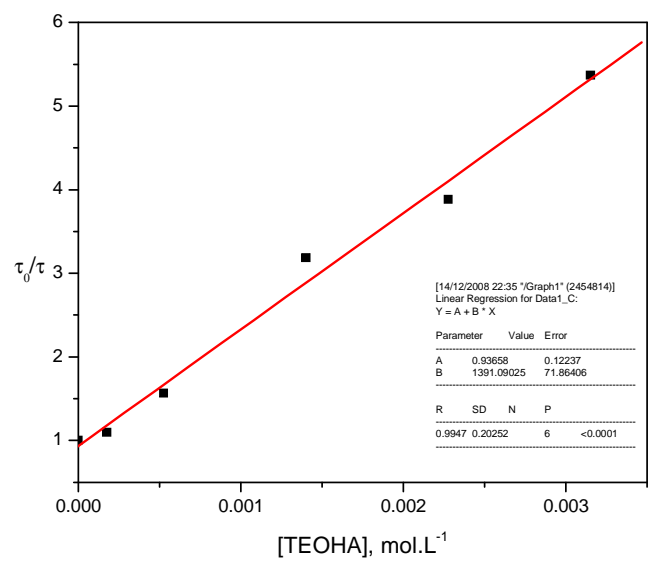

B

Figura 71. (A) Decaimentos de absorção do transiente de PS+TX em $660 \mathrm{~nm}$ no solvente dimetilformamida, em diferentes concentrações de TEOHA. (B) Gráfico de Stern-Volmer da supressão de PS+TX em dimetilformamida por diferentes concentrações de TEOHA.

A Figura 72A ilustra os decaimentos de absorção do transiente de PS+TX em $660 \mathrm{~nm}$ no solvente tetrahidrofurano, em diferentes concentrações de TEOHA. A Figura 72B ilustra o gráfico de Stern-Volmer da supressão do tempo de vida do estado triplete de PS+TX em tetrahidrofurano por diferentes concentrações de TEOHA. O valor econtrado para a constante de velocidade de supressão $\left(\mathrm{k}_{\mathrm{q}}\right)$ está resumido na Tabela 9.

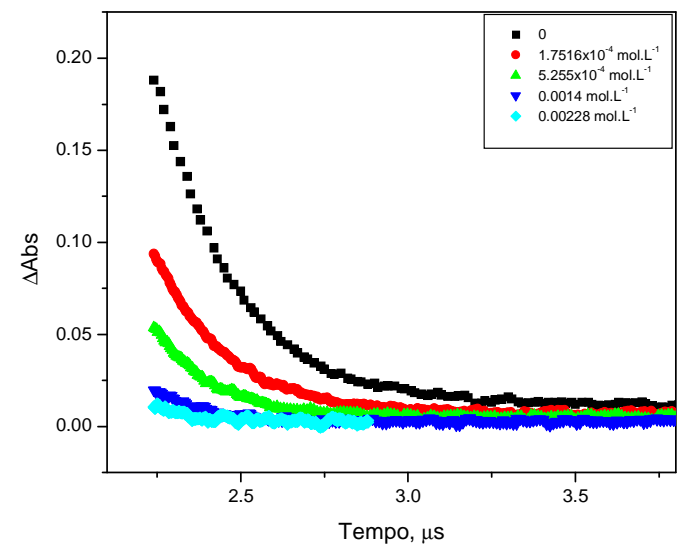

A

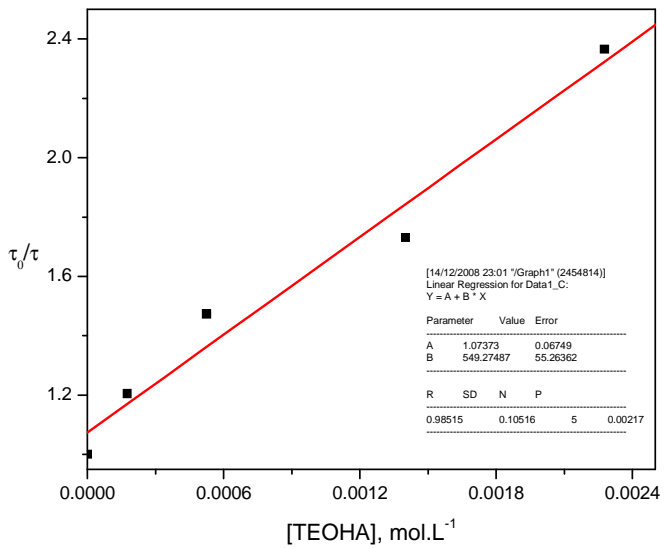

B

Figura 72. (A) Decaimentos de absorção do transiente de PS+TX em $660 \mathrm{~nm}$ no solvent tetrahidrofurano, em diferentes concentrações de TEOHA. (B) Gráfico de Stern-Volmer da supressão de PS+TX em tetrahidrofurano por diferentes concentrações de TEOHA. 


\section{Copolímero PS-TX I}

A constante de velocidade de supressão foi obtida do decaimento do estado triplete em $660 \mathrm{~nm}$ em função da concentração de TEOHA. Na Figura 73 está representado o gráfico de Stern-Volmer das constantes de decaimento do triplete do copolímero PS-TX I $\left(k_{o b s}\right)$, no solvente dimetilformamida, em diferentes concentrações de TEOHA. O valor econtrado para a constante de velocidade de supressão $\left(\mathrm{k}_{\mathrm{q}}\right)$ está resumido na Tabela 9.

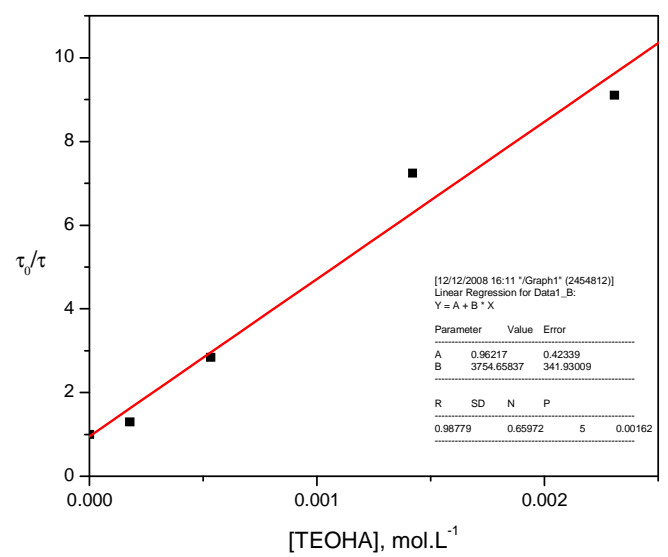

Figura 73. Gráfico de Stern-Volmer da supressão de PS-TX I em dimetilformamida por diferentes concentrações de TEOHA.

A Figura 74 ilustra o gráfico de Stern-Volmer das constantes de decaimento do triplete do copolímero PS-TX I $\left(k_{o b s}\right)$, em tetrahidrofurano, em diferentes concentrações de TEOHA. O valor econtrado para a constante de velocidade de supressão $\left(\mathrm{k}_{\mathrm{q}}\right)$ está resumido na Tabela 9.

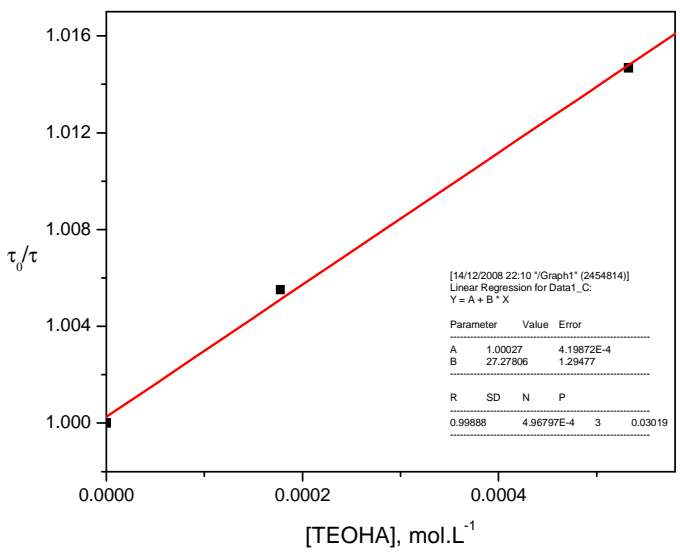

Figura 74. Gráfico de Stern-Volmer da supressão de PS-TX I em tetrahidrofurano por diferentes concentrações de TEOHA. 


\section{Copolímero PS-TX II}

A constante de velocidade de supressão foi obtida do decaimento do estado triplete em $660 \mathrm{~nm}$ em função da concentração de TEOHA. Na Figura 75 está representado o gráfico de Stern-Volmer das constantes de decaimento do triplete do copolímero PS-TX II $\left(k_{\text {obs }}\right)$, em dimetilformamida, em diferentes concentrações de TEOHA. O valor econtrado para a constante de velocidade de supressão $\left(\mathrm{k}_{\mathrm{q}}\right)$ está resumido na Tabela 9.

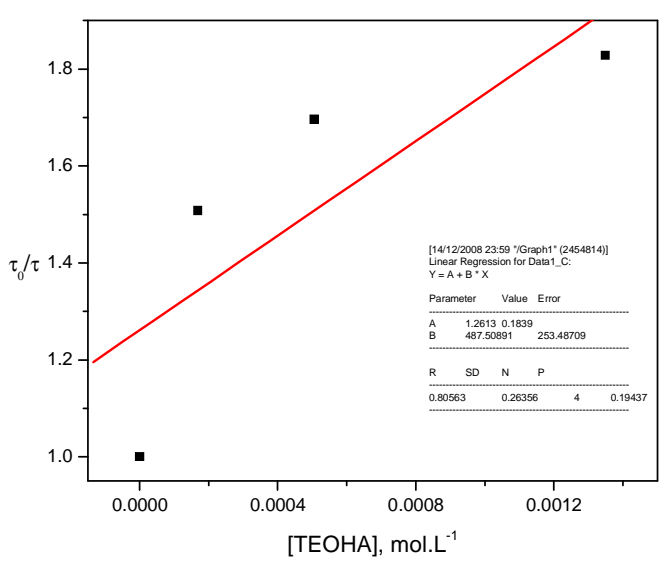

Figura 75. Gráfico de Stern-Volmer da supressão de PS-TX II em dimetilformamida por diferentes concentrações de TEOHA.

A Figura 76 ilustra o gráfico de Stern-Volmer das constantes de decaimento do triplete do copolímero PS-TX II ( $\left.k_{o b s}\right)$, em tetrahidrofurano, em diferentes concentrações de TEOHA. O valor econtrado para a constante de velocidade de supressão $\left(\mathrm{k}_{\mathrm{q}}\right)$ está resumido na Tabela 9.

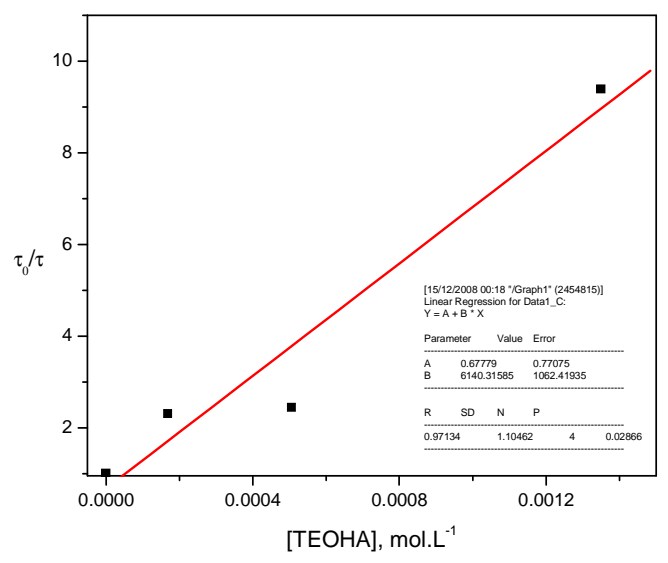

Figura 76. Gráfico de Stern-Volmer da supressão de PS-TX II em tetrahidrofurano por diferentes concentrações de TEOHA. 
A Tabela 9 sumariza as constantes de velocidade de supressão para o triplete de tioxantona por TEOHA. São também tabelados os parâmetros de polaridade dos solventes.

Tabela 9. Constantes de velocidade de supressão dos tempos de vida do estado triplete dos sistemas estudados e parâmetros de polaridade do solvente

\begin{tabular}{|c|c|c|c|c|c|}
\hline TX & $k_{q}\left(L \cdot \mathrm{mol}^{-1} \cdot \mathrm{s}^{-1}\right)$ & $\pi^{*}$ & $\beta$ & $\alpha$ & $\mathbf{E}_{\mathrm{T}}(\mathbf{3 0})$ \\
\hline Dimetilformamida & $7.41 \times 10^{8}$ & 0,88 & 0,69 & 0,00 & 43,8 \\
\hline Tetrahidrofurano & $1.83 \times 10^{9}$ & 0,58 & 0,55 & 0,00 & 37,4 \\
\hline Benzeno & $2.20 \times 10^{9}$ & 0,59 & 0,10 & 0,00 & 34,3 \\
\hline Acetonitrila & $1.95 \times 10^{9}$ & 0,75 & $0,31 / 0,4$ & 0,19 & 45,6 \\
\hline PS+TX & $k_{q}\left(L \cdot m^{-1} \cdot s^{-1}\right)$ & $\pi^{*}$ & $\beta$ & $\alpha$ & $\mathbf{E}_{\mathrm{T}}(\mathbf{3 0})$ \\
\hline Dimetilformamida & $9.67 \times 10^{8}$ & 0,88 & 0,69 & 0,00 & 43,8 \\
\hline Tetrahidrofurano & $2.14 \times 10^{9}$ & 0,58 & 0,55 & 0,00 & 37,4 \\
\hline PS-TX I & $k_{q}\left(L \cdot m^{-1} \cdot s^{-1}\right)$ & $\pi^{*}$ & $\beta$ & $\alpha$ & $\mathbf{E}_{\mathrm{T}}(30)$ \\
\hline Dimetilformamida & $1.06 \times 10^{9}$ & 0,88 & 0,69 & 0,00 & 43,8 \\
\hline Tetrahidrofurano & $7.01 \times 10^{7}$ & 0,58 & 0,55 & 0,00 & 37,4 \\
\hline PS-TX II & $\mathrm{k}_{\mathrm{q}}\left(\mathrm{L} \cdot \mathrm{mol}^{-1} \cdot \mathrm{s}^{-1}\right)$ & $\pi^{*}$ & $\beta$ & $\alpha$ & $\mathbf{E}_{\mathbf{T}}(\mathbf{3 0})$ \\
\hline Dimetilformamida & $7.83 \times 10^{7}$ & 0,88 & 0,69 & 0,00 & 43,8 \\
\hline Tetrahidrofurano & $2.22 \times 10^{9}$ & 0,58 & 0,55 & 0,00 & 37,4 \\
\hline
\end{tabular}

Os valores obtidos para os diversos sistemas estudados nos vários solventes de características diferentes estão apresentados na Tabela 9, juntamente com os valores dos parâmetros solvatocrômicos $\Pi^{*}$ que mede a habilidade do solvente estabilizar uma carga ou um dipolo em virtude de seu efeito dielétrico, $\alpha$ que descreve a habilidade do solvente para doar um próton do solvente para a ligação de hidrogênio do soluto e $\beta$ que fornece uma medida da habilidade do solvente para aceitar um próton do soluto para a ligação hidrogênio do solvente ${ }^{33}$.

Os dados mostram que $\mathrm{k}_{\mathrm{q}}$, para TEOHA, depende do solvente utilizado, mostrando que ocorre uma diminuição com a polaridade do solvente, isto é, $\mathrm{k}_{\mathrm{q}}$ diminue de um solvente não polar (benzeno) para um polar (DMF) em solventes com $\alpha=0 . \mathrm{O}$ mesmo comportamento foi encontrado nos demais sistemas investigados, exceto para o copolímero PS-TX I.

Por outro lado, analisando os resultados da Tabela 9 pode-se dizer que as constantes de velocidade de supressão $\left(\mathrm{k}_{\mathrm{q}}\right)$ para os sistemas tioxantona livre e tioxantona na presença de poliestireno ficaram na ordem de $10^{9}$, ou seja, na ordem difusional. Tal resultado é coerente quando se compara a estrutura de ambos os sistemas. 
Já os copolímeros PS-TX I em tetrahidrofurano e PS-TX II em dimetilformamida apresentaram valores de constantes de velocidade de supressão menores que $10^{9}$, diferentemente dos valores encontrados para a tioxantona livre (ordem difusional). Este comportamento pode estar relacionado com os solventes utilizados e com as diferenças estruturais entre os copolímeros (PS-TX I, PS-TX II) e a tioxantona livre. A tioxantona incorporada em uma estrutura polimérica torna a difusão mais lenta, ou seja, o encontro entre a amina e a TX é dificultada, diminuindo assim o valor da constante de velocidade de supressão $\left(\mathrm{k}_{\mathrm{q}}\right)$. 


\section{CONCLUSÕES}

A tioxantona que foi utilizada como fotossensibilizador mostrou-se eficiente na fotodegradação do poliestireno, em atmosfera de ar e nitrogênio. O comportamento do sensibilizador tioxantona na fotodegradação do polímero segue praticamente os mesmos mecanismos estudados para a benzofenona.

Os quatro sistemas estudados: tioxantona livre (TX), tioxantona na presença de poliestireno (PS+TX) e os copolímeros estireno-co-tioxantona (PS-TX I e PS-TX II) apresentaram através dos estudos de fotólise por pulso de laser o máximo de absorção $T-T$ na região de $600 \mathrm{~nm}$. Os deslocamentos no máximo de absorção entre os sistemas podem ser explicados pela influência do solvente e também pela estrutura dos copolímeros quando comparados com a tioxantona livre.

A tioxantona livre (TX) e na presença do poliestireno (PS+TX) apresentaram valores de constante de velocidade de supressão $\left(\mathrm{k}_{\mathrm{q}}\right)$ na ordem de $10^{9}$, ou seja, difusional. Já os valores de $\mathrm{k}_{\mathrm{q}}$ para os copolímeros PS-TX I e PS-TX II foram menores que $10^{9}$ para os solventes tetrahidrofurano e dimetilformamida, respectivamente. Os dados mostram que $\mathrm{k}_{\mathrm{q}}$, para TEOHA, depende do solvente utilizado, mostrando que ocorre uma diminuição com a polaridade do solvente, isto é, $\mathrm{k}_{\mathrm{q}}$ diminue de um solvente não polar (benzeno) para um polar (DMF) em solventes com $\alpha=0$. O mesmo comportamento foi encontrado nos demais sistemas investigados, exceto para o copolímero PS-TX I. 


\section{REFERÊNCIAS BIBLIOGRÁFICAS}

${ }^{1}$ REICH, L.; STIVA, S.S. Elements of polymer degradation. New York: McGraw-Hill, 1971. $361 \mathrm{p}$.

${ }^{2}$ O'DONNEL, J.H.; SANGSTER, D.F. Principles of radiation chemistry. London: Edward Arnold, 1970. $176 \mathrm{p}$.

${ }^{3}$ RANBY, B.G.; RABEK, J.F. Photodegradation, photo-oxidation and photostabilization of polymers: principles and applications. Bristol: John Wiley, 1975. 573 p.

${ }^{4}$ ANDRADY, A.; AMIN, M.B.; HAMID, S.H.; HU, X.Z.; TORIKAI, A. Effects of increased solar ultraviolet-radiotion on materials. Ambio, v. 24, p. 191-196, 1995.

${ }^{5}$ SARON, C.; ZULLI, F.; GIORDANO, M.; FELISBERTI, M. Influence of copperphthalocyanine on the photodegradation of polycarbonate. Polymer Degradation and Stability, v. 91, p. 3301-3311, 2006.

${ }^{6}$ GRASSIE, N.; SCOTT, G. Polymer degradation and stabilization. Cambridge: Cambridge University Press, 1985. 222 p.

${ }^{7}$ ALLEN, N.S.; McKELLAR, J.F. Photochemistry of dyed and pigmented polymers. London: Applied Science Publication, 1980. 296 p.

${ }^{8}$ THANKI, P.N.; SINGH, R.P. Photostabilization of nylon 66 in presence of acid blue dyes. Polymer Degradation and Stability, v. 75, p. 423- 430, 2002.

${ }^{9}$ ALLEN, N. S. Photofading and light stability of dyed and pigmented polymers. Polymer Degradation and Stability, v. 44, p. 357-374, 1994.

${ }^{10}$ MILLAN, M.D.; LOCKLIN, J.; FULGHUM, T.; BABA, A.; ADVINCULA, R.C. Polymer thin film photodegradation and photochemical crosslinking: FT-IR imaging, evanescent waveguide spectroscopy, and QMC investigations. Polymer, v. 46, p. 5556-5568, 2005.

${ }^{11}$ SIKKEMA, K.; CROSS, G.; HANNER, M.; PRIDDY, D. Photo-degradable polystyrene Part I: enhancing the photo-degradability of polystyrene by the addition of photosensitizers. Polymer Degradation and Stability, v. 38, p. 113-118, 1992.

${ }^{12}$ KACZMAREK, H.; KAMINSKA, A.; SWIATEK, M.; SANYAL, S. Photoinitiated degradation of polystyrene in the presence of low-molecular organic compounds. European Polymer Journal, v. 36, p. 1167-1173, 2000.

${ }^{13}$ TORIKAI, A.; TAKEUCHI, T.; FUEKI, K. Photodegradation of polystyrene and polystyrene containing benzophenone. Polymer Photochemistry, v. 3, p. 307-320, 1983.

${ }^{14}$ RABEK, J.F. Mechanisms of photochemical reactions in polymers: theory and aplications. Bristol: John Wiley, 1987. 756 p.

${ }^{15}$ ONU, A.; PALAMARU, M.; TUTOVAN, E.; CIOBANU, C. Photodegradation of a polyamidehydroxyurethane type polymer in aqueous solution. The role of some dyes in the degradation. Polymer Degradation and Stability, v. 60, p. 465-470, 1998. 
${ }^{16}$ KONSTANTINOVA, T.; LAZAROVA, R.; BOJINOV, V. On the photostability of some naphthalimide dyes and their copolymers with methyl methacrylate. Polymer Degradation and Stability, v. 82, p. 115- 118, 2003.

${ }^{17} \mathrm{COSA}, \mathrm{G}$. Photodegradation and photosensitization in pharmaceutical products: Assessing drug phototoxicity. Pure and Applied Chemistry, v. 76, p. 263-275, 2004.

${ }^{18}$ SMOLUCHOWSKI, R. Theory of grain boundary diffusion. Physical Review, v. 87, p. 482-487, 1952.

${ }^{19}$ MAILHOT, B.; GARDETTE, J. Polystyrene photooxidation. 1 Indentification of the IRabsorbing photoproducts formed at short and long wavelengths. Macromolecules, v. 25, p. 4119-4126, 1992.

${ }^{20}$ LUCAS, E. F.; SOARES, B. G.; MONTEIRO, E. Caracterização de polímeros: determinação de peso molecular e análise térmica. Rio de Janeiro: E-Papers, 2001. 366 p.

${ }^{21}$ ASAHI, T.; FURUBE, A.; FUKUMURA, H.; ICHIKAWA, M.; MASUHARA, H. Development of a fentosecond diffuse reflectance spectroscopic system, evaluation of its temporal resolution, and applications to organic powder systems. Review of Scientific Instruments, v. 69, p. 361-371, 1998.

${ }^{22}$ TEMEL, G.; ARSU, N.; YAGCI, Y. Polymeric side chain thioxanthone photoinitiator for free polymerization. Polymer Bulletin, v. 57, p. 51-57, 2006.

${ }^{23}$ BHUTTO, A.A. Fourier transform infrared analysis of deuterated polystyrene. Journal of Research, v. 14(2), p. 261-269, 2003.

${ }^{24}$ KACZMAREK, H.; KAMINSKA, A.; HERK, A. van. Photooxidative degradation of poly(alkyl methacrylate)s. European Polymer Journal, v. 36, p. 767-777, 2000.

${ }^{25}$ JIANG, X.; YIN, J. Polymeric photoinitiator containing in-chain thioxanthone and coinitiator amines. Macromolecular Rapid Communications, v. 25, p. 748-752, 2004.

${ }^{26}$ DAS, D.; NATH, D.N. Photoreaction of thioxanthone with indolic and phenolic derivatives of biological relevance: magnetic field effect study. Journal of Physical Chemistry A, v. 112, p. 11619-11626, 2008.

${ }^{27}$ WILKISON, F.; WILLSHER, C. J.; PRITCHARD, R. B. Laser flash photolysis of dyed fabrics and polymers - I. European Polymer Journal, v. 24, p. 333-341, 1985.

${ }^{28}$ LEY, C.; SAVARY, F.M.; FOUASSIER, J.P.; JACQUES, P. The spectral shape dependence of xanthone triplet-triplet absorption on solvent polatity. Journal of Photochemistry and Photobiology A: Chemistry, v. 137, p. 87-92, 2000.

${ }^{29}$ FERREIRA, G.C.; SCHMITT, C.C.; NEUMANN, M.G. Dependence of the thioxanthone triplet-triplet absorption spectrum with solvent polarity and aromatic ring substitution.

Journal Brazilian Chemical Society, v. 17, p. 905-909, 2006. 
${ }^{30}$ BURGET, D.; JACQUES, P. Unusual solvent effects on the fluorescence quenching rate constants of a thioxanthone derivative by n-butylamine and isoprene. Chemical Physics Letters, v. 291, p.207-214, 1998.

${ }^{31}$ SAVARY, F.M.; JACQUES, C.L.; WIEDER, F.; FOUASSIER, J.P. Time dependent solvent effects on the $T_{1}-T_{n}$ absorption spectra of thioxanthone: a picoseconds investigation. Journal of Photochemistry and Photobiology A: Chemistry, v. 126, p. 7-14, 2000.

${ }^{32}$ ALLEN, N.S.; SALLEH, N.G.; EDGE, M.; SHAH, M.; LEY, C.; MORLET-SAVARY, F.; FOUASSIER, J.P.; CATALINA, F.; GREEN, A.; NAVARATNAM, S.; PARSONS, B.J. Photophysical properties and photoinduced polymerisation activity of novel 1-cloro-4oxy/acyloxythioxanthone initiators. Polymer, v. 40, p. 4181-4193, 1999.

${ }^{33}$ FOUASSIER, J.P.; JACQUES, P.; ENCINAS, M.V. Solvent effects on the thioxanthone triplet quenching by vinyl monomers. Chemical Physics Letters, v. 148, p. 309-312, 1988.

${ }^{34}$ ENCINAS, M.V.; LISSI, E.A.; LEMP, E.; ZANOCCO, A.; SCAIANO, J.C. Temperature dependence of the photochemistry of aryl alkyl ketones. Journal of Americam Chemical Society, v. 105 p. 1856-1860, 1983.

${ }^{35}$ NETTO-FERREIRA, J.C.; LEIGH, W.J.; SCAIANO, J.C. Laser flash photolysis study of the photochemistry of ring substituted $\beta$-phenylpropiophenones. Journal of Americam Chemical Society, v. 107 p. 2617-2622, 1985. 